\title{
HETEROGENEITY IN BODY CONDITION, SURVIVAL, AND SEASONAL ORIGINS AMONG LESSER SNOW AND ROSS'S GEESE
}

\author{
A Dissertation \\ presented to \\ the Faculty of the Graduate School \\ at the University of Missouri-Columbia \\ In Partial Fulfillment \\ of the Requirements for the Degree \\ Doctor of Philosophy \\ by \\ DREW N FOWLER \\ Dr. Elisabeth Webb, Dissertation Supervisor \\ DECEMBER 2018
}


The undersigned, appointed by the dean of the Graduate School, have examined the dissertation entitled

\section{HETEROGENEITY IN BODY CONDITION, SURVIVAL, AND SEASONAL ORIGINS AMONG LESSER SNOW AND ROSS'S GEESE}

presented by Drew Fowler,

a candidate for the degree of doctor of philosophy,

and hereby certify that, in their opinion, it is worthy of acceptance.

Dr. Elisabeth Webb

Dr. Jeff Firman

Dr. Craig Paukert

Dr. Mitch Weegman

Dr. Mark Vrtiska 


\section{ACKNOWLEDGEMENTS}

The completion of this dissertation was only by the support of numerous individuals and agencies who entrusted me with research and encouraged me throughout the process. While portions of my four years at the University of Missouri were trying, I am beyond grateful for the opportunity that was afforded to me, and relish future opportunities to work with individuals impassioned for waterfowl, waterbird, and wetland conservation. Throughout my time in graduate school, I have been inspired by "life-long learners" and their dedication to make their work relevant to society. My advisor, Dr. Lisa Webb, and committee members Drs. Jeff Firman, Craig Paukert, Mark Vrtiska, and Mitch Weegman were a fully supportive group that enabled my learning and challenged my defiant, but often wrong, tendencies. A PhD degree is a long process, and I am very grateful that Lisa consistently supported my work for four years, even through a few dead-end endeavors. I am thankful for her mentorship and patient willingness to teach me.

The Nebraska Game and Parks Commission (NGPC) initiated and funded the bulk of my research and graduate research assistantship. My research and my family were well supplied because of the NGPC's professionalism and support for funding applied research. Mark Vrtiska (NGPC),-offered endless support (and manuscript formatting edits!) for my project, and I thoroughly enjoyed all our discussions about harvest management and the Light Goose Conservation Order. I hope there will be more to come. Additionally, I received financial support from Ducks Unlimited Canada's Institute for Wetland and Waterfowl Research, an organization that makes incredible efforts to provide student researchers opportunities for enhancing their work, and I am 
thankful for their contributions. I am also thankful for receiving the Dianna L. Hallett Fellowship through the School of Natural Resources at the University of Missouri.

Undoubtedly, my research questions, understanding of light goose ecology and harvest management, and quantitative analyses were enhanced by patient conversations with many wise colleagues. I am thankful for conversations with Ken Abraham, Ray Alisauskas, Frank Baldwin, Tom Bonnot, Rod Brook, Evan Cooch, Josh Dooley, Leigh Fredrickson, Keith Hobson, Dave Koons, Jim Leafloor, Rocky Rockwell, and Gary White. Each of these individuals provided insights that made my work better. I am particularly grateful to Qing Zhao who daily welcomed me into his office to debug JAGS code and build my understanding of Bayesian approaches to analyze banding data. Similarly, Mitch Weegman and Tom Bonnot co-taught Population Dynamics and Quantitative Ecology, which were the most exciting and profitable courses I took at the University of Missouri.

I could not have physically collected and processed all the data required for my research on my own. Many individuals helped me with heavy lifting and moral support. Brendan Woodall volunteered to be my right hand man within days of my arrival to the University of Missouri, and he never let me down. Brendan is a premiere snow goose stalker, lab technician, and friend. Additional field support came from Luke Naylor (Arkansas Game and Fish), Andy Raedeke and Doreen Mengel (Missouri Department of Conservation), Alex Engel (NGPC), and Rocco Murano (South Dakota Game, Fish, and Parks). I am especially grateful for Tom Welstead (NGPC) who opened up his home for me to stay in to wait out a late spring winter storm while collecting geese. Tom and his wife fed me from their kitchen every night for a week, and I am thankful for their 
friendship. Many other technicians were instrumental in my data collection and processing: E.J. Gelvin, Cody Klekamp, Kevin Koenig, Kaitlin Marre, Jordan Piercefield, and Jacob Roney. The existential conversations that arose during hours of goose dissections were fantastic, and I thank Jordan Piercefield for that. I also had an immensely supportive network of fellow graduate students and residents of the ABNR basement: Travis Schepker, Brian Hidden, Jackie Dearbon, Julia Guyton, Kyle Kuechle, Rachel Owens, Dane Smith, Maggie MacPherson, and Anson Main. You folks are great. I'm convinced we will need to do a karaoke reunion. Niki Fuemmeler, Karen Decker, and Angela Carey provided constant administrative support while the Missouri Cooperative Fish and Wildlife Research Unit provided the logistical support required for my project. Additionally, I am extremely grateful for Delta Waterfowl and their complete financing of the first Delta Waterfowl Breeding Waterfowl Ecology Field Course. Frank Rhower and Luke Laborde put on an incredible field-based learning experience which every waterfowl student should aim to participate in. Beyond the ecology, the new friends, endless badminton, and bananas foster will never be beat.

Throughout my masters and $\mathrm{PhD}$ degree I have been inspired by two important mentors. Sammy King and John Vradenburg have been tangible examples of what it looks like to be a present husband, father, and friend, all while excelling as ecologists. They have been a source of calm, wisdom, and lots of jokes as I've navigated my way through adult life. Travelling to China with them and Jim Harris is a trip I never will forget.

My family has been a tremendous support during this degree. I am so thankful for my father, Tracy, mother, Cheryl, and brother's, Lee and Nick, who have loved me 
unconditionally. Additionally, my wife's family: John, Kathy, and Kristie Vahle have loved and supported our family across many moves and life decisions. Similarly, The Crossing Church became our home away from home. I cannot fully express my gratitude to the church for loving us with the gospel of Jesus Christ and being a community of friends during a season of life when we desperately needed it. Anthony and Megan Alphin, Ryan and Kelly Wampler, Jeff Parrett, Nathan Tiemeyer, Justin Garrett, the Loeppke's, Miller's, and Brant's: we love you all.

My wife Katie is absolutely tired of hearing me talk about snow geese during dinner, but she has been the most supportive, loving, and enduring friend I have had through this process. Thank you, Katie, for your sacrificial love and patience when I have not always done the same. Our two daughters, Adelynn and Amelia, have spent too many weekends without their Papa, but I could always count on them for a hug and a smile. Finally, LORD, I am convinced more and more that this life is not a cosmic accident, and that therefore, your Earth matters. Help me to use my work for your glory.

"You make known to me the path of life; in your presence there is fullness of joy"

- Psalms 16:11 


\section{TABLE OF CONTENTS}

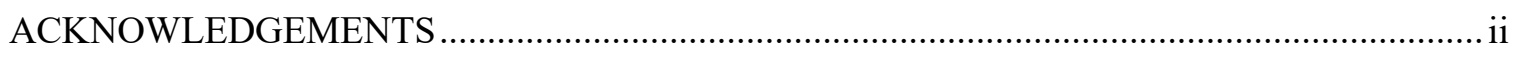

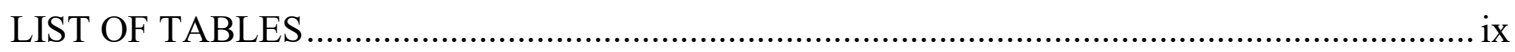

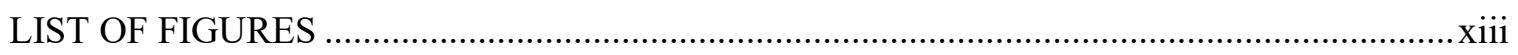

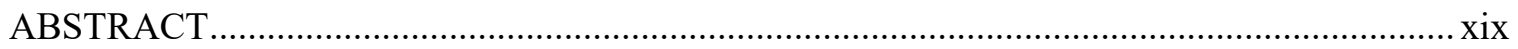

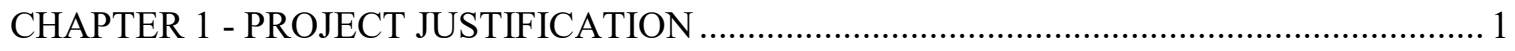

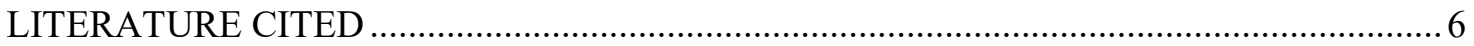

CHAPTER 2 - CONDITION BIAS OF HUNTER HARVEST: HETEROGENEITY IN BODY CONDITION OF LONG-LIVED GEESE SPECIES UNDER SPRING HARVEST .................. 14

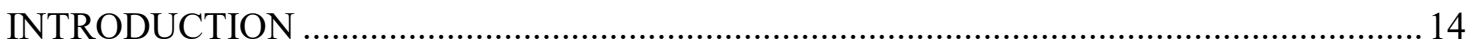

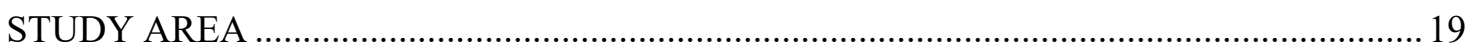

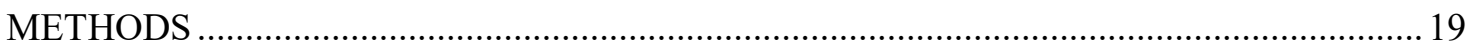

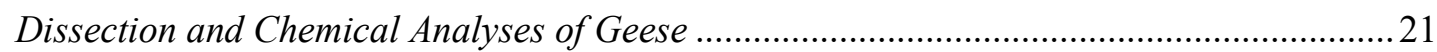

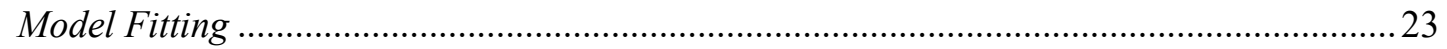

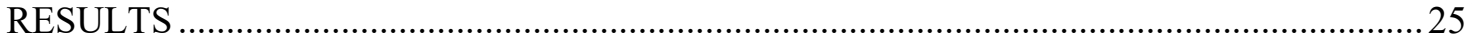

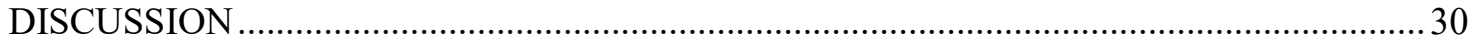

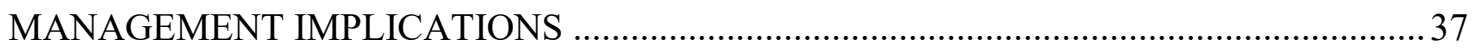

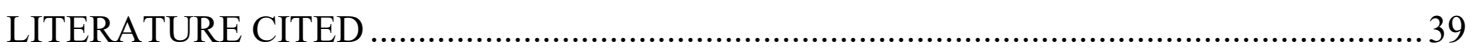

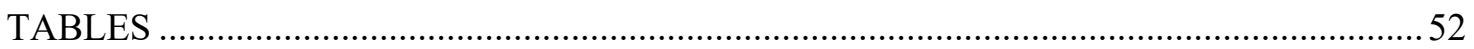

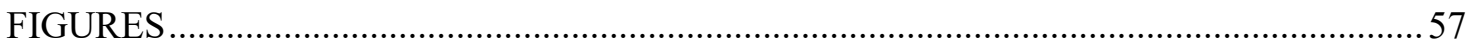

CHAPTER 3 - ESTIMATING INDIVIDUAL VARIATION IN SURVIVAL OF LESSER SNOW GEESE USING MARK-RECOVERY DATA: POSSIBILITIES AND LIMITATIONS 65 


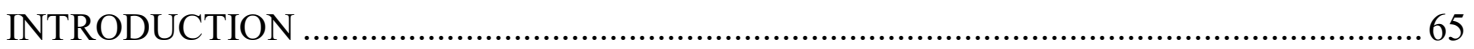

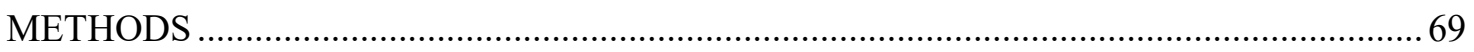

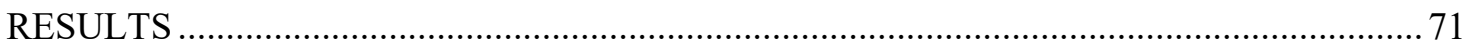

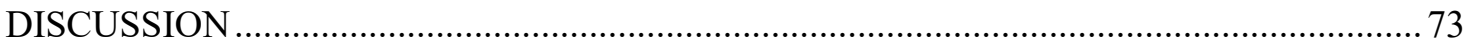

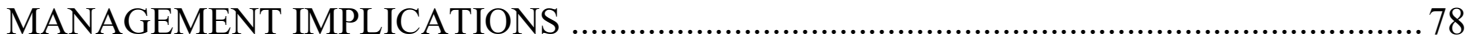

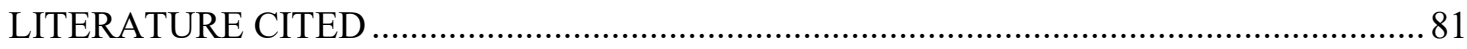

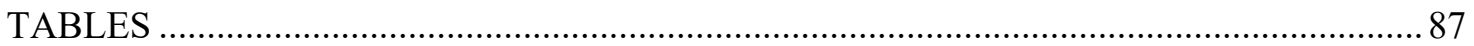

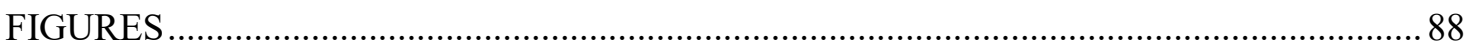

CHAPTER 4 - THE ROLE OF WINTERING AND BREEDING LOCATIONS ON SPRING

BODY CONDITION IN A LONG DISTANT MIGRANT …................................................. 95

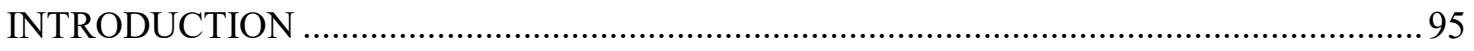

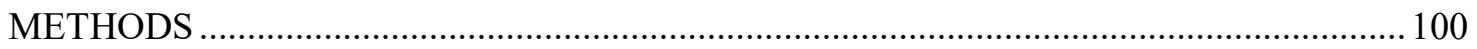

Collection of spring individuals to assess body condition and seasonal origins .................. 100

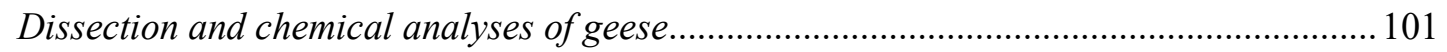

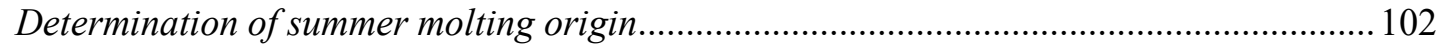

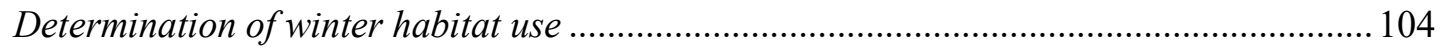

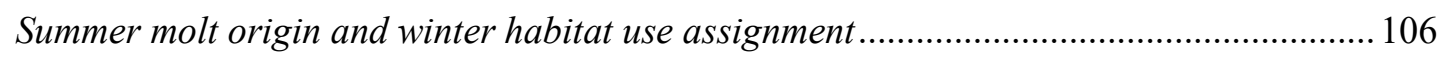

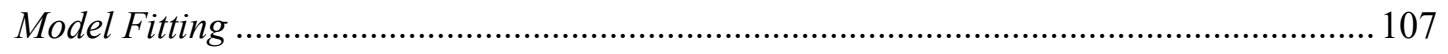

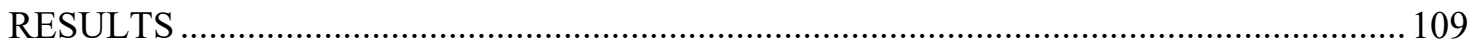

Stable isotope values of snow goose feathers collected from reference breeding colonies and

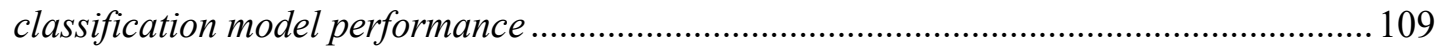

Body condition of spring migrants classified to summer origin categories.......................... 110 
Stable isotope values of snow goose muscle tissue collected from reference winter habitats

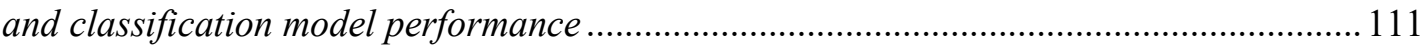

Body condition of spring migrants classified to winter habitat categories........................... 112

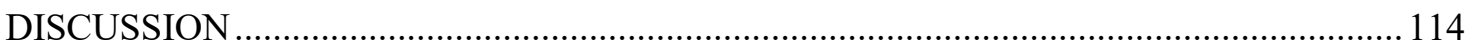

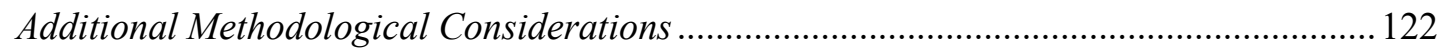

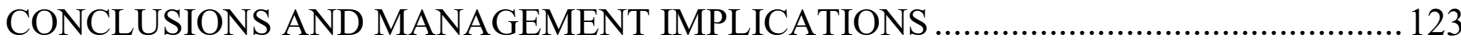

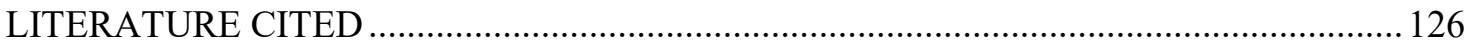

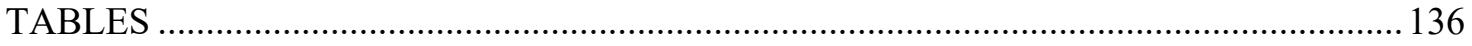

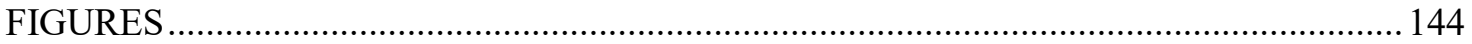

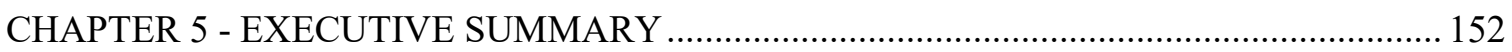

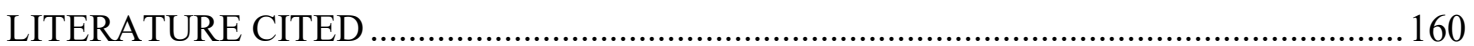

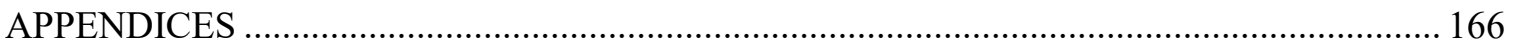

VITA 


\section{LIST OF TABLES}

TABLE

PAGE

Table 2.1 - Relationship between nutrient reserves and a univariate index of body size in lesser snow ( $n=759)$ and Ross' geese $(n=154)$ used to correct nutrient reserves for body size. Geese were collected in Arkansas, Missouri, Nebraska, and South Dakota during the spring Light Goose Conservation Order in 2015 and 2016.

Table 2.2 - Results of general linear mixed models explaining variation in lipid content $(\mathrm{g})$, protein content $(\mathrm{g})$, and ingesta-free body mass $(\mathrm{g})$ of lesser snow geese $(n=759)$ collected during the spring Light Goose Conservation Order in 2015 and 2016. Predictor variables included sex (male or female), age (“AHY" - adults; "HY" juveniles), harvest region (Arkansas, Missouri, Nebraska, South Dakota), and harvest type (decoy or jump shot)

Table 2.3- Results of general linear model explaining variation in body size (PC1) of lesser snow geese $(n=759)$ collected during the spring Light Goose Conservation Order in 2015 and 2016. Predictor variables included sex (male or female), age (“AHY" - adults; "HY" - juveniles), and harvest type (decoy or jump shot).

Table 2.4 - Results of general linear mixed models explaining variation in lipid content (g), protein content (g), and ingesta-free body mass (g) of Ross's geese $(n=154)$ collected during the spring Light Goose Conservation Order in 2015 and 2016. Predictor variables included sex (male or female), age ("AHY" - adults; "HY" juveniles), harvest region (Arkansas, Missouri, Nebraska, South Dakota), and harvest type (decoy or jump shot) .55 
Table 2.5- Results of general linear model explaining variation in body size (PC1) of Ross's geese $(n=154)$ collected during the spring Light Goose Conservation Order in 2015 and 2016. Predictor variables included sex (male or female), age ("AHY"adults; "HY" - juveniles), and harvest type (decoy or jump shot).................................56

Table 3.1 - Posterior estimates of time constant survival and recovery probabilities, and individual survival variance, of midcontinent lesser snow geese analyzed from marked and hunter recovered individuals from 1999-2016 using a state-space Bayesian modeling approach. Marked individuals were analyzed separately between an Arctic breeding colony (Karrak Lake) and a subarctic breeding colony (La Pérouse Bay). Model 1 does not estimate individual variation in survival, while Model 2 and Model 3 estimate individual variation as a random effect using uninformative and informative priors, respectively

Table 4.2 - Mean and standard error of stable hydrogen $\left(\delta^{2} \mathrm{H}\right)$ isotope values in flight feathers collected from adult lesser snow geese at Arctic and subarctic colonies during summer banding in 2014 and 2016. 136

Table 4.3 - Model performance of linear discriminant function derived to classify summer molt origin of adult lesser snow geese using stable hydrogen $\left(\delta^{2} \mathrm{H}\right)$ isotope values. Discriminant function was built using known reference samples from three subregions ("Subarctic", "Karrak Lake", and "BISI Complex"). Model performance was assessed using $\mathrm{k}$-fold cross-validation $(\mathrm{k}=10)$.

Table 4.4 - Results of general linear mixed models explaining variation in lipid content (g), protein content $(\mathrm{g})$, and univariate index of body size of lesser snow geese $(n=$ 324 ) with predicted summer molt origin collected in Arkansas, Missouri, Nebraska, 
and South Dakota during spring migration in 2015 and 2016. Predictor variables included sex (male or female), summer molting origin ("Subarctic"”; "Karrak Lake",; "BISI complex ${ }^{3 ")}$, the random effect for harvest type (decoy or jump shot), and the random effect for Julian date of collection.

Table 4.4 - Mean and standard error of stable hydrogen $\left(\delta^{2} \mathrm{H}\right)$, carbon $\left(\delta^{13} \mathrm{C}\right)$, nitrogen $\left(\delta^{15} \mathrm{~N}\right)$, and sulfur $\left(\delta^{34} \mathrm{~S}\right)$ isotope values in bicep muscle tissue from adult and juvenile lesser snow geese collected in 2017 coastal marsh ("Texas Coast"; Louisiana Coast") and rice based agricultural habitat ("Arkansas MAV").

Table 4.5 - Mean and standard error of stable hydrogen $\left(\delta^{2} \mathrm{H}\right)$, carbon $\left(\delta^{13} \mathrm{C}\right)$, nitrogen $\left(\delta^{15} \mathrm{~N}\right)$, and sulfur $\left(\delta^{34} \mathrm{~S}\right)$ isotope values in bicep muscle tissue collected from adult and juvenile lesser snow geese grouped by habitat type. Reference individuals representing rice agriculture were collected in Arkansas, while individuals representing coastal marsh habitats were collected in Louisiana and Texas, January 2017.

Table 4.6 - Candidate linear discriminant models built for classifying state level winter geographic origins, or habitat type, based on stable isotope values from bicep muscle tissue in lesser snow geese $(n=60)$ collected from known locations in January 2017. Model accuracy was assessed using $k$-fold $(k=10)$ cross validation. 141

Table 4.6 - Comparison in model performance between top linear discriminant models when classifying state origins versus habitat types using stable isotope values $\left(\delta^{13} \mathrm{C}\right.$, $\delta^{15} \mathrm{~N}$, and $\delta^{34} \mathrm{~S}$ ) derived from bicep muscle tissue of lesser snow geese collected in January 2017. 
Table 4.7 - Results of general linear mixed models explaining variation in lipid content $(\mathrm{g})$, protein content $(\mathrm{g})$, and univariate index of body size of lesser snow geese $(\mathrm{n}=$ 137) with predicted winter habitat origin collected in Arkansas, Missouri, and Nebraska during the spring migration in 2015 and 2016. Predictor variables included sex (male or female), age (juvenile or adult), winter habitat type ("Coastal Marsh"; "Rice"), the random effect for harvest type (decoy or jump shot), and the random effect for Julian date of collection. 


\section{LIST OF FIGURES}

FIGURE

PAGE

Fig. 2.1 - Sampling regions of lesser snow $(n=759)$ and Ross's geese $(n=154)$ collected during spring migration 2015 and 2016, in Arkansas, Missouri, Nebraska, and South Dakota, USA.

Fig. 2.2- Least-square means and 95\% confidence intervals of lipid content (A), protein content (B), ingesta-free body mass (C), and body size (D) in lesser snow geese $(n=759)$ by age class (after-hatch year [AHY] and hatch-year [HY]) and harvest type collected during the spring Light Goose Conservation Order in 2015 and 2016. Closed circles are decoy-harvested individuals, open circles are jump shot individuals.

Fig. 2.3 - Least square means and 95\% confidence intervals of lipid content in lesser snow geese $(n=759)$ by harvest region and harvest type collected during the spring Light Goose Conservation Order in 2015 and 2016. Closed circles are decoy-harvested individuals, open circles are jump shot individuals.

Fig. 2.4 - Least square means and $95 \%$ confidence intervals of protein content in lesser snow geese $(n=759)$ by harvest region collected during the spring Light Goose Conservation Order in 2015 and 2016.

Fig. 2.5 - Least square means and $95 \%$ confidence intervals of ingesta-free body mass in lesser snow geese $(n=759)$ by harvest region and harvest type collected during the spring Light Goose Conservation Order in 2015 and 2016. Closed circles are decoyharvested individuals, open circles are jump shot individuals. .61 
Fig. 2.7- Least square means and 95\% confidence intervals of lipid content (A), protein content (B), and ingesta-free body mass (C) in Ross's geese $(n=154)$ by harvest region collected during the spring Light Goose Conservation Order in 2015 and 2016 .

Fig. 2.8 - Least square means and 95\% confidence intervals of body size in Ross's geese $(n=154)$ by age class (after-hatch year and hatch-year) and harvest type collected during the spring Light Goose Conservation Order in 2015 and 2016. Closed circles are decoy-harvested individuals, open circles are jump shot individuals.

Fig. 3.1 - Trace plot of state-space Bayesian model analyzing time constant survival and recovery probabilities of midcontinent population lesser snow geese at La Pérouse Bay (LPB) and Karrak Lake colonies from 1999 - 2016 based on mark-recovery data reported by hunters. Survival and recovery probabilities are reported on the logit scale. Model was based on three Markov Chain Monte Carlo chains (identified by unique colors) of 50,000 iterations after a burn-in of 20,000 and thinning interval of 10.

Fig. 3.2 - Posterior density plot of state-space Bayesian model analyzing time constant estimates of survival (A) and recovery (B) probabilities of midcontinent population lesser snow geese at La Pérouse Bay (LPB) (green) and Karrak Lake (blue) colonies from $1999-2016$ based on mark-recovery data reported by hunters. Survival and recovery probabilities are reported on the logit scale. Model was based on three Markov Chain Monte Carlo chains of 50,000 iterations after a burn-in of 20,000 and thinning interval of 10 . 
Fig. 3.3 - Trace plot of state-space Bayesian model analyzing time constant survival and recovery probabilities of midcontinent population lesser snow geese at La Pérouse Bay (LPB) and Karrak Lake colonies from 1999 - 2016 based on mark-recovery data reported by hunters. Model includes time constant estimate of survival variance $\left(\sigma^{2}\right)$ among individuals parameterized with uninformative priors. Survival and recovery probabilities as well as $\sigma^{2}$ are reported on the logit scale. Model was based on three Markov Chain Monte Carlo chains (identified by unique colors) of 50,000 iterations after a burn-in of 20,000 and thinning interval of 10 .

Fig. 3.4 - Posterior density plots of two state-space Bayesian models analyzing time constant survival and recovery probabilities of midcontinent population lesser snow geese at La Pérouse Bay (LPB) (green) and Karrak Lake (blue) colonies from 1999 2016 based on mark-recovery data reported by hunters. Model estimates on the left (A-C) include time constant estimate of survival variance $\left(\sigma^{2}\right)$ among individuals parameterized with uninformative priors. Model estimates on the right (D-F) include time constant estimate of survival variance $\left(\sigma^{2}\right)$ among individuals parameterized with informative priors (mean of prior denoted by dashed vertical red line). Estimates of individual variance in survival $\left(\sigma^{2}\right)$ are reported on the logit scale. Models were based on three Markov Chain Monte Carlo chains of 50,000 iterations after a burn-in of 20,000 and thinning interval of 10.

Fig. 3.5 - Trace plot of state-space Bayesian model analyzing time constant survival and recovery probabilities of midcontinent population lesser snow geese at La Pérouse Bay (LPB) and Karrak Lake colonies from 1999 - 2016 based on mark-recovery data reported by hunters. Model includes time constant estimate of survival variance $\left(\sigma^{2}\right)$ 
among individuals parameterized with informative priors. Survival and recovery probabilities as well as $\sigma^{2}$ are reported on the logit scale. Model was based on three Markov Chain Monte Carlo chains (identified by unique colors) of 50,000 iterations after a burn-in of 20,000 and thinning interval of 10 .

Fig. 3.6 -Density plots of survival probability among individual lesser snow geese from La Pérouse Bay (A) and Karrak Lake (B) colonies based on 10,000 simulated individuals drawn from a normal distribution with model derived estimates of mean survival probability and variance $\left(\sigma^{2}\right)$. Dashed red vertical lines represent the $2.5 \%$ and $97.5 \%$ quantiles. Parameter estimates were derived from a state-space Bayesian model analyzing time constant survival and recovery probabilities of midcontinent population lesser snow geese from 1999 - 2016 based on mark-recovery data reported by hunters. Model includes time constant estimate of survival variance $\left(\sigma^{2}\right)$ among individuals parameterized with informative priors. Model was based on three Markov Chain Monte Carlo chains of 50,000 iterations after a burn-in of 20,000 and thinning interval of 10 .

Fig. 4.1 - Location of sampled breeding colonies where newly grown flight feathers of adult midcontinent lesser snow geese were collected for quantification of $\delta^{2} \mathrm{H}$ isotope signatures in July 2014. A second year of collections occurred at all colonies except Karrak Lake in July 2016.

Fig. 4.2 - Probability density functions of lesser snow geese assigned to discrete geographic origins of summer molt using the "Summer Origin LDF" linear discriminant function. Lesser snow geese were collected during spring migration in Arkansas, Missouri, Nebraska, and South Dakota during 2015 and 2016. Individuals 
with a posterior probability $\geq 0.70$ (red vertical line) were kept for analysis to evaluate the influence of summer geographic location on spring body condition and overall body size.

Fig. 4.3 - Model least square means and standard errors of body size among spring migrant male and female lesser snow geese classified to discrete geographic molt origins based on $\delta^{2} \mathrm{H}$ isotope values in flight feathers. Index of body size was derived from the first principal component of length of tarsus, culmen, head, body, and wing chord. "BISI" refers to individuals classified to the Baffin and Southampton Islands complex, and "Subarctic" represents origins south of $60^{\circ} \mathrm{N}$. Open circles represent males. Closed circles represent females.

Fig. 4.4 - Probability density functions of lesser snow geese assigned to discrete winter habitat types using the "Winter Habitat LDF" linear discriminant function. Lesser snow geese were collected during spring migration in Arkansas, Missouri, and Nebraska 2016. Individuals with a posterior probability $\geq 0.80$ (red vertical line) were kept for analysis to evaluate the influence of winter habitat type on spring body condition and overall body size.

Fig. 4.5 - Stable isotope values of lesser snow goose bicep muscle tissue from individuals serving as reference samples of known coastal marsh habitat (blue) and agricultural rice based habitat (pink). Spring migrants of unknown origin were classified to either coastal marsh habitats (green) or rice habitats (orange) using a linear discriminant function derived from reference samples.

Fig. 4.7 - Model least square means and standard errors of size adjusted protein content across age (A), sex (B), and winter habitat use (C) in lesser snow geese ( $n=$ 
137) collected during spring migration in 2016 in Arkansas, Missouri, and Nebraska.

Fig. 4.8 - Model least square means and standard errors of body size across age (A), sex (B), and winter habitat use $(\mathrm{C})$ in lesser snow geese $(n=137)$ collected during spring migration in 2016 in Arkansas, Missouri, and Nebraska. Index of body size was derived from the first principal component of length of tarsus, culmen, head, body, and wing chord. 


\begin{abstract}
Individual heterogeneity in fitness within a population is well established and provides the required variability for natural selection to take place. Yet, in the case of overabundant midcontinent lesser snow (Anser caerulescens caerulescens) and Ross's geese (A. rossii), individual variation in regards to harvest effects on population growth has largely not been considered when evaluating management actions to reduce population size. In this dissertation, I first examined heterogeneity in body condition among hunter harvested individuals and the general population of midcontinent lesser snow and Ross's geese during the spring Light Goose Conservation Order in 2015 and 2016 across Arkansas, Missouri, Nebraska, and South Dakota. I found a body condition bias in decoy harvested geese, such that individuals removed by hunters were in lower body condition (less lipid content) relative to the general population. This finding suggests that disproportionate removal of lower conditioned individuals is a feature of the currently observed compensatory nature of harvest among midcontinent light geese. I also explored methods to estimate the magnitude of individual variation in survival rates of adult lesser snow geese using mark-recovery data via a Bayesian state-space model. I identified limitations to estimating heterogeneous survival rates using mark-recovery data alone and suggest future simulations to explore alternative methodological approaches. Finally, I evaluated differences in spring body condition among individuals using different wintering habitats through stable isotope analysis. I found that individuals overwintering in coastal marsh habitats had lower lipid reserves relative to those individuals overwintering in rice-based agricultural landscapes, suggesting a carry-over effect from winter habitat use that may influence harvest susceptibility or other fitness parameters. In conclusion, continued research to identify the amount of individual variation in survival parameters of cohort specific geese can further elucidate the role of heterogeneity on the Light Goose Conservation Order attempts to reduce population size.
\end{abstract}




\section{CHAPTER 1 - PROJECT JUSTIFICATION}

In many cases, human-mediated alterations to ecosystems can shift species native to an ecosystem to invasive status (Valery et al. 2009, Simberloff 2011, Carey et al. 2012). As a result, the functional response of the ecosystem can change (Didham et al. 2007, Peltzer et al. 2010), often creating challenges in management actions to restore a sustainable equilibrium (Carey et al. 2012). Effects of overabundant species on ecosystem function are diverse and can result in increased interspecific competition leading to species endangerment (Nelson et al. 2007), altered or reduced plant diversity (Bobbink and Williams 1987, Horsley et al. 2003), and altered community structure (Levine et al. 2003). While frequently controversial, Garrott et al. (1993) recommended that managers and conservation biologists address the issues of controlling populations of native species to reverse negative effects of overabundance.

The midcontinent population of light geese, comprised of two species, the lesser snow goose (Anser caerulescens caerulescens) and the Ross's goose (A. rossii), is a classic example of unprecedented population growth in response to anthropogenic alterations of ecosystems and subsequent difficulty in managing for a controlled population size (Jefferies et al. 2003, Abraham et al. 2005, Alisauskas et al. 2011). The increase in light goose population size and expanded nesting areas have raised concern for degradation of arctic ecosystems, including tidal marshes (Abraham and Jefferies 1997) and upland tundra (Iacobelli and Jefferies 1991), as well as indirect impacts to species using the same habitats throughout their migratory range (Pearse et al. 2010, Webb et al. 2010, Pearse et al. 2013, but see Dinges et al. (2015). The overabundance of light geese has most notably affected subarctic tundra habitats in the west Hudson Bay 
lowlands used primarily as a staging area for arctic bound geese, and to a lesser extent, a local nesting cohort representing approximately $10 \%$ of the overall midcontinent population (Alisauskas et al. 2011). Here, intensive and destructive foraging methods (grubbing and pulling) have resulted in substantial vegetative biomass loss (Williams et al. 1993, McLaren and Jefferies 2004, and Abraham et al. 2012). The denuded landscape induces considerable abiotic changes within tundra soils, prohibiting new plant growth, resulting in slow recovery of degraded arctic and subarctic habitats (Abraham et al. 2005, Alisauskas et al. 2006). As a result, changes in tundra habitat resulting from light geese overabundance have also indirectly affected other avian species in the Hudson Bay lowlands including yellow rails (Coturnicops novemoracensi), savannah sparrows (Passerculus sandwichensis), northern shovelers (Anas clypeata), and American wigeon (A. americana) (Rockwell et al. 1997, Peterson et al. 2014). Similarly, growing population sizes of lesser snow geese and greater snow geese (A. atlantica) nesting in the Canadian High Arctic seem to have induced trophic cascades that negatively affect nesting shorebird density and increased predation pressure, particularly for the American golden-plover (Pluvialis dominica) (Hines 2010, Lamarre et al. 2017).

Within the last twenty-five years, conservation efforts have been aimed at reducing the light goose population size to sustainable levels (United States Fish and Wildlife Service 2007). Liberalization of regular season hunting regulations and initiation of a conservation order, known as the light goose conservation order (LGCO), were implemented in both Canada and the United States in 1999 in an effort to increase harvest mortality, with the goal of decreasing midcontinent light goose populations and alleviating impacts to northern habitats. However, despite temporary increased light 
goose harvest (Kruse and Fronczak 2013) attributed to the liberalization of hunting regulations and implementation of the LGCO, harvest rates have not increased proportionally with population size, and cumulative harvest efforts have been ineffective in reducing light goose populations or managing population growth (Alisauskas et al. 2011, Koons et al. 2014, Calvert et al. 2017). Additionally, original estimates of population size suggested that the necessary harvest rates required to reduce survival were realistic (Batt et al. 1997), however, more recent analysis determined these estimates were severely underestimated (Alisauskas et al. 2009, Alisauskas et al. 2011). Rather, recent attenuation in population growth appears related to reduced annual productivity resulting from increased phenological mismatch of vegetative growth and hatching date, as well as increased density-dependence related to protein availability at terminal staging areas (Ross et al. 2017). Nonetheless, population size still remains above target goals and the LGCO continues to receive support as the established management plan to reduce population size. While harvest rates required to reduce adult survival appear unachievable given the current population size and low overall harvest rates, there are likely additional considerations that reduce efficacy of the LGCO, which motivated the Nebraska Game and Parks Commission to initiate funding for the research presented in this dissertation.

Individual heterogeneity in fitness within a population is well established (Vaupel et al. 1979, Vindenes and Landangen 2015, Gimenez et al. 2018) and provides required variability for natural selection to take place (Endler 1986, Hamel et al. 2018). Mechanisms that introduce heterogeneous fitness within a population are vast but can occur as fixed heterogeneity that result from genetic differences or environmental 
variation during early development (Nussey et al. 2005, Senner et al. 2015) or exist as dynamic heterogeneity influenced by annual carry-over effects (Harrison et al. 2011, Sedinger and Alisauskas 2014). In the case of midcontinent light geese, individual variation in regards to harvest effects on population growth has largely not been considered when evaluating LGCO contributions to reduce population size. For example, in addition to harvest rates being of sufficient size to reduce survival rates, population reductions would also benefit from harvest of individuals who would otherwise survive and recruit offspring. Alternatively, the disproportionate harvest of frail or less fit individuals could weaken the influence of total harvest on reduced survival rates (Lebreton et al. 2005, Sandercock et al. 2011, Sedinger and Herzog 2012).

In this dissertation, I examined diverse examples of individual heterogeneity in midcontinent light geese and their influence on harvest management decisions within the framework of the LGCO. In chapter 2, I evaluated evidence for the condition bias hypothesis in lesser snow and Ross's geese harvested by LGCO participants during spring migration. Preliminary data collected during spring 2012 in Nebraska indicated light geese harvested over decoys weighed approximately $100 \mathrm{~g}$ less than those harvested by pass shooting or sneaking and stalking. Therefore, harvested individuals may have poorer body condition, similar to results reported for mallards by Hepp et al. (1986), and reduced fitness parameters that limit their overall survival or potential fecundity (Ankney and MacInnes 1978). Evidence for a condition biased harvest is well supported in diving ducks (Bain 1980) and dabbling ducks (Greenwood et al. 1986, Hepp et al. 1986, Reinecke and Shaiffer 1988, and Dufour et al. 1993), yet these trends have not been confirmed in light geese (Morez et al. 2000). If the LGCO primarily removes individuals 
of poorer body condition then the role of harvest in affecting population size may be further constrained.

In Chapter 3, I explored a Bayesian state-space modeling approach to estimate the extent of individual variation in survival from band recoveries of midcontinent lesser snow geese. Mark-recovery data are often used to estimate vital rates and assess responses to harvest pressure, however, they require explicit assumptions of homogeneity among individuals within a cohort (Pollock and Raveling 1982). Therefore, in this chapter I attempted to estimate the range and distribution of individual variation in adult survival and discuss the challenges associated with identifying heterogeneous vital rates.

In Chapter 4, I examined the role in which variable wintering habitat use and breeding destination influence lipid and protein reserves during early spring migration. Developments in the use of stable isotopes to determine breeding origins via inert isotope values stored in flight feathers (Hobson et al. 1999, Fowler et al. 2018), and winter habitat use via metabolically active muscle tissue (Hénaux et al. 2012), provide an opportunity to assess potential carry-over effects that influence body condition and potentially harvest susceptibility. I conclude with an executive summary in Chapter 5.

Each chapter was written with the intention for peer-reviewed publication. Therefore, some introductory material are repeated through this dissertation and an independent literature cited section follows each chapter. Additionally, all writing from herein uses plural nouns "we" and "our" to reflect the collaboration of my co-authors. 


\section{LITERATURE CITED}

Abraham, K. F., and R. L. Jefferies. 1997. High goose populations: causes, impacts, and implications. Pages 7-72 in B. D. J. Batt, editor. Arctic ecosystem in peril: report of the arctic goose habitat working group. Arctic goose joint venture special publication. U.S. Fish and Wildlife Service, Washington, DC, and Canadian Wildlife Service, Ottawa, Ontario, Canada.

Abraham, K. F., R. L. Jefferies, and R. T. Alisauskas. 2005. The dynamics of landscape change and snow geese in mid-continent North America. Global Change Biology 11:841-855.

Abraham, K. F., R. L. Jefferies, R. T. Alisauskas, and R. F. Rockwell. 2012. Northern wetland ecosystems and their response to high densities of Lesser Snow Geese and Ross's Geese. Pages 9-45 in J. O. Leafloor, T. J. Moser, and B. D. J. Batt, editors. Evaluation of Special Management Measures for Midcontinent Lesser Snow Geese and Ross’s Geese. Arctic Goose Joint Venture Special Publication. U.S. Fish and Wildlife Service, Washington, D.C., and Canadian Wildlife Service, Ottawa, Ontario.

Alisauskas, R. T., J. W. Charlwood, and D. K. Kellett. 2006. Vegetation correlates of the history and density of nesting by Ross's geese and lesser snow geese at Karrak Lake, Nunavut. Arctic 59:201-210.

Alisauskas, R. T., K. L. Drake, and J. D. Nichols. 2009. Filling a void: Abundance estimation of North American populations of Arctic geese using hunter 
recoveries. Pages 463-489 in D. L. Thomson, E. G. Cooch, and M. J. Conroy, editors. Modeling Demographic Processes in Marked Populations. Springer US, Boston, MA.

Alisauskas, R. T., R. F. Rockwell, K. W. Dufour, E. G. Cooch, G. Zimmerman, K. L. Drake, J. O. Leafloor, T. J. Moser, and E. T. Reed. 2011. Harvest, survival, and abundance of midcontinent lesser snow geese relative to population reduction efforts. Wildlife Monographs 179:1-42.

Ankney, C. D., and C. D. MacInnes. 1978. Nutrient reserves and reproductive performance of female Lesser Snow Geese. Auk 95:459-471.

Bobbink, R. and J. H. Willems. 1987. Increasing dominance of Brachypodium pinnatum (L) Beauv in chalk grasslands: a threat to a species-rich ecosystem. Biological Conservation 40:301-14.

Calvert, A. M., R. T. Alisauskas, and G. C. White. 2017. Annual survival and seasonal hunting mortality of midcontinent snow geese. Journal of Wildlife Management 81:1009-1020.

Carey, M. P., Sanderson, B. L., Barnas, K. A., and J. D Olden. 2012. Native invaders challenges for science, management, policy, and society. Frontiers in Ecology and the Environment 10:373-381.

Didham, R. K., J. M. Tylianakis, N. J. Gemmell, T. A. Rand, and R. M. Ewers. 2007. Interactive effects of habitat modification and species invasion on native species decline. Trends in Ecology and Evolution 22:489-96. 
Dinges, A. J., E. B. Webb, and M. P. Vrtiska. 2015. Effects of the Light Goose Conservation Order on non-target waterfowl distribution during spring migration. Wildlife Biology 21:88-97.

Dufour, K. W., C. D. Ankney, and P. J. Weatherhead. 1993. Condition and vulnerability to hunting among mallards staging at Lake St. Clair, Ontario. Journal of Wildlife Management 57:209-215.

Endler, J. A. 1986. Natural selection in the wild. Princeton University Press, Princeton, NJ, USA.

Fowler, D. N., E. B. Webb, F. B. Baldwin, M. P. Vrtiska, and K. A. Hobson. 2018. A Multi-isotope $\left(\delta^{2} \mathrm{H}, \delta^{13} \mathrm{C}, \delta^{15} \mathrm{~N}, \delta^{34} \mathrm{~S}\right)$ approach to establishing migratory connectivity in lesser snow geese: Tracking an overabundant species. PloS One 13:e0203077.

Garrott, R. A., P. J. White, and C. A. Vanderbildt White. 1993. Overabundance: an issue for conservation biologists? Conservation Biology 7:946-949.

Gimenez, O., E. Cam, and J. M. Gaillard. 2018. Individual heterogeneity and capturerecapture models: What, why and how? Oikos 127:664-686.

Greenwood, H. R., R. G. Clark, and P. J. Weatherhead. 1986. Condition bias of huntershot mallards (Anas platyrhynchos). Canadian Journal of Zoology 64:599-601. 
Harrison, X. A., J. D. Blount, R. Inger, D. R. Norris, and S. Bearhop. 2011. Carry-over effects as drivers of fitness differences in animals. Journal of Animal Ecology 80:4-18.

Hénaux, V., L. A. Powell, M. P. Vrtiska, and K. A. Hobson. 2012. Establishing Winter origins of migrating lesser snow geese using stable isotopes. Avian Conservation and Ecology 7:5.

Hepp, G. R., Blohm, R. J., Reynolds, R. E., Hines, J. E. and J. D. Nichols. 1986 Physiological condition of autumn-banded mallards and its relationship to hunting vulnerability. Journal of Wildlife Management 50:177-183.

Hines, J. E. 2010. The effects on lowland habitat, breeding shorebirds and songbirds in the Banks Island Migratory Bird Sanctuary Number 1 by the growing colony of lesser snow geese (Chen caerulescens caerulescens). Environment Canada, Canadian Wildlife Service.

Hobson, K. A. 1999. Tracing origins and migration of wildlife using stable isotopes: A review. Oecologia 120:314-326.

Horsley, S. B., S. L. Stout, and D. S. DeCalesta. 2003. White-tailed deer impact on the vegetation dynamics of a northern hardwood forest. Ecological Applications 13:98-118.

Iacobelli, A., and R. L. Jefferies. 1991. Inverse salinity gradients in coastal marshes and the death of stands of Salix: the effects of grubbing by geese. Journal of Ecology 79:61-73. 
Jefferies, R. L., R. F. Rockwell, and K. F. Abraham. 2003. The embarrassment of riches: agricultural food subsidies, high goose numbers, and loss of Arctic wetlands - a continuing saga. Environmental Reviews 11:193-232.

Koons, D. N., Rockwell, R. F., and L. M. Aubry. 2014. Effects of exploitation on an overabundant species: the lesser snow goose predicament. Journal of Animal Ecology 3:365-374.

Kruse, K. L., and D. Fronczack. 2013. Light geese in the Central and Mississippi Flyways. U.S. Fish and Wildlife Service, Denver, Colorado, USA.

Lamarre, J. F., P. Legagneux, G. Gauthier, E. T. Reed, and J. Bêty. 2017. Predatormediated negative effects of overabundant snow geese on arctic-nesting shorebirds. Ecosphere 8: e01788.

Lebreton, J. D. 2005. Dynamic and statistical models for exploited populations. Australian and New Zealand Journal of Statistics 47:49-63.

Levine, J. M., M. Vila, C. M. D. Antonio, J. S. Dukes, K. Grigulis, and S. Lavorel. 2003. Mechanisms underlying the impacts of exotic plant invasions. Proceedings of the Royal Society of London B: Biological Sciences 270:775-781.

McLaren, J. R., and R. L. Jefferies. 2004. Initiation and maintenance of vegetation mosaics in an arctic salt marsh. Journal of Ecology 92:648-660. 
Morez, V., G. G. Gauthier, and A. Reed. 2000. Effect of body condition on vulnerability of greater snow geese to hunting and capture. Journal of Wildlife Management 64:875-886.

Nelson J. L., B. L. Cypher, C. D. Bjurlin, and S. Creel. 2007. Effects of habitat on competition between kit foxes and coyotes. Journal of Wildlife Management 71:1467-1475.

Pearse, A. T., G. L. Krapu, D. A. Brandt, and P. J. Kinzel. 2010. Changes in agriculture and abundance of snow geese affect carrying capacity of Sandhill cranes in Nebraska. Journal of Wildlife Management 74:479-488.

Pearse, A. T., Krapu, G. L., and R. R. Cox. 2013. Comparative spring-staging ecology of sympatric arctic-nesting geese in south-central Nebraska. American Midland Naturalist, 169:371-381.

Peltzer, D. A., R. B. Allen, G. M. Lovett, D. Whitehead, and D. A. Wardle. 2010. Effects of biological invasions on forest carbon sequestration. Global Change Biology $16: 732-746$.

Peterson, S. L., R. F. Rockwell, C. R. Witte, and D. N. Koons. 2014. Legacy effects of habitat degradation by Lesser Snow Geese on nesting Savannah Sparrows. Condor 116:527-537. 
Pollock, K., and D. Raveling. 1982. Assumptions of modern band-recovery models, with emphasis on heterogeneous survival rates. Journal of Wildlife Management $46: 88-98$.

Reinecke, K.J. and C. W. Shaiffer. 1988. A field test for differences in condition among trapped and shot mallards. Journal of Wildlife Management 52:227-232.

Rockwell, R. F., Cooch, E. G., and S. Brault. 1997. Dynamics of the midcontinent population of lesser snow geese: projected impacts of reduction in survival and fertility on population growth rates. Pages $73-100$ in B. D. J. Batt, editor. Arctic ecosystems in peril: report of the Arctic Goose Joint Venture Habitat Working Group. Arctic Goose Joint Venture Special Publication. U.S. Fish and Wildlife Service, Washington, D.C., USA, and Canadian Wildlife Service, Ottawa, Ontario, Canada.

Ross, M. V, R. T. Alisauskas, D. C. Douglas, and D. K. Kellett. 2017. Decadal declines in avian herbivore reproduction: density-dependent nutrition and phenological mismatch in the arctic. Ecology 98:1869-1883.

Sandercock, B. K., E. B. Nilsen, H. Brøseth, and H. C. Pedersen. 2011. Is hunting mortality additive or compensatory to natural mortality? Effects of experimental harvest on the survival and cause-specific mortality of willow ptarmigan. Journal of Animal Ecology 80:244-258.

Sedinger, J. S., and M. P. Herzog. 2012. Harvest and dynamics of duck populations. Journal of Wildlife Management 76:1108-1116. 
Sedinger, J. S., and R. T. Alisauskas. 2014. Cross-seasonal effects and the dynamics of waterfowl populations. Wildfowl Special Issue No. 4:277-304.

Simberloff D. 2011. Native invaders. In: Simberloff D and M. Rejmánek (Eds). Encyclopedia of biological invasions. University of California Press. Berkeley and Los Angeles, CA, USA.

United States Fish and Wildlife Service. 2007. Final Environmental Impact Statement: Light Goose Management. U. S. Fish and Wildlife Service, Washington, D.C., USA.

Valéry, L., H. Fritz, J.-C. Lefeuvre, and D. Simberloff. 2009. Invasive species can also be native. Trends in Ecology and Evolution 24:585.

Vaupel, J. W., K. G. Manton, and E. Stallard. 1979. The impact of heterogeneity in individual frailty on the dynamics of mortality. Demography 16:439-454.

Vindenes, Y., and Ø. Langangen. 2015. Individual heterogeneity in life histories and ecoevolutionary dynamics. Ecology Letters 18:417-432.

Webb, E. B., Smith, L. M., Vrtiska, M. P., and T. G. Lagrange. 2010. Effects of local and landscape variables on wetland bird habitat use during migration through the Rainwater Basin. Journal of Wildlife Management 74:109-119.

Williams, T. D., E. G. Cooch, R. L. Jefferies, and F. Cooke. 1993. Environmental degradation, food limitation and reproductive output: juvenile survival in lesser snow geese. Journal of Animal Ecology 62:766-777. 


\section{CHAPTER 2 - CONDITION BIAS OF HUNTER HARVEST: HETEROGENEITY IN BODY CONDITION OF LONG-LIVED GEESE SPECIES UNDER SPRING}

\section{HARVEST}

\section{INTRODUCTION}

Following depletion of many wild game populations by commercial trapping and harvest throughout the $19^{\text {th }}$ and early $20^{\text {th }}$ century, game harvest has been managed with a general underlying premise to sustain, rather than exploit, wildlife populations (Phillips and Lincoln 1930, Johnson et al. 1993). Despite an overall cultural decline in hunting throughout North America, waterfowl continue to experience popular recreational harvest (Miller and Hay 1981, Humburg et al. 2018) and evaluating effective harvest regulations and population responses to harvest is an extensive focus of current wildlife research and management (Williams and Johnson 1995, Nichols et al. 1995, Cooch et al. 2014). Broadly, effects of harvest mortality on waterfowl populations can either be additive to sources of natural mortality or compensatory, such that for a range of harvest rates up until a threshold, harvest affects no change in overall survival (or total mortality) (Anderson and Burnham 1976, Sedinger and Herzog 2012). However, additive and compensatory mortality are likely best conceptualized as opposite endpoints on a continuum, along which variations in life history among species, harvest and environmental pressures, as well as population heterogeneity can result in a partial compensatory harvest effect (Conroy and Krementz 1990, Lebreton 2005, Lindberg et al. 2013). Therefore, the realization of harvest mortality on this continuum can greatly impact potential for harvest to influence populations (Cooch et al. 2014). 
Density-dependence and individual heterogeneity (or some combination) are two often-identified underlying mechanisms for wildlife populations experiencing some degree of compensatory harvest effects. In populations exhibiting density-dependence, compensatory harvest mortality can offset natural mortality by alleviating a densitydependent pressure, such as limited habitat availability, so that if harvest mortality is high, natural mortality will decrease (Nichols 1991, Johnson et al. 1993). In contrast, when harvest mortality is low in populations experiencing density-dependence, natural mortality will be greater. Support for density-dependence as a mechanism for compensatory harvest, particularly in ducks, has been mixed (Pöysä et al. 2004, Viljugrein et al. 2005, Murray et al. 2010, Sedinger and Herzog 2012), but it is evident that density-dependent pressures must be substantial in order to affect survival rates (Bonenfant et al. 2009). Nonetheless, individual variation in survival can serve as a mechanism for compensation and can have profound implications for effects of harvest on population change (Lebreton 2005, Caudill et al. 2017). Caudill et al. (2017) demonstrated that given some degree of additive harvest in a population comprised of individuals with heterogeneous survival, disproportionate harvest of low quality individuals (i.e. those with lower survival and reproductive rates) served to mitigate, or partially compensate, harvest mortalities due to the greater probability of natural mortality in the larger proportion of harvested individuals. Therefore, even in the absence of density-dependence and with substantial harvest rates, bias towards harvest of low quality individuals can dampen harvest impacts on population reduction (Lebreton 2005, Cooch et al. 2014). 
Individual heterogeneity in survival can result from a variety of factors including phenotype or genotype (Gimenez et al. 2018) and reproductive success (Iverson et al. 2014), however these factors are often mediated through a proximate mechanism: body condition (Owen and Black, 1989, Hill et al. 2003, Blums et al. 2005). Regarding harvest mortality, it is generally established that individuals in poorer body condition are more vulnerable to harvest, particularly among duck species (Greenwood et al. 1986, Sheeley and Smith 1989, Dufour et al. 1993, Pace and Afton 1999). Inherent to the condition bias hypothesis is that nutrient reserve levels influence harvest vulnerability and receptiveness to decoys, where nutrient deficient individuals are more risk prone and experience greater harvest (Greenwood et al. 1986, Reinecke and Shaiffer 1988). Accordingly, hunter harvested ducks are suspected to have lower natural survival probabilities than those not harvested (Sedinger and Herzog 2012, Péron 2013). Compared to other waterfowl, ducks are short-lived species and are therefore expected to display greater levels of individual heterogeneous survival relative to longer-lived species that implement bethedging strategies to minimize annual risks of mortality and buffer against genetic and environmental perturbations, through a process known as canalization (Waddington 1953, Nevoux et al. 2010, Peron et al. 2016). In canalization, population structure is over representative of individuals who possess phenotypes that maximize fitness, resulting from a suppression of phenotypic variation at earlier life stages via enhanced mortality (Wagner et al. 1997, Hamel et al. 2018).

Tests of the condition bias hypothesis have been limited among longer-lived waterfowl, such as geese. Inferences from the canalization hypothesis suggest reduced individual heterogeneity in both annual survival and body condition due to their longer 
life-histories (Peron 2016). Morez et al. (2000) appears to be the only study to directly evaluate a condition bias in longer-lived, harvested waterfowl (but see Hill et al. 2003) and reported limited support for a condition bias in either juvenile or adult decoy harvested greater snow geese (Anser caerulescens atlanticus) relative to individuals captured in baited or un-baited rocket nets, however, decoyed individuals did exhibit smaller structural size. This study occurred only during fall migration and the authors stressed the importance for continued study of condition biases among waterfowl under a range of hunting conditions (Morez et al. 2000). Indeed, heterogeneous harvest vulnerability is likely to vary temporally and spatially given the extent of existing harvest pressures and spatial segregation of high and low quality individuals during migration (Lindberg et al. 2013). Similarly, hunting pressure in spring may induce non-lethal energetic costs on a population that further facilitates condition biases of individuals subject to hunter mortality (Béchet et al. 2004). During spring migration, light geese compete for energetic reserves, largely in the form of lipids, to meet the energetic costs of migration, while also acquiring sufficient proteins and additional lipids for eventual clutch formation (Ankney and MacInnes 1978, Alisauskas 2002). Therefore, in this chapter we further evaluated the condition bias hypothesis in long-lived waterfowl species subject to harvest uniquely during spring migration, using two North American goose species as a case study.

The lesser snow goose (A. caerulescens caerulescens) and the Ross's goose ( $A$. rossi) (herein referred collectively as light geese) are species of arctic nesting geese that have experienced rapid population growth in the last half century (Batt et al. 1997, Alisauskas et al. 2011). Their rapid population growth led to concerns of habitat 
degradation in breeding grounds (Abraham et al. 2005), adverse impacts to agricultural production along migration corridors (Wagner et al. 1997b), and potential competition with more sensitive species with overlapping habitat requirements (Lamarre et al. 2017). Consequently, the United States Fish and Wildlife Service and Canadian Wildlife Service initiated a conservation order in 1999 allowing for the unlimited daily take of light geese during spring migration throughout the United States and Canada in an effort to reduce population numbers to a sustainably managed size (U.S. Fish and Wildlife Service 2007). These two species, as well as the greater snow goose (A. atlantica), are currently the only species that experience legal take beyond the dates established by the Migratory Bird Treaty Act in 1918, commonly known as the Light Goose Conservation Order ([LGCO];Batt et al. 1997). Therefore, current harvest of light geese occurs throughout three major phases of the annual life-cycle: fall migration, overwintering, and spring migration, each of which unique, differential levels of nutritional requirements (Alisauskas 2002, Hénaux et al. 2012).

Understanding the role of harvest, when condition biases are present, is particularly relevant in worldwide goose populations given their overall increase in size and management decisions to control populations through harvest strategies (Alisauskas et al. 2011, Fox and Madsen 2017). If condition biases extend into longer-lived waterfowl species such as geese, as well as across seasons (spring migration), then individual heterogeneity in survival resulting from differential body condition, likely has additional implications for the effect of harvest on population change via compensatory mortality, beyond low rates of current take (Calvert et al. 2017). Our objective was to evaluate variation in body size and body mass, as well as lipid and protein reserves 
between light geese harvested over decoys, the predominant method used by LGCO participants to harvest light geese (M. Vrtiska, unpublished data) and randomly selected individuals representative of the overall population during spring migration. We predicted that individuals collected over decoys would have reduced lipid and protein levels as well as reduced overall body size, relative to randomly sampled individuals.

\section{STUDY AREA}

We collected light geese across east-central Arkansas and southeast Missouri (Region 1), northwest Missouri (Region 2), southeastern Nebraska (Region 3), and eastcentral South Dakota (Region 4), USA, during spring migration from 2 February - 31 March 2015 and 11 February - 7 March 2016 (Fig. 2.1). These regions were characterized by intensive agricultural production of rice (Oryza sativa), corn (Zea mays), and winter wheat (Triticum aestivum) and typify landscape characteristics that light geese use during spring migration (Abraham et al. 2005). Furthermore, band recovery and harvest estimates indicate a greater proportion of light geese were harvested in these states compared to other states in the Mississippi and Central flyways and these states were considered key light goose staging areas during spring migration (Webb et al. 2010, Alisauskas et al. 2011, Kruse and Fronzcak 2013). Therefore, we collected birds in these states to ensure a heterogeneous sample range of nutrient reserves among sex and age classes representative of light goose populations during spring migration.

\section{METHODS}

We obtained light geese from participants in the Light Goose Conservation Order that harvested birds over decoys during springs 2015 and 2016. Concurrently, we collected light geese by jump shooting random flocks of feeding or loafing geese within 
$25 \mathrm{~km}$ of collection locations for decoy harvested birds. The decision of when to collect geese for this study was mediated by both the estimation of peak migration in each region as well as the presence of LGCO participants. Often, the presence of LGCO participants in a region coincided with peak numbers of light geese in the area. However, on occasion, we observed large numbers of light geese utilizing a region as a stopover site but LCGO participants were not present. Avian body condition can fluctuate rapidly during migration because of extensive energetic expenditures related to flight movements or sudden changes in weather events (Jenni and Jenni-Eiermann 1998). Therefore, to make unbiased comparisons of body condition between decoy harvested birds and those from the overall population, we attempted to collect both decoy and jump shot birds within a 3-7 day time period in each region when weather conditions were generally consistent. When logistically possible, we collected decoy and jump shot birds on the same day. To avoid potential sampling biases related to particular decoy spreads, we only used birds sampled from individual decoy spreads one time. To determine sufficient sample size we used unpublished data (M. Vrtiska, NGPC, unpublished data) for light geese $(n=157)$ collected by both decoys and random jump shooting in southeast Nebraska in 2014. We conducted a power analysis using Proc Power in SAS 9.4 (SAS Institute 9.4) to calculate the number of samples needed to detect a $100 \mathrm{~g}$ difference in body mass at a $\beta=0.9$. Based on the power analysis, we attempted to collect sixty (60) light geese by each harvest type (decoy or jump shot) within each region for each sampling year. When logistically possible, we collected no more than 15 individuals per collection method each day, per region. If more than 15 geese were available for 
collection in a given day, a stratified random sample was taken based on the proportional composition of species, sex, and age demographics available.

All light goose collections were conducted in accordance with the United States Fish and Wildlife Service scientific collection permit number MB47969B-1, Arkansas state permit number 102320141, Missouri state permit number 16217, Nebraska state permit number 535, South Dakota state permit numbers 1 and 5, and University of Missouri Animal Care and Use Committee permit number 8191 . Within 8 hours of collection, we assigned each bird a unique identification number and recorded the time and location of collection on a standardized data sheet (Appendix 1). Afterwards, we tagged and froze collected geese until dissection and analysis at the University of Missouri.

\section{Dissection and Chemical Analyses of Geese}

We aged light geese as hatch-year or after hatch-year (HY or AHY, respectively) by plumage characteristics, foot color, and the absence of caruncles in Ross's geese and recorded sex based on reproductive organs during dissections (Baldassare 2014). We weighed thawed individuals to the nearest $0.5 \mathrm{~g}$ with an electronic scale. We measured head length, culmen length, and total tarsus length with digital calipers to the nearest 0.1 $\mathrm{mm}$, and measured body length and un-flattened wing chord to the nearest mm using a measuring board (Dzubin and Cooch 1993). A complete description of dissection methods and chemical analyses for collected geese are detailed in Fowler et al. (2018), but in brief, we shaved individuals of their feathers to remove potential biases in protein estimates, and weighed and removed ingesta-contents to achieve an ingesta-free body

mass $(\mathrm{g})$. We ground individual carcasses through an industrial meat grinder and then 
dried a subsample $(50.0 \mathrm{~g})$ to a constant mass. We submitted pulverized homogenates samples to the University of Missouri Agricultural Experiment Station Chemical Laboratory for proximate analysis of crude lipid and protein following standardized procedures (Alisauskas 2002, Horwitz 2006).

To account for potential correlation between nutrient levels and body size (Akney and MacInnes 1978, Alisauskas 2002) we used a principal components analysis from the correlation matrix of body length, wing chord, head length, tarsus length, and culmen to derive the first principle component (PC1), which provided a univariate index of body size. Loadings of original variables on PC1 for lesser snow geese were 0.49 for head length, 0.47 for body length, 0.45 for culmen length, 0.41 for tarsus length, and 0.40 for wing chord. The first principal component accounted for $64 \%$ of variation in all variables. The first principal component for Ross's geese explained $62 \%$ of the variation in the same 5 variables and loadings included 0.47 for body length, 0.46 for culmen length, 0.46 for head length, 0.42 for tarsus length, and 0.42 for wing chord. Following Alisauskas (2002), we pooled sexes and related ingesta free body mass (g), proximate lipids (g), and proximate protein (g) to PC1 as an index of body size for each species (Table 2.1). Each $i^{\text {th }}$ nutrient reserve for $j^{\text {th }}$ birds, $u_{i j}$, then was corrected for covaration with PC1, $u_{i f}{ }^{*}$, by adding residuals from each respective regression above to means of the $i^{\text {th }}$ nutrient reserve, $\bar{u}_{\mathrm{i}}$, following:

$$
\mu_{i j}^{*}=\overline{\mathrm{u}}_{j}+\mu_{i j}-\left(a_{j}+b_{j}\left(P C 1_{j}\right)\right)
$$

where $a_{j}$ and $b_{j}$ are intercepts and slopes respectively for regression between $i^{\text {th }}$ nutrient reserves and PC1 (Alisauskas 2002). As a result, ingesta free body mass, lipid, and 
protein reserves were scaled to body size allowing for differences in sex, age, and harvest type to be evaluated while accounting for variation in body size (Alisauskas and Ankney 1987).

\section{Model Fitting}

We developed models for four response variables for both snow and Ross's geese: size-adjusted lipid reserves, size-adjusted protein reserves, size-adjusted ingesta free body mass, and body size (represented by the univariate PC1). For models explaining variation in body condition, we formulated a single general linear mixed model using sex, age, harvest type, region of harvest, and year as explanatory variables. To explain variation in body size, we built a single general linear model for each species using sex, age, and harvest type as explanatory variables. Thus, we avoided model selection methods for philosophical and operational reasons (Clark 2007, Hobbs et al. 2012), primarily because of the ambiguity and subjectivity of selecting a top model from a set of candidates (Kadane and Lazat 2004, Harrison et al. 2018). Instead, we formulated models based on well-established, biological foundations that would address our specific research objective to evaluate the importance of harvest type in influencing body condition relative to other mechanistic parameters. Therefore, we formulated our body condition models as:

$$
\begin{aligned}
\text { Condition }= & \beta_{0}+\beta_{1} *[\mathrm{Sex}]+\beta_{2} *[\text { Age }]+\beta_{3} *[\text { Region }]+\beta_{4} *\left[\mathrm{H}_{\text {Type }}\right]+\beta_{5} \\
& *\left[\mathrm{H}_{\text {Type }} * \text { Age }\right]+\beta_{6} *\left[\mathrm{H}_{\text {Type }} * \text { Region }\right]+\varepsilon
\end{aligned}
$$

where $\beta_{0}$ was the intercept, $\beta_{1}, \beta_{2}, \beta_{3}, \beta_{4}, \beta_{5}$, and $\beta_{6}$ were regression coefficients describing the linear relationship between size adjusted body condition (lipid, protein, or body mass) 
and sex, age, region of harvest, harvest type, the interaction between harvest type and age, and the interaction between harvest type and region, respectively, and $\varepsilon$ is a random year effect. In addition to the main effects, we included two interactions based on the premise that 1) body condition differences between harvest types may vary disproportionately between age classes because of increased harvest susceptibility of naive juveniles (Leafloor et al. 2012) and 2) magnitude of body condition differences between harvest types may not be consistent across sampling regions. Similarly, we modeled variation in body size as:

$$
\begin{aligned}
\text { Body Size }= & \beta_{0}+\beta_{1} *[\mathrm{Sex}]+\beta_{2} *[\text { Age }]+\beta_{3} *[\mathrm{Sex} * \text { Age }]+\beta_{4}\left[\mathrm{H}_{\text {Type }}\right]+\beta_{5} \\
& *\left[\mathrm{H}_{\text {Type }} * \text { Age }\right]
\end{aligned}
$$

where $\beta_{0}$ was the intercept, $\beta_{1}, \beta_{2}, \beta_{3}, \beta_{4}$, and $\beta_{5}$ were regression coefficients describing the linear relationship between body size (univariate PC1) and sex, age, the interaction of sex and age, harvest type, and the interaction between harvest type and age, respectively.

We analyzed general linear models using the base package of Program R (Version, 3.3.3, R Core Team 2018) and used the lme4 package for Program R (Bates et al. 2014) to formulate mixed-effects models. We assessed goodness of fit by calculating conditional and marginal $\mathrm{R}^{2}$ values (Nakagawa and Schielzeth 2012) with the r.squaredGLMM function in the MuMIn package for Program R (Barton 2017). We considered covariates significant when $95 \%$ confidence intervals did not overlap with zero $(\alpha=0.05)$. To estimate least square means (Harvey 1960) for factor combinations of interest and visualize model estimates and their effect size, we used the lmerTest package for Program $\mathrm{R}$ (Kuznetsova et al. 2017). 


\section{RESULTS}

We collected 354 lesser snow geese between 2 February and 31 March 2015 and 405 between 11 February and 7 March 2016 (Appendix 2). Among individuals collected in $2015,185(52 \%)$ were harvested over decoys and 169 (48\%) were randomly collected via jump shooting. Females represented $43 \%$ of individuals harvested over decoys and $53 \%$ of the jump shot sample. Adults harvested over decoys comprised $47 \%$ of the sample while predominating the jump shot sample (84\%). In 2016, we collected 201 snow geese harvested over decoys (49\%) and 205 via jump shooting (51\%). Similar trends in demographic proportion of individuals collected between the two collection treatments in 2015 were also evident in 2016. Females comprised $42 \%$ of the decoyed sample while $52 \%$ of decoyed individuals were adults. Jump shooting resulted in $52 \%$ females but the overall sample composition was heavily skewed to adults (94\%).

Lipid content (adjusted for body size) averaged 137.9 g [standard deviation (SD) $=65.7 \mathrm{~g}$ ) and ranged $332.9 \mathrm{~g}$ across the sample with a minimum value of $7.9 \mathrm{~g}$ to a maximum of $340.8 \mathrm{~g}$. Protein content (adjusted for body size) averaged $369.2 \mathrm{~g} \mathrm{(SD}=$ $28.9 \mathrm{~g}$ ) and ranged $215.3 \mathrm{~g}$ across the sample with a minimum value of $245.6 \mathrm{~g}$ to a maximum of $460.9 \mathrm{~g}$. Ingesta-free body mass (adjusted for body size) averaged $1891.4 \mathrm{~g}$ $(\mathrm{SD}=146.8)$ and ranged $880.9 \mathrm{~g}$ across the sample with a minimum value of $1489.6 \mathrm{~g}$ to a maximum of $2370.5 \mathrm{~g}$. PC1 for lesser snow geese was centered around zero (SD = 1.79) and loadings ranged from -6.2 to 5.9 .

Lipid content in lesser snow geese varied based on the interactions between harvest type and age, and harvest type and collection region. Our model explained approximately $28 \%$ of the overall variation in the lipid content, and the random effect of 
year accounted for $2 \%$ of the explained variation (marginal R-squared $=0.26$; conditional $\mathrm{R}$-squared $=0.28$; Table 2.2). Least square means of lipids in decoy harvested adult geese was 59.9 g (95\% CI: 49.7, 70.2; 38.7\% decrease) lower than individuals collected by jump shooting, while lipid content in hatch-year decoy harvested geese was $29.7 \mathrm{~g}$ (95\% CI: $11.4,47.9 ; 16.5 \%$ decrease) lower than jump shot individuals of the same age (Fig. 2.2A). Averaging across sex and age, least square means of lipid content in decoyharvested individuals from Arkansas was $30.6 \mathrm{~g}$ (95\% CI: 14.1, 46.9; 21.0\% decrease) lower than randomly collected individuals (Fig. 2.3). Similarly, lipid content in decoy harvested individuals from Missouri was $43.7 \mathrm{~g}$ (95\% CI: 26.3, 61.2; 30.8\% decrease) lower, and lipids in birds collected in Nebraska and South Dakota was $39.6 \mathrm{~g}$ (95\% CI: $22.7,56.4 ; 23.9 \%$ decrease) and $65.4 \mathrm{~g}(95 \% \mathrm{CI}: 46.9,83.9 ; 30.9 \%$ decrease $)$, respectively, lower than lipids in individuals collected by jump shooting (Fig. 2.3).

Protein content in lesser snow geese varied by the main effects of age and harvest region, but not by harvest type ( $\beta_{4}=6.95 ; 95 \%$ CI: $-1.34,15.24$; Fig. $\left.2.2 \mathrm{~B}\right)$. Our model explained approximately $17 \%$ of the overall variation in the data, and the random effect of year accounted for 3\% of the explained variation (marginal R-squared $=0.14$; conditional R-squared $=0.17$; Table 2.2). Protein declined for all individuals with increasing latitude across the collection area (Fig. 2.4) such that protein content was 15.4 g (95\% CI: 9.8, 24.1; 4.0\% decrease) lower in South Dakota relative to individuals collected in Arkansas. Averaging across sex, region, and harvest type, protein content was $17.5 \mathrm{~g}(95 \% \mathrm{CI}: 12.4,22.54 .6 \%$ decrease) lower in hatch-year individuals compared to adults. 
Ingesta-free body mass in lesser snow geese varied by the interactions between harvest type and age, and harvest type and collection region. Our model explained approximately $30 \%$ of the overall variation in the data, and the random effect of year accounted for $2 \%$ of the explained variation (marginal R-squared $=0.28$; conditional Rsquared $=0.30$; Table 2.2). Least square means of ingesta-free body mass in decoy harvested adult geese was $129.3 \mathrm{~g}$ (95\% CI: 106.6, 151.9; 6.6\% decrease) lower than individuals collected by jump shooting, while ingesta-free body mass in hatch-year decoy harvested geese was $77.6 \mathrm{~g}$ (95\% CI: 37.2, 117.9; $4.1 \%$ decrease) lower than individuals collected by jump shooting (Fig. 2.2C). Averaging across sex and age, the least square mean estimate of ingesta-free body mass in decoy-harvested individuals from Arkansas was $55.2 \mathrm{~g}(95 \%$ CI: 17.6, 92.8; 2.9\% decrease) lower than jump shot individuals (Fig. 2.5). Similarly, ingesta-free body mass in decoy harvested individuals from Missouri was $104.1 \mathrm{~g}$ (95\% CI: $65.4,142.8 ; 5.5 \%$ decrease) lower than individuals collected by jump shooting. Ingesta-free body mass in decoy collected birds in Nebraska and South Dakota was 75.8 g (95\% CI: 38.4, 113.2; 3.9\% decrease) and 178.5 g (95\% CI: 137.6, $219.5 ; 8.8 \%$ decrease), respectively, lower than ingesta-free body mass in individuals collected by jump shooting (Fig. 2.5). Body size in lesser snow geese was not different between decoy-harvested and jump shot individuals $\left(\beta_{4}=0.08\right.$; 95\% CI: $-0.18-0.34$; Fig. 2.2D), but was influenced by the main effects of sex, age, and their interaction (Table 2.3).

We collected 87 Ross' geese between 2 February and 31 March in 2015, and 67 geese between 11 February and 7 March in 2016 (Appendix 2). Among individuals collected in 2015, 36 (41\%) were harvested over decoys and 51 (59\%) were randomly 
collected via jump shooting. Females represented $53 \%$ of individuals harvested over decoys and $39 \%$ of the jump shot sample. Adults harvested over decoys comprised $47 \%$ of the sample while $84 \%$ of individuals collected via jump shooting were adults. In 2016 , 32 Ross' geese were harvested over decoys (48\%) and 35 were collected via jump shooting (52\%). Adults comprised $72 \%$ of the decoy sample while only $32 \%$ of the overall sample were females. Jump shooting resulted in $49 \%$ females and was heavily skewed to adults $(94 \%)$.

Lipid content (adjusted for body size) in Ross's geese averaged 90. $3 \mathrm{~g}$ [standard deviation $(\mathrm{SD})=44.9 \mathrm{~g})$ and ranged $216.5 \mathrm{~g}$ across the sample with a minimum value of $7.5 \mathrm{~g}$ to a maximum of $224.0 \mathrm{~g}$. Protein content (adjusted for body size) averaged 237.9 $\mathrm{g}(\mathrm{SD}=19.5 \mathrm{~g})$ and ranged $199.6 \mathrm{~g}$ across the sample with a minimum value of $189.7 \mathrm{~g}$ to a maximum of $309.5 \mathrm{~g}$. Ingesta-free body mass (adjusted for body size) averaged $1261.9 \mathrm{~g}(\mathrm{SD}=120.0)$ and ranged $567.1 \mathrm{~g}$ across the sample with a minimum value of $1007.9 \mathrm{~g}$ to a maximum of $1575.0 \mathrm{~g}$. PC1 for Ross's geese was centered around zero (SD $=1.75)$ and loadings ranged from -4.4 to 5.8 .

Lipid content in Ross's geese varied by the main effects of sex, region of harvest, and harvest type, but interactions between harvest type and age, and harvest type and harvest region were not important (Table 2.4). Our model explained approximately 37\% of the overall variation in the data, and the random effect of year accounted for $3 \%$ of the explained variation $($ marginal $\mathrm{R}$-squared $=0.34$; conditional $\mathrm{R}$-squared $=0.37$; Table 2.4). Averaging across age, sex, and region, least square means of lipids in decoy harvested geese was $41.1 \mathrm{~g}$ (95\% CI: 26.2, 55.9; 38.7\% decrease) lower than individuals collected by jump shooting (Fig. 2.6A). In contrast to lesser snow geese, lipid content 
did not increase with increasing latitude of region of harvest. Rather, average lipid content initially decreased after collections in Arkansas such that individuals collected in Missouri and Nebraska had 28.1g (95\% CI: 10.2, 45.9; 26.9\% decrease) and $33.9 \mathrm{~g}$ (95\% CI: 14.7, 53.1; 32.4\% decrease) less lipids, respectively. (Fig. 2.7A). Individuals collected in South Dakota had regained lipid reserves and lipid levels did not differ from individuals collected in Arkansas (Fig. 2.7A).

Protein content in Ross's geese varied only by the main effects of region, decreasing as latitude of collection region increased (Fig. 2.7B). Protein content was not influenced by harvest type, however, the p-value for the slope coefficient of harvest type approximated our designated alpha level $\left(\beta_{4}=11.53\right.$; d.f. $=142, P$-value $=0.067$; Table 2.4, Fig. 2.6B). Our model explained approximately $28 \%$ of the overall variation in the data, and the random effect of year did not account for any portion of the explained variation $($ marginal $\mathrm{R}$-squared $=0.28$; conditional $\mathrm{R}$-squared $=0.28$; Table 2.4$)$.

Ingesta-free body mass in Ross's geese varied by the main effects of age, region of harvest, and harvest type, but interactions between harvest type and age, and harvest type and harvest region were not important (Table 2.4). Our model explained approximately $51 \%$ of the overall variation in the data, and the random effect of year accounted for $6 \%$ of the explained variation (marginal R-squared $=0.45$; conditional Rsquared $=0.51$; Table 2.4). Averaging across age, sex, and region, the least square mean estimate of ingesta-free body mass in decoy harvested geese was $118.9 \mathrm{~g}(95 \%$ CI: 83.4, 154.5; 9.2\% decrease) lower than individuals collected by jump shooting (Fig. 2.6C). Ingesta-free body mass closely followed patterns observed in lipid content across harvest regions. Least square mean estimates of ingesta-free body mass in Missouri and 
Nebraska were 79.9 g (95\% CI: 37.5, 122.5; $6.2 \%$ decrease) and 88.6 g (95\% CI: 43.0, $134.2 ; 6.9 \%$ decrease), respectively, lower relative to individuals collected in Arkansas (Fig. 2.7C). Individuals collected in South Dakota were not different in estimates of ingesta-free body mass, relative to those collected in Arkansas (Fig. 2.7C). Body size in Ross's geese was influenced by the main effects of sex and the interaction between harvest type and age such that decoy shot hatch year individuals were larger than jump shot hatch year individuals (Table 2.5). However, body size did not differ between harvest types for adults (Fig. 2.8).

\section{DISCUSSION}

Our findings support the body condition bias hypothesis in a long-lived species during spring migration. While the condition bias hypothesis has received much support for shorter-lived duck species (Greenwood et al. 1986, Hepp et al. 1986, Pace and Afton 1999), our study is the first to directly identify condition biases in a longer-lived goose species and is in contrast to the only other study known to test this hypothesis in geese (Morez et al. 2000). We found that both age classes of lesser snow and Ross's geese harvested over decoys had lower size-adjusted body mass and lipid reserves, relative to individuals in the general population. Despite canalization in long-lived species (Peron 2016), our study demonstrates that the LGCO harvest primarily removes from the population a cohort of individuals of lower body condition and likely more risk prone resulting from an increased need to acquire energy stores used for migration. Therefore, future harvest assessments on population change in light geese should additionally consider the effect of removing individuals who likely have lower overall fitness. 
Spring migration is an energetically costly event and requires a balance of water, protein, and lipid reserves for optimal energy expenditure (Klassen 1996, Jenni and Jenni-Eiermann 1998). While we predicted that condition biases would affect both lipid and protein content, lower body mass in decoy-harvested individuals coincided with reduced lipid content only and did not influence protein reserves. This result is consistent with the use of lipid reserves as the primary fuel source for migration (Jenni and JenniEiermann 1998). Because of their high energy content per unit, lipid reserves contain eight to ten times more labile energy than protein or glycogen (McWilliams et al. 2004). However, we also found that the significance test of harvest type as a predictor for protein content in Ross's geese closely approached our designated alpha level of $0.05(P$ value $=0.067$ ), suggesting that under more extreme conditions than in our study, decoy harvested geese may also experience reduced protein levels. Proteins can be catabolized for energy, but their stores largely provide the structural capacity for flight (McWilliams et al. 2004). Therefore, individuals with reduced protein, in addition to reduced lipid reserves, would likely have an increased vulnerability for harvest. Overall, our results support the condition bias hypothesis that decoy harvested individuals are more susceptible to harvest resulting from a reduction in their primary source of energetic reserves, leading to an increased willingness to respond to decoys that signal foraging opportunities.

Moreover, we found that, regardless of harvest type, increases in body mass associated with increased latitude were explained by improved lipid reserves, while protein reserves simultaneously declined. Long-term declines of protein reserves in prebreeding lesser snow and Ross's geese arriving to nesting colonies were documented 
from 1993-2008 (Traylor 2010). Yet, protein reserves remained unchanged during the same time period on the Canadian prairies, which suggests that protein limitation occurs north of the Canadian prairies (Ross et al. 2017) and outside of the collection area of our study. Decreases in protein at earlier stages of migration observed in our study may be in part a necessity to maintain an optimum wing loading while building lipid reserves, thus requiring a reduction in protein reserves (Klassen 1996). Additionally, reduced protein could be an artifact of food availability throughout the landscape we sampled in, where the predominate food type was waste corn which is carbohydrate rich but has low protein content (Abraham et al. 2005).

The influence of reduced body condition to harvest susceptibility occurred at different magnitudes between adults and juveniles in our study. In general, juvenile light geese have greater harvest susceptibilities compared to adults during the regular harvest season (Leafloor et al. 2012) and it has been hypothesized this increased harvest susceptibility is a result of limited experience (i.e. increased naivety to decoys) and poorer body condition relative to older birds (Morez et al. 2000, Alisauskas et al. 2006). Morez et al. (2000) did not find evidence for a condition bias (based on size adjusted total body mass) in adult greater snow geese sampled between 1993-1995, but did report support for greater harvest susceptibility of juvenile geese that exhibited lower body condition at the time of banding. However, in our study, we found lipid condition biases were greater in decoy-harvested adults ( $38.7 \%$ decrease) compared to juveniles $(16.5 \%$ decrease). Additionally, despite overall lower body mass, juvenile geese maintained lipid reserves equal to adults, or greater, in the case of lesser snow geese. Juvenile lipid content levels comparable to those observed in adults may be a product of their social 
behavior to remain in family groups for at least a year after hatching, thereby benefitting from parental provision which affords access to protected foraging locations (Prevett and MacInnes 1980). However, an additional consideration for high lipid content in juveniles is the timing of our sampling in spring. It may be a reasonable assumption that variation in body condition among juveniles is greater earlier in the first year of life, but processes of natural and hunter mortality during the fall and winter remove those with lower fitness so that only fitter individuals remain into the spring.

We chose to use jump shooting as a method to sample from the general population to serve as a control group for decoy shot individuals. We selected jump shooting techniques because it allowed for the sampling of individuals without the presence of decoys and presumably mixed individuals in the flock when they were flushed. The control sample should be truly random but jump shooting may incur biases of its own. While we are confident that our jump shot geese are more representative of the general population compared to decoy shot individuals, body condition in jump shot individuals may be slightly skewed towards dominant family groups. Evidence points towards more dominant family groups capitalizing edges along a feeding flock (Black et al. 1992, Rowcliff et al. 2004, Poisbleau et al. 2006). Due to logistical constraints, sneaking up on foraging geese required approaching the flock from a habitat edge. While we were deliberate in flushing birds prior to shooting to maximize the mixing of individuals, it is possible that our sample contained a disproportionate number of individuals who were in better body condition because of social dominance. Nonetheless, our results demonstrate that individuals with greater body condition are not the predominate type of bird harvested over decoys. 
In long distant migrants, relative body size influences the capacity for energy storage, so that larger bodied individuals have an increased capacity for nutrient transport (Ankney and MacInnes 1978, Alisauskas and Ankney 1990, Klassen et al. 2006). Therefore, one possible extension of the condition bias hypothesis is the idea that decoy harvested individuals would be smaller bodied than the general population. Interestingly, while Morez et al. (2000) did not find evidence of reduced condition in decoy shot individuals, they did report decoyed individuals were structurally smaller than those captured with cannon-nets. However, we did not observe a difference in body size between harvest types in lesser snow geese. Instead, body size was influenced by sex and age, which is consistent with previous studies (Alisauskas 2002). Nonetheless, in Ross's geese we found a significant interaction between harvest type and age. No difference in body size and harvest type occurred in adults, but surprisingly, jump shot juvenile geese were smaller than decoy shot geese. Between juvenile and adult individuals, we would expect greater variation in body size to exist in juveniles due to the increase phenotypic heterogeneity among a cohort in the first year of life. Yet, we expected increased susceptibility to harvest in smaller bodied individuals, not those of larger body size. Currently, we do not have a working hypothesis for the response found in our study other than an anomaly associated with relatively low sample size.

Differences in body condition between decoy harvested and jump shot individuals are likely a reflection of population heterogeneity resulting from individual variation in decisions or abilities to allocate time, energy, and nutrients to enhance their fitness (Stearns 1992, Vedder and Bouwhuis 2018). Individual variation is the core means of natural selection for traits within a population (Giminez et al. 2018) and discussions in 
regards to various mechanisms contributing to individual heterogeneity of traits continue (see Cam et al. 2016, Vedder and Bouwhuis 2018). Nonetheless, environmental conditions during early development (i.e. "silver spoon" effects) and seasonal-carry over effects are an important contribution to heterogeneous body condition and fitness within a population (Van der Pool et al. 2006, Cam and Aubry 2011, and Sedinger and Alisauskas 2014). However, because we did not find strong evidence for differences in body size between harvest types, heterogeneous body condition identified in our study more likely occurs on an inter-seasonal or inter-annual basis rather than a legacy effect during early growth and development. Differences in winter habitat quality may be one factor influencing spring body condition (see Chapter 4 for further details). Additionally, Souchay et al. (2014) found that the cost of reproduction in greater snow geese negatively influenced breeding propensity the following year and that nesting success was likely driven by individual quality. Further, Koons et al. (2014a) reported significant positive effects of age senescence in lesser snow geese on natural mortality. In these examples, body condition was concluded as a likely proximate mechanism for observed differential fitness rates, such that poorer quality individuals have increased probabilities of mortality (Conroy et al. 1989, Sedinger and Herzog 2012, Peron 2013) or reduced breeding propensity (Béchet et al. 2004, Souchay et al. 2014). Therefore, in our study, observed differences in body condition within and between harvest types suggest non-homogenous survival rates among adult lesser snow and Ross's geese. Currently, survival parameters of most goose species are estimated for juvenile and adult cohorts (Calvert et al. 2017) and sometimes additionally include sub-adults (Iverson et al. 2014). Yet, homogenous estimation of adult (categorized either as $>1$ or 2 years old) survival ignores potential 
variation in individuals experiencing differential life history events. For instance, Iverson et al. (2014) separately analyzed survival between breeding Canada geese (Branta canadensis) and non-reproductive individuals (determined by the proportion of juveniles in flocks during routine banding) and found that non-reproductive geese had lower survival than successful breeders and that their harvest served to partially compensate the overall effect of hunter harvest. Similarly, it is reasonable to expect that heterogeneous survival exists within other goose species, including lesser snow and Ross's geese, who exhibit differential levels of body condition, particularly during energetically costly lifehistory events such as spring migration. Given the development of analytical methods to evaluate heterogeneous survival rates (Pledger and Schwarz 2002, Gimenez et al. 2018), future studies should consider assessing individual variation among cohorts to estimate the range and distribution of population vital rates and better describe impacts of different realized life-histories to fitness.

Inferences of our results as a comprehensive representation of body condition differences between decoyed geese and the general population during the LGCO harvest should additionally consider the combinations of annual and inter-seasonal environmental variability that may influence body condition and harvest susceptibility, as well as harvest tactics that result in the successful removal of individuals with differential body condition. In general, differences in body condition between decoy harvested individuals and the remaining population may best be considered a dynamic spatial and temporal trait, rather than a static pattern. For example, peak annual participation in the LGCO often coincides with peak migration or after peak migration to capitalize on the increased naivety to decoys of juveniles that often lag in migration phenology (personal 
observation). In contrast, harvest aimed at the "vanguard" is often more difficult because this cohort is largely comprised of adults whose advanced migration phenology coincides with improved body condition and advanced nest initiation (Ebbinge and Spanns 1995, Béty et al. 2003). While we did not sample geese in the "vanguard" of migration, harvest still occurs and it is possible that differences in body condition within this cohort are smaller between decoyed and available cohorts. Secondly, environmental pressures, such as weather severity, experienced during migration could differentially affect individuals within the population dispersed spatially across a flyway (Bety et al. 2004, Robson and Barriocanal 2008). Therefore, the extent of difference in individual body condition between harvest types could vary annually or within the season dependent upon conditions encountered during migration. Nonetheless, our two year assessment suggests that, at least during periods of peak migration and peak LGCO participation, harvested individuals have poorer body condition.

\section{MANAGEMENT IMPLICATIONS}

Efforts to reduce populations of light geese via liberalized harvest regulations and implementation of a conservation order have been in place since 1999. Over the current time period, previous research identified virtually no impact of the LGCO on adult survival rates or population decline (Alisauskas et al. 2011, Koons et al. 2014b, Calvert et al. 2017). More recently, light goose population growth has slowed but this is attributed to density dependent conditions occurring at terminal staging areas during spring migration and at breeding colonies (Ross et al. 2017). The inability of the LGCO to reduce adult survival rates results largely from overall low harvest rates and an inability to sustain proportional harvest rates as the population increased (Alisauskas et al. 2011). 
Currently, it is estimated that more adult individuals die of natural mortality on an annual basis than those that experience harvest mortality (Calvert et al. 2017). Therefore, to successfully reduce adult survival rates the LGCO would need to generate substantially greater annual adult harvest rates (Leafloor et al. 2012). However, our findings provide an additional consideration regarding the potential for harvest to reduce population size through reduced survival rates. The likely presence of heterogeneous survival via variation in body condition allows for possible harvest compensation without requiring density-dependence (Lebreton 2005, Caudill et al. 2017). Therefore, disproportionate harvest of poorer conditioned lesser snow and Ross's geese in decoy hunting situations may serve as an additional buffer against any realized effects of harvest. Indeed, Lindberg et al. (2013) found that compensation for harvest mortality decreased as the proportion of high-quality individuals harvested increased. Harvest has generally been considered additive in most goose species given their high natural survival rates (Rexstad 1992, Koons et al. 2014b). Yet, current observed levels of harvest in light geese fail to indicate evidence of additivity (Calvert et al. 2017). Therefore, in addition to insufficient harvest rates, harvest of individuals exhibiting poorer body condition relative to the general population suggest that the LGCO primarily pre-emptively removes individuals from the population that are more likely to die of natural mortality at later stages of migration. 


\section{LITERATURE CITED}

Abraham, K. F., R. L. Jefferies, and R. T. Alisauskas. 2005. The dynamics of landscape change and snow geese in mid-continent North America. Global Change Biology $11: 841-855$.

Alisauskas, R. T. 2002. Arctic climate, spring nutrition, and recruitment in midcoontinent lesser snow geese. Journal of Wildlife Management 66:181-193.

Alisauskas, R. T., and C. D. Ankney. 1987. Age-related variation in the nutrient reserves of breeding American Coots (Fulica americana). Canadian Journal of Zoology $65: 2417-2420$.

Alisauskas, R. T., and C. D. Ankney. 1990. Body Size and fecundity in lesser snow geese. Auk 107:440-443.

Alisauskas, R. T., K. L. Drake, S. M. Slattery, and D. K. Kellett. 2006. Neckbands, harvest, and survival of Ross's geese from Canada's central arctic. Journal of Wildlife Management 70:89-100.

Alisauskas, R. T., R. F. Rockwell, K. W. Dufour, E. G. Cooch, G. Zimmerman, K. L. Drake, J. O. Leafloor, T. J. Moser, and E. T. Reed. 2011. Harvest, survival, and abundance of midcontinent lesser snow geese relative to population reduction efforts. Wildlife Monographs 179:1-42. 
Anderson, D. R., and K. P. Burnham. 1976. Population ecology of the mallard: VI. The effect of exploitation on survival. U. S. Fish and Wildlife Service, Washington D.C., USA.

Ankney, C. D., and C. D. MacInnes. 1978. Nutrient reserves and the reproductive performance of female lesser snow geese. Auk 95:459-471.

Baldassarre, G. A. 2014. Ducks, Geese, and Swans of North America. John Hopkins University Press, Baltimore, Maryland, USA.

Barton, K. 2017. MuMIn: multi-model inference. R package version 1.40.0. R Foundation for Statistical Computing, Vienna, Austria. [online] URL: https://cran.rproject.org/web/packages/MuMIn/

Bates, D., M. Mächler, B. Bolker, and S. Walker. 2014. Fitting linear mixed-effects models using lme4. arXiv preprint arXiv:1406.5823.

Batt, B. 1997. Arctic ecosystems in peril: Report of the Arctic goose habitat working group. U.S. Fish and Wildlife Service, Washington, D.C. and Canadian Wildlife Service, Ottawa, Ontario.

Béchet, A., J.-F. Giroux, and G. Gauthier. 2004. The effects of disturbance on behaviour, habitat use and energy of spring staging snow geese. Journal of Applied Ecology 41:689-700. 
Bêty, J., G. Gauthier, and J.-F. Giroux. 2003. Body condition, migration, and timing of reproduction in snow geese: a test of the condition-dependent model of optimal clutch size. American Naturalist 162:110-121.

Bêty, J., J.-F. Giroux, and G. Gauthier. 2004. Individual variation in timing of migration: causes and reproductive consequences in greater snow geese (Anser caerulescens atlanticus). Behavioral Ecology and Sociobiology 57:1-8.

Black, J. M., C. Carbone, R. L. Wells, and M. Owen. 1992. Foraging dynamics in goose flocks: the cost of living on the edge. Animal Behaviour 44:41-50.

Blums P., J. D. Nichols, J. E. Hines, M. S. Lindberg, and A. Mednis. 2005. Individual quality, survival variation and patterns of phenotypic selection on body condition and timing of nesting in birds. Oecologia 143:365-376.

Bonenfant, C., J. Gaillard, T. Coulson, M. Festa-Bianchet, A. Loison, M. Garel, L. E. Loe, P. Blanchard, N. Pettorelli, and N. Owen-Smith. 2009. Empirical evidence of density-dependence in populations of large herbivores. Advances in Ecological Research 41:313-357.

Calvert, A. M., R. T. Alisauskas, and G. C. White. 2017. Annual survival and seasonal hunting mortality of midcontinent snow geese. Journal of Wildlife Management 81:1009-1020.

Cam, E., and L. Aubry. 2011. Early development, recruitment and life history trajectory in long-lived birds. Journal of Ornithology 152:187-201. 
Cam, E., L. M. Aubry, and M. Authier. 2016. The conundrum of heterogeneities in life history studies. Trends in Ecology and Evolution 31:872-886.

Cooch, E. G., M. Guillemain, G. S. Boomer, J.-D. Lebreton, and J. D. Nichols. 2014. The effects of harvest on waterfowl populations. Wildfowl Special Issue No. 4:220276.

Caudill, D., M. R. Guttery, T. M. Terhune, J. A. Martin, G. Caudill, D. K. Dahlgren, and T. A. Messmer. 2017. Individual heterogeneity and effects of harvest on greater sage-grouse populations. Journal of Wildlife Management 81:764-765.

Clark, J. M. 2007. Models for ecological data. Princeton University Press, Princeton, New Jersey, USA.

Conroy, M. J., G. R. Costanzo, and D. B. Stotts. 1989. Winter survival of female American black ducks on the Atlantic Coast. Journal of Wildlife Management 53:99-109.

Conroy, M. J., and D. G. Krementz. 1990. A review of the evidence for the effects of hunting on American black duck populations. Pages 501-517 in. Transactions of the North American Wildlife and Natural Resources Conference. Volume 55.

Dufour, W. K., C. D. Ankney, and J. P. Weatherhead. 1993. Condition and vulnerability to hunting among Mallards staging at Lake St. Clair, Ontario. Journal of Wildlife Management 57:209-215. 
Dzubin, A., and E. G. Cooch. 1992. Measurements of geese: general field methods. California Waterfowl Association, Sacramento, California, USA.

Ebbinge, B. S., and B. Spaans. 1995. The importance of body reserves accumulated in spring staging areas in the temperate zone for breeding in dark-bellied brent geese Branta b. bernicla in the high Arctic. Journal of Avian Biology 105-113.

Fowler, D. N., K. J. Kuechle, B. A. Woodall, M. P. Vrtiska, and E. B. Webb. 2018. Evaluating indices of lipid and protein content in lesser snow and Ross's geese during spring migration. Wildlife Society Bulletin 42:295-303.

Fox, A. D., and J. Madsen. 2017. Threatened species to super-abundance: The unexpected international implications of successful goose conservation. Ambio 46:179-187.

Gimenez, O., E. Cam, and J. M. Gaillard. 2018. Individual heterogeneity and capturerecapture models: What, why and how? Oikos 127:664-686.

Greenwood, H. R., R. G. Clark, and P. J. Weatherhead. 1986. Condition bias of huntershot mallards (Anas platyrhynchos). Canadian Journal of Zoology 64:599-601.

Hamel, S., J. M. Gaillard, M. Douhard, M. Festa-Bianchet, F. Pelletier, and N. G. Yoccoz. 2018. Quantifying individual heterogeneity and its influence on lifehistory trajectories: different methods for different questions and contexts. Oikos 127:687-704. 
Harrison, X. A., L. Donaldson, M. E. Correa-Cano, J. Evans, D. N. Fisher, C. E. D. Goodwin, B. S. Robinson, D. J. Hodgson, and R. Inger. 2018. A brief introduction to mixed effects modelling and multi-model inference in ecology. PeerJ 6:e4794.

Harvey, W. 1960. Least-squares analysis of data with unequal subclass numbers. Technical report, Agricultural Research Service, U.S. Department of Agriculture, Washington D.C., USA.

Hénaux, V., L. A. Powell, M. P. Vrtiska, and K. A. Hobson. 2012. Establishing Winter origins of migrating lesser snow geese using stable isotopes. Avian Conservation and Ecology 7:5.

Hepp, G. R., Blohm, R. J., Reynolds, R. E., Hines, J. E. and J. D. Nichols. 1986. Physiological condition of autumn-banded mallards and its relationship to hunting vulnerability. Journal of Wildlife Management 50:177-183.

Hill, M. R. J., R. T. Alisauskas, C. D. Ankney, and J. O. Leafloor. 2003. Influence of body size and condition on harvest and survival of juvenile Canada geese. Journal of Wildlife Management 67:530-541.

Hobbs, N. T., H. Andrén, J. Persson, M. Aronsson, S. E. Applications, N. July, N. T. Hobbs, H. Andrén, J. Persson, M. Aronsson, and G. Chapron. 2012. Native predators reduce harvest of reindeer by Sámi pastoralists. Ecological Applications $22: 1640-1654$.

Horwitz, W. 2006. Official methods of analysis of AOAC International. Gaithersburg, Maryland, USA. 
Humburg, D.D., M. G. Anderson, M. G. Brasher, M. F. Carter, J. M. Eadie, D. C. Fulton, F. A. Johnson, M. C. Runge, M. P. and Vrtiska. 2018. Implementing the 2012 North American Waterfowl Management Plan revision: populations, habitat, and people. Journal of Wildlife Management, 82: 275-286.

Iverson, S. A., E. T. Reed, R. John Hughes, and M. R. Forbes. 2014. Age and breeding stage-related variation in the survival and harvest of temperate-breeding Canada Geese in Ontario. Journal of Wildlife Management 78:24-34.

Jenni, L., and S. Jenni-Eiermann. 1998. Fuel supply and metabolic constraints in migrating birds. Journal of Avian Biology 29:521-528.

Johnson, F. A., B. K. Williams, J. D. Nichols, J. El Hines, W. L. Kendall, G. W. Smith, and D. F. Caithamer. 1993. Developing an adaptive management strategy for harvesting waterfowl in North America. Transactions of the North American Wildlife and Natural Resources Conference 58:565-583.

Kadane, J. B., and N. A. Lazat. 2004. Methods and criteria for model selection. Journal of the American Statistical Association 99:279-209.

Klaassen, M. 1996. Metabolic constraints on long-distance migration in birds. Journal of Experimental Biology 199:57-64.

Klaassen, M., K. F. Abraham, R. L. Jefferies, and M. P. Vrtiska. 2006. Factors affecting the site of investment, and the reliance on savings for arctic breeders: the capitalincome dichotomy revisited. Ardea 94:371-384. 
Koons, D. N., M. Gamelon, J.-M. Gaillard, L. M. Aubry, R. F. Rockwell, F. Klein, R. Choquet, and O. Gimenez. 2014a. Methods for studying cause-specific senescence in the wild. Methods in Ecology and Evolution 5:924-933.

Koons, D. N., R. F. Rockwell, and L. M. Aubry. 2014b. Effects of exploitation on an overabundant species: the lesser snow goose predicament. Journal of Animal Ecology 3:365-374.

Kruse, K. L., and D. Fronczack. 2013. Light geese in the Central and Mississippi Flyways. U.S. Fish and Wildlife Service, Denver, Colorado, USA.

Kuznetsova, A., P. B. Brockhoff, and R. H. B. Christensen. 2017. ImerTest Package: Tests in linear mixed effects models. Journal of Statistical Software 82.

Lamarre, J. F., P. Legagneux, G. Gauthier, E. T. Reed, and J. Bêty. 2017. Predatormediated negative effects of overabundant snow geese on arctic-nesting shorebirds. Ecosphere 8: e01788.

Leafloor, J. O., T. J. Moser, and B. D. J. Batt. 2012. Evaluation of special management measures for midcontinent lesser snow geese and Ross's geese. Arctic Goose Joint Venture Special Publication. Washington, D.C, Ottawa, Ontario.

Lebreton, J.-D. 2005. Dynamic and statistical models for exploited populations. Australian and New Zealand Journal of Statistics 47:49-63. 
Lindberg, M. S., J. S. Sedinger, and J. Lebreton. 2013. Individual heterogeneity in black brant survival and recruitment with implications for harvest dynamics. Ecology and Evolution 3:4045-4056.

McWilliams, S. R., C. Guglielmo, B. Pierce, and M. Klaassen. 2004. Flying, fasting, and feeding in birds during migration: A nutritional and physiological ecology perspective. Journal of Avian Biology 35:377-393.

Miller, J. R., and M. J. Hay. 1981. Determinants of hunter participation: duck hunting in the Mississippi flyway. American Journal of Agricultural Economics 63:677-684.

Morez, V., G. Gauthier, and A. Reed. 2000. Effect of body condition on vulnerability of greater snow geese to hunting and capture. Journal of Wildlife Management 64:875-886.

Murray, D. L., M. G. Anderson, and T. D. Steury. 2010. Temporal shift in density dependence among North American breeding duck populations. Ecology 91:571581.

Nakagawa, S., and H. Schielzeth. 2013. A general and simple method for obtaining R ${ }^{2}$ from generalized linear mixed-effects models. Methods in Ecology and Evolution 4:133-142.

Nevoux, M., J. Forcada, C. Barbraud, J. Croxall, and H. Weimerskirch. 2010. Bethedging response to environmental variability, an intraspecific comparison. Ecology 91:2416-2427. 
Nichols, J. D. 1991. Extensive monitoring programmes viewed as long-term population studies: the case of North American waterfowl. Ibis 133:89-98.

Nichols, J. D., F. A. Johnson, and B. K. Williams. 1995. Managing North American waterfowl in the face of uncertainty. Annual Review of Ecology and Systematics 26:177-199.

Owen, M., and J. M. Black. 1989. Factors affecting the survival of barnacle geese on migration from the breeding grounds. Journal of Animal Ecology 58:603-617.

Pace III, R. M., and A. D. Afton. 1999. Direct recovery rates of lesser scaup banded in northwest Minnesota: sources of heterogeneity. Journal of Wildlife Management 63:389-395.

Péron, G. 2013. Compensation and additivity of anthropogenic mortality: life-history effects and review of methods. Journal of Animal Ecology 82:408-417.

Péron, G., J. M. Gaillard, C. Barbraud, C. Bonenfant, A. Charmantier, R. Choquet, T. Coulson, V. Grosbois, A. Loison, G. Marzolin, N. Owen-Smith, D. Pardo, F. Plard, R. Pradel, C. Toïgo, and O. Gimenez. 2016. Evidence of reduced individual heterogeneity in adult survival of long-lived species. Evolution 70:2909-2914.

Phillips, J., and F. C. Lincoln. 1930. American Waterfowl: Their present situation and outlook for the future. Houghton Mifflin, Boston, USA.

Pledger, S., and C. J. Schwarz. 2002. Modelling heterogeneity of survival in bandrecovery data using mixtures. Journal of Applied Statistics 29:315-327. 
Poisbleau, M., H. Fritz, M. Valeix, P.-Y. Perroi, S. Dalloyau, and M. M. Lambrechts. 2006. Social dominance correlates and family status in wintering dark-bellied brent geese, Branta bernicla bernicla. Animal Behaviour 71:1351-1358.

Prevett, J. P., and C. D. MacInnes. 1980. Family and other social groups in snow geese. Wildlife Monographs 71:3-46.

R Development Core Team (2018). R: A language and environment for statistical computing. R Foundation for Statistical Computing, Vienna, Austria. ISBN 3900051-07-0, URL http://www.R-project.org.

Reinecke, K. J., and C. W. Shaiffer. 1988. A field test for differences in condition among trapped and shot mallards. Journal of Wildlife Management 52:227-232.

Rexstad, E. A. 1992. Effect of hunting on annual survival of Canada geese in Utah. Journal of Wildlife Management 56:297-305.

Robson, D., and C. Barriocanal. 2008. The influence of environmental conditions on the body mass of barn swallows (Hirundo rustica) during spring migration. Journal of Ornithology 149:473-478.

Ross, M. V., R. T. Alisauskas, D. C. Douglas, and D. K. Kellett. 2017. Decadal declines in avian herbivore reproduction: density-dependent nutrition and phenological mismatch in the Arctic. Ecology 98:1869-1883. 
Rowcliffe, J. M., R. A. Pettifor, and C. Carbone. 2004. Foraging inequalities in large groups: quantifying depletion experienced by individuals in goose flocks. Journal of Animal Ecology 73:97-108.

Sedinger, J. S., and M. P. Herzog. 2012. Harvest and dynamics of duck populations. Journal of Wildlife Management 76:1108-1116.

Sheeley, D. G., and L. M. Smith. 1989. Tests of diet and condition bias in hunter-killed northern pintails. Journal of Wildlife Management 53:765-769.

Souchay, S. G., and G. G. Gauthier. 2014. To breed or not : a novel approach to estimate breeding propensity and potential trade-offs in an Arctic-nesting species. Ecology 95:2745-2756.

Stearns, S. C. 1992. The evolution of life histories. - Oxford University Press, London, United Kingdom.

U.S. Fish and Wildlife Service. 2007. Final environmental impact statement: light goose management. U.S. Department of the Interior, Washington, D.C., USA.

van de Pol, M., and S. Verhulst. 2006. Age-dependent traits: a new statistical model to separate within-and between-individual effects. American Naturalist 167:766773.

Vedder, O., and S. Bouwhuis. 2018. Heterogeneity in individual quality in birds: Overall patterns and insights from a study on common terns. Oikos 127:719-727. 
Waddington, C. 1953. Genetic assimilation of an acquired character. Evolution 7:118126.

Wagner, G. P., G. Booth, and H. Bagheri-Chaichian. 1997a. A population genetic theory of canalization. Evolution 51:329-347.

Wagner, K. K., R. H. Schmidt, and M. R. Conover. 1997b. Compensation programs for wildlife damage in North America. Wildlife Society Bulletin 25:312-319.

Webb, E. B., Smith, L. M., Vrtiska, M. P., and T. G. Lagrange. 2010. Effects of local and landscape variables on wetland bird habitat use during migration through the Rainwater Basin. Journal of Wildlife Management 74:109-119.

Williams, B. K., and F. A. Johnson. 1995. Adaptive management and the regulation of waterfowl harvests. Wildlife Society Bulletin 23:430-436.

Viljugrein, H., N. C. Stenseth, G. W. Smith, and G. H. Steinbakk. 2005. Density dependence in North American ducks. Ecology 86:245-254. 


\section{TABLES}

Table 2.1 - Relationship between nutrient reserves and a univariate index of body size in lesser snow $(n=759)$ and Ross' geese $(n=154)$ used to correct nutrient reserves for body size. Geese were collected in Arkansas, Missouri, Nebraska, and South Dakota during the spring Light Goose Conservation Order in 2015 and 2016.

\begin{tabular}{llc}
\hline Species & Simple linear regression & Goodness of fit \\
\hline Lesser snow goose & Lipids $=139.02+3.66\left(\mathrm{PC}^{\mathrm{a}}\right)$ & $\mathrm{r}^{2}=0.01$ \\
Lesser snow goose & Protein $=369.13+19.13(\mathrm{PC} 1)$ & $\mathrm{r}^{2}=0.58$ \\
Lesser snow goose & Body Mass $=1891.93+88.71(\mathrm{PC} 1)$ & $\mathrm{r}^{2}=0.53$ \\
Ross's goose & Lipids $=90.31+4.74(\mathrm{PC} 1)$ & $\mathrm{r}^{2}=0.02$ \\
Ross's goose & Protein $=237.89+11.68(\mathrm{PC} 1)$ & $\mathrm{r}^{2}=0.52$ \\
Ross's goose & Body Mass $=1261.90+55.54(\mathrm{PC} 1)$ & $\mathrm{r}^{2}=0.51$ \\
\hline $\begin{array}{l}{ }^{a} \text { Index of body size derived from principal components analysis of length of tarsus, culmen, head, body, } \\
\text { and wing chord. }\end{array}$
\end{tabular}


Table 2.2 - Results of general linear mixed models explaining variation in lipid content (g), protein content (g), and ingesta-free body mass $(\mathrm{g})$ of lesser snow geese $(n=759)$ collected during the spring Light Goose Conservation Order in 2015 and 2016 . Predictor variables included sex (male or female), age (“AHY” - adults; "HY” - juveniles), harvest region (Arkansas, Missouri, Nebraska, South Dakota), and harvest type (decoy or jump shot).

\begin{tabular}{|c|c|c|c|c|c|c|c|c|c|}
\hline & \multicolumn{3}{|c|}{ Lipid Model } & \multicolumn{3}{|c|}{ Protein Model } & \multicolumn{3}{|c|}{ Body Mass Model } \\
\hline & Estimate & & $95 \% \mathrm{CI}$ & Estimate & & $95 \% \mathrm{CI}$ & Estimate & & $95 \%$ CI \\
\hline$(\text { Intercept })^{a}$ & $89.66^{* * *}$ & \pm & 20.42 & $378.24^{* * *}$ & \pm & 8.80 & $1865.55^{* * *}$ & \pm & 40.19 \\
\hline Sex (Male) & -3.53 & \pm & 8.02 & 2.59 & \pm & 3.83 & 6.10 & \pm & 17.76 \\
\hline Age (HY) & $54.50^{* * *}$ & \pm & 11.75 & $-15.39^{* * *}$ & \pm & 5.61 & -7.05 & \pm & 26.02 \\
\hline Region (Missouri) & -13.11 & \pm & 15.18 & $-8.40^{*}$ & \pm & 7.25 & $-82.98^{* * *}$ & \pm & 33.63 \\
\hline Region (Nebraska) & 10.30 & \pm & 15.91 & $-12.85^{* * *}$ & \pm & 7.59 & $-40.60^{*}$ & \pm & 35.24 \\
\hline Region (South Dakota) & $30.53^{* * *}$ & \pm & 16.31 & $-18.43^{* * *}$ & \pm & 7.78 & -6.68 & \pm & 36.12 \\
\hline Harvest Type (Jump) & $45.70^{* * *}$ & \pm & 17.36 & 6.95 & \pm & 8.29 & $81.04^{* * *}$ & \pm & 38.46 \\
\hline Harvest Type x Age (Jump, HY) & $-30.31^{* *}$ & \pm & 20.89 & -4.18 & \pm & 9.97 & $-51.70^{*}$ & \pm & 46.27 \\
\hline Harvest Type x Region (Jump, Missouri) & 13.17 & \pm & 22.13 & 1.50 & \pm & 10.56 & 48.90 & \pm & 49.02 \\
\hline Harvest Type x Region (Jump, Nebraska) & 9.05 & \pm & 22.31 & 1.24 & \pm & 10.65 & 20.64 & \pm & 49.42 \\
\hline Harvest Type x Region (Jump, South Dakota) & $34.88^{* *}$ & \pm & 23.14 & 6.05 & \pm & 11.05 & $123.32^{* * *}$ & \pm & 51.26 \\
\hline Marginal $\mathrm{R}^{2}$ & \multicolumn{3}{|c|}{0.26} & \multicolumn{3}{|c|}{0.14} & \multicolumn{3}{|c|}{0.28} \\
\hline Conditional $\mathrm{R}^{2}$ & \multicolumn{3}{|c|}{0.28} & \multicolumn{3}{|c|}{0.17} & \multicolumn{3}{|c|}{0.30} \\
\hline Variance: Year (Intercept) & \multicolumn{3}{|c|}{106.39} & \multicolumn{3}{|c|}{17.92} & \multicolumn{3}{|c|}{366.51} \\
\hline Variance: Residual & \multicolumn{3}{|c|}{3145.08} & \multicolumn{3}{|c|}{716.51} & \multicolumn{3}{|c|}{15430.54} \\
\hline
\end{tabular}

${ }^{* * *} \mathrm{p}<0.001,{ }^{* *} \mathrm{p}<0.01,{ }^{*} \mathrm{p}<0.05$

${ }^{\text {a }}$ Intercept referenced on adult female geese collected in Arkansas over decoys 
Table 2.3- Results of general linear model explaining variation in body size (PC1) of lesser snow geese $(n=759)$ collected during the spring Light Goose Conservation Order in 2015 and 2016. Predictor variables included sex (male or female), age ("AHY" adults; "HY" - juveniles), and harvest type (decoy or jump shot).

\begin{tabular}{lccc}
\hline & \multicolumn{3}{c}{ Body Size Model } \\
\hline & Estimate & & $\mathbf{9 5 \% ~ C I ~}$ \\
(Intercept) $^{\mathrm{a}}$ & $-0.66^{* * *}$ & \pm & 0.25 \\
Sex (Male) & $1.93^{* * *}$ & \pm & 0.25 \\
Age (HY) & $-0.96^{* * *}$ & \pm & 0.39 \\
Sex x Age (Male, HY) & $-0.54^{*}$ & \pm & 0.45 \\
Harvest Type (Jump) & 0.08 & \pm & 0.26 \\
Harvest Type x Age (Jump, HY) & 0.14 & \pm & 0.54 \\
\hline N observations & \multicolumn{3}{c}{759} \\
Adj. R ${ }^{2}$ & \multicolumn{3}{c}{0.33} \\
RMSE & \multicolumn{3}{c}{1.46} \\
\hline${ }^{* * *} \mathrm{p}<0.001{ }^{* *} \mathrm{p}<0.01{ }^{*}{ }^{*} \mathrm{p}<0.05$ &
\end{tabular}

${ }^{* * *} \mathrm{p}<0.001,{ }^{* *} \mathrm{p}<0.01,{ }^{*} \mathrm{p}<0.05$

${ }^{\text {a }}$ Intercept referenced on adult female geese collected over decoys 
Table 2.4 - Results of general linear mixed models explaining variation in lipid content ( $\mathrm{g}$ ), protein content (g), and ingesta-free body mass $(\mathrm{g})$ of Ross's geese $(n=154)$ collected during the spring Light Goose Conservation Order in 2015 and 2016. Predictor variables included sex (male or female), age (“AHY" - adults; "HY” - juveniles), harvest region (Arkansas, Missouri, Nebraska, South

Dakota), and harvest type (decoy or jump shot).

\begin{tabular}{|c|c|c|c|c|c|c|c|c|c|}
\hline & \multicolumn{3}{|c|}{ Lipid Model } & \multicolumn{3}{|c|}{ Protein Model } & \multicolumn{3}{|c|}{ Body Mass Model } \\
\hline & Estimate & & $95 \% \mathrm{CI}$ & Estimate & & $95 \% \mathrm{CI}$ & Estimate & & $95 \%$ CI \\
\hline$\left(\right.$ Intercept) ${ }^{\mathrm{a}}$ & $94.06^{* * *}$ & \pm & 24.00 & $238.81^{* * *}$ & \pm & 10.73 & $1257.14^{* * *}$ & \pm & 64.83 \\
\hline Sex (Male) & $-14.33^{*}$ & \pm & 11.42 & 3.59 & \pm & 5.30 & -2.43 & \pm & 27.15 \\
\hline Age (HY) & -4.32 & \pm & 17.70 & -5.46 & \pm & 8.71 & $-56.50^{*}$ & \pm & 45.60 \\
\hline Region (Missouri) & -27.30 & \pm & 26.52 & -9.20 & \pm & 13.11 & -66.22 & \pm & 67.66 \\
\hline Region (Nebraska) & $-37.29^{*}$ & \pm & 26.47 & $-17.86^{* *}$ & \pm & 13.10 & $-94.38^{* *}$ & \pm & 67.33 \\
\hline Region (South Dakota) & -14.12 & \pm & 23.39 & -10.27 & \pm & 11.58 & -44.39 & \pm & 59.37 \\
\hline Harvest Type (Jump) & $40.08^{* *}$ & \pm & 24.25 & 11.53 & \pm & 12.01 & $112.81^{* * *}$ & \pm & 61.55 \\
\hline Harvest Type x Age (Jump, HY) & -0.37 & \pm & 26.97 & -4.37 & \pm & 13.36 & 4.45 & \pm & 68.43 \\
\hline Harvest Type x Region (Jump, Missouri) & -1.58 & \pm & 32.31 & 6.87 & \pm & 15.99 & -27.53 & \pm & 82.93 \\
\hline Harvest Type x Region (Jump, Nebraska) & 6.70 & \pm & 34.68 & 5.28 & \pm & 17.18 & 11.59 & \pm & 88.01 \\
\hline Harvest Type x Region (Jump, South Dakota) & -0.32 & \pm & 29.72 & -3.35 & \pm & 14.72 & 31.69 & \pm & 75.46 \\
\hline Marginal $\mathrm{R}^{2}$ & \multicolumn{3}{|c|}{0.34} & \multicolumn{3}{|c|}{0.28} & \multicolumn{3}{|c|}{0.45} \\
\hline Conditional $\mathrm{R}^{2}$ & \multicolumn{3}{|c|}{0.37} & \multicolumn{3}{|c|}{0.28} & \multicolumn{3}{|c|}{0.51} \\
\hline Variance: Year (Intercept) & \multicolumn{3}{|c|}{53.51} & \multicolumn{3}{|c|}{2.11} & \multicolumn{3}{|c|}{809.26} \\
\hline Variance: Residual & \multicolumn{3}{|c|}{1336.01} & \multicolumn{3}{|c|}{288.84} & \multicolumn{3}{|c|}{7560.9} \\
\hline
\end{tabular}

${ }^{* * *} \mathrm{p}<0.001,{ }^{* *} \mathrm{p}<0.01,{ }^{*} \mathrm{p}<0.05$

${ }^{\text {a }}$ Intercept referenced on adult female geese collected in Arkansas over decoys 
Table 2.5- Results of general linear model explaining variation in body size (PC1) of Ross's geese $(n=154)$ collected during the spring Light Goose Conservation Order in 2015 and 2016. Predictor variables included sex (male or female), age (“AHY”- adults; "HY" - juveniles), and harvest type (decoy or jump shot).

\begin{tabular}{lccc}
\hline & \multicolumn{3}{c}{ Body Size Model } \\
\hline & Estimate & $\mathbf{9 5 \%}$ CI \\
(Intercept) ${ }^{\mathrm{a}}$ & $-0.64^{*}$ & \pm & 0.56 \\
Sex (Male) & $1.57^{* * *}$ & \pm & 0.54 \\
Age (HY) & -0.74 & \pm & 0.89 \\
Sex x Age (Male, & -0.43 & \pm & 1.05 \\
Harvest Type (Jump) & 0.02 & \pm & 0.55 \\
Harvest Type x Age & $-1.69^{* *}$ & \pm & 1.13 \\
\hline N observations & \multicolumn{4}{l}{} \\
Adj. ${ }^{2}$ & 0.33 & \\
RMSE & 1.44 & \\
${ }^{* * *} \mathrm{p}<0.001,{ }^{* *} \mathrm{p}<0.01,{ }^{*} \mathrm{p}<0.05$ & \\
${ }^{\mathrm{a}}$ Intercept referenced on adult female geese collected over decoys
\end{tabular}




\section{FIGURES}

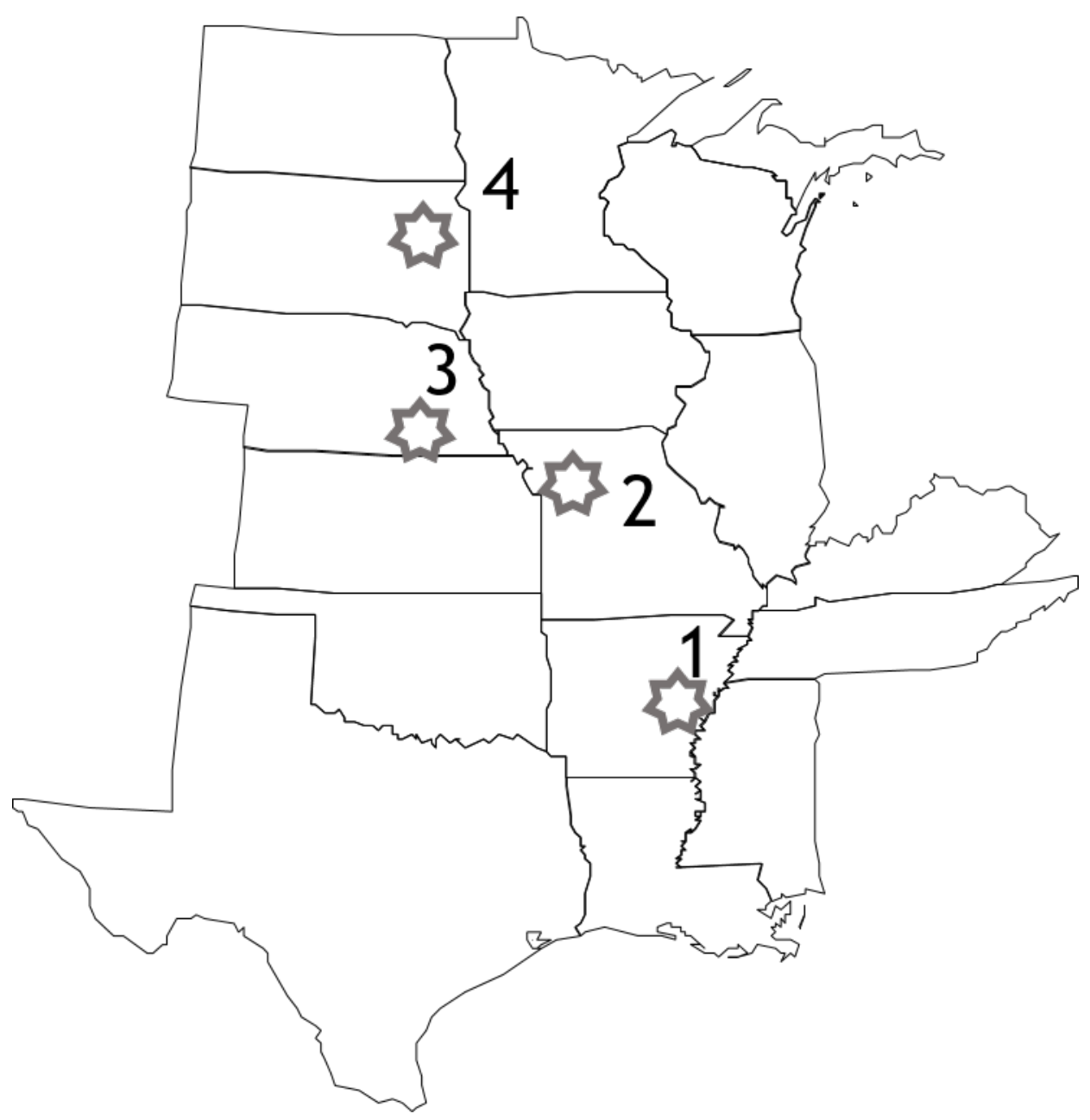

Fig. 2.1 - Sampling regions of lesser snow $(n=759)$ and Ross's geese $(n=154)$ collected during spring migration 2015 and 2016, in Arkansas, Missouri, Nebraska, and South Dakota, USA. 

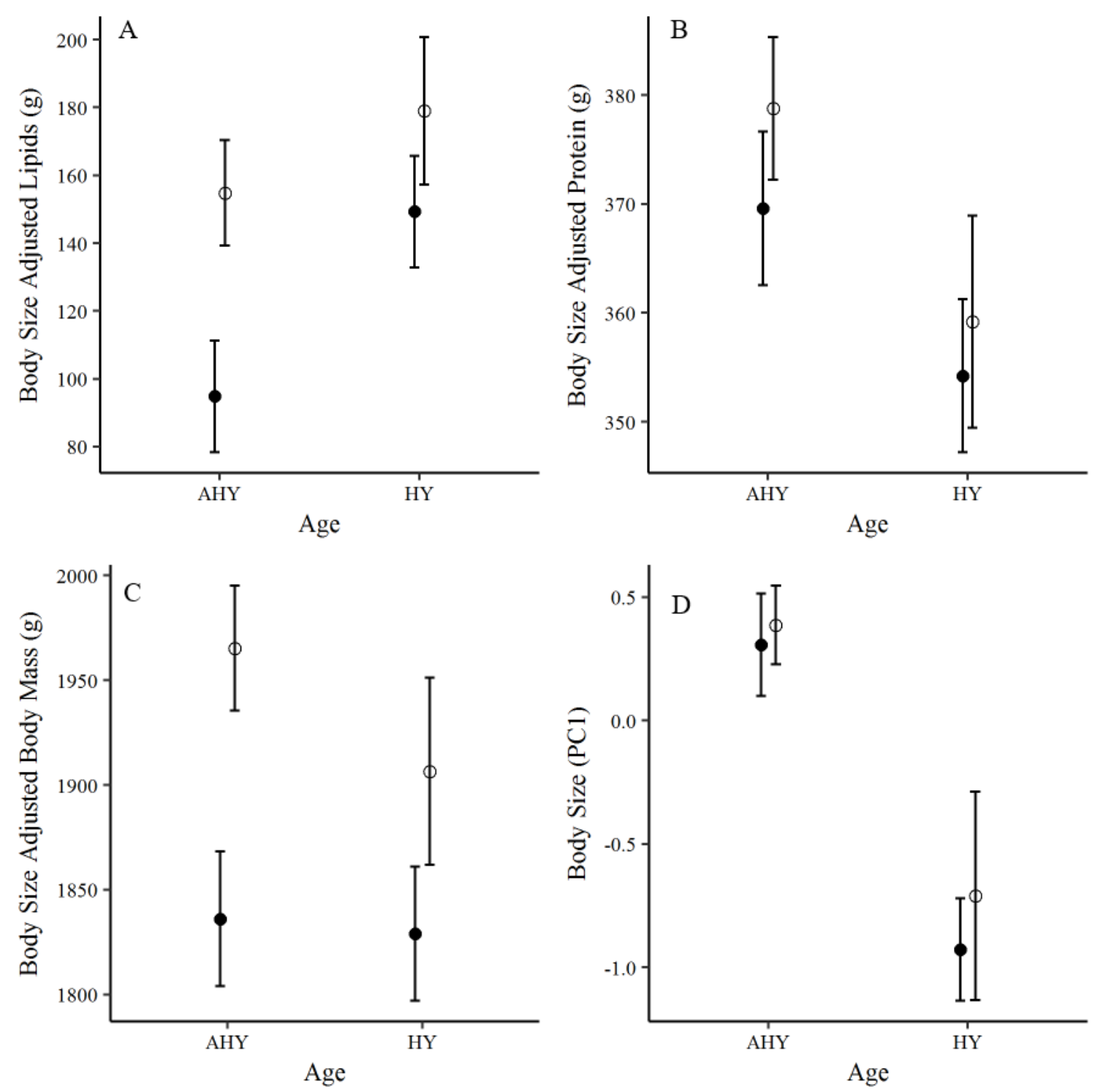

Fig. 2.2- Least-square means and 95\% confidence intervals of lipid content (A), protein content (B), ingesta-free body mass (C), and body size (D) in lesser snow geese $(n=759)$ by age class (after-hatch year [AHY] and hatch-year [HY]) and harvest type collected during the spring Light Goose Conservation Order in 2015 and 2016. Closed circles are decoy-harvested individuals, open circles are jump shot individuals. 


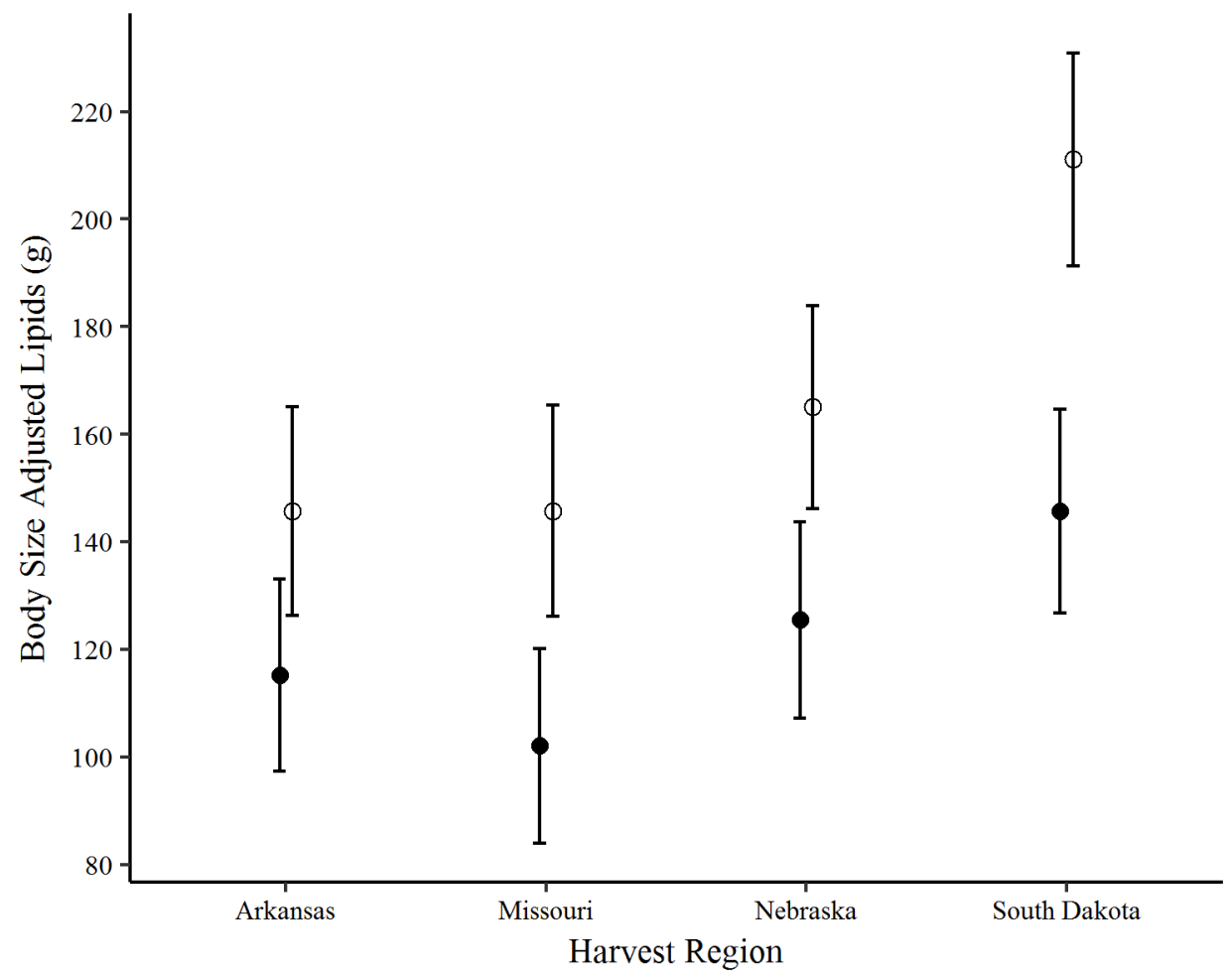

Fig. 2.3 - Least square means and 95\% confidence intervals of lipid content in lesser snow geese $(n=759)$ by harvest region and harvest type collected during the spring Light Goose Conservation Order in 2015 and 2016. Closed circles are decoy-harvested individuals, open circles are jump shot individuals. 


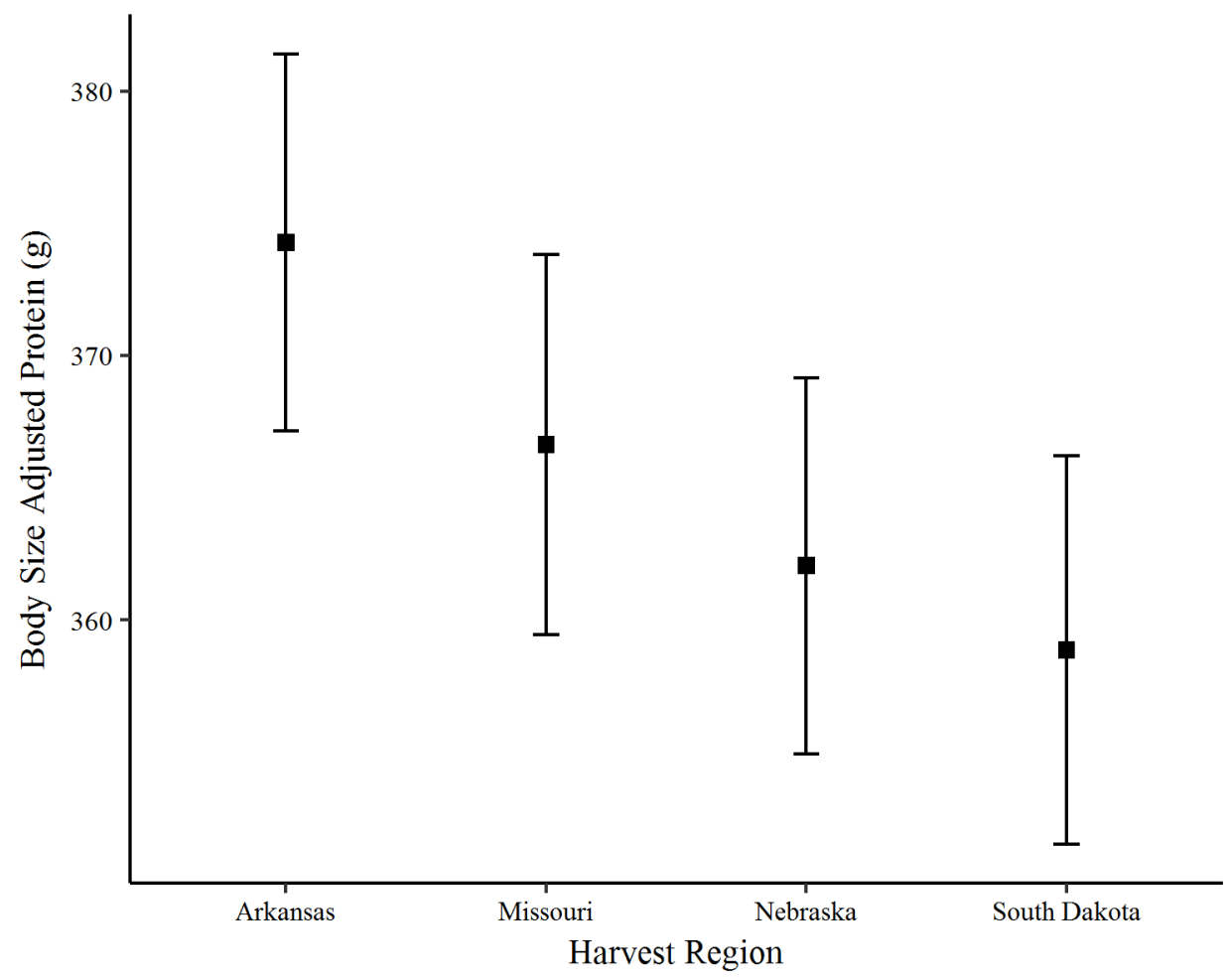

Fig. 2.4 - Least square means and 95\% confidence intervals of protein content in lesser snow geese $(n=759)$ by harvest region collected during the spring Light Goose Conservation Order in 2015 and 2016. 


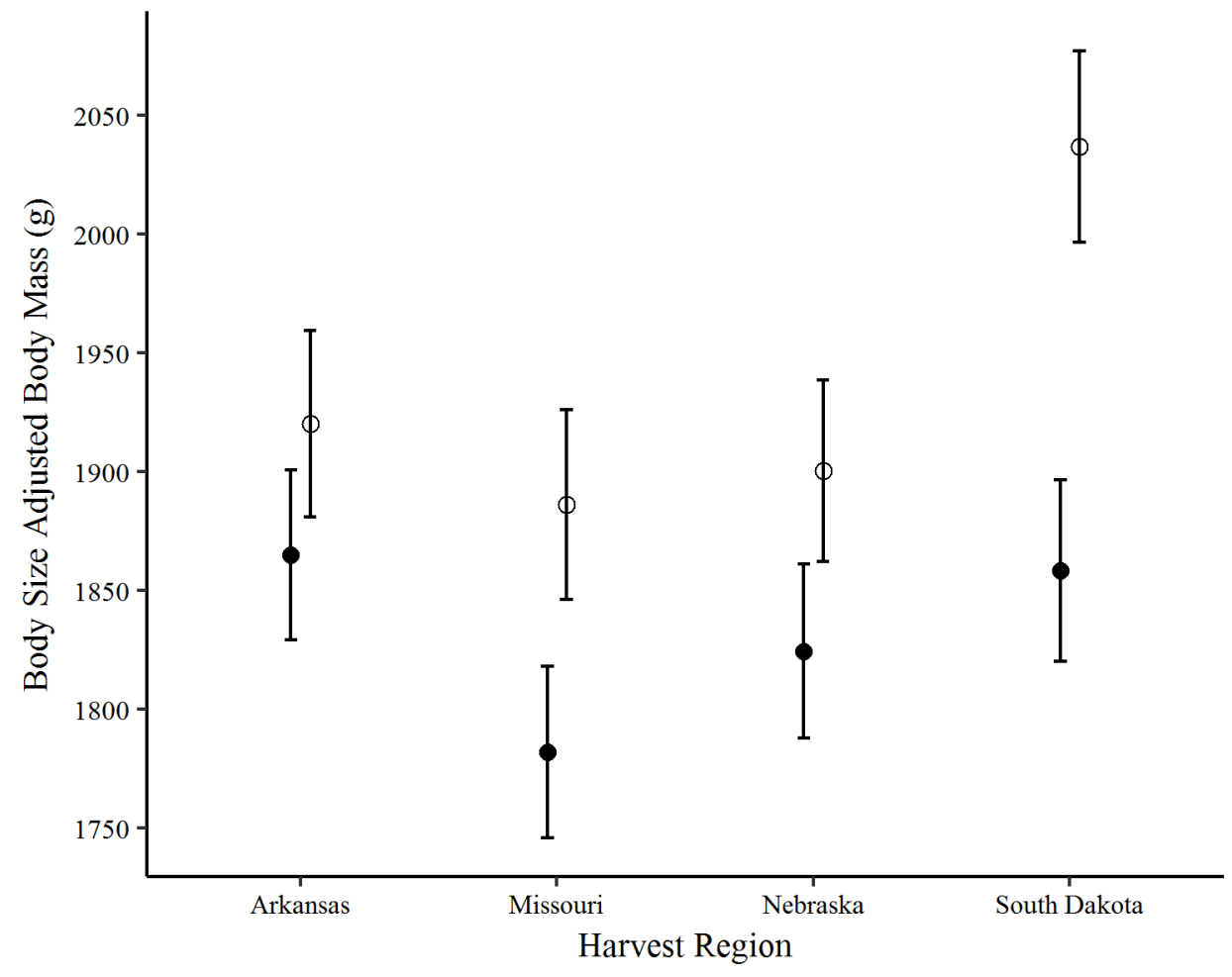

Fig. 2.5 - Least square means and 95\% confidence intervals of ingesta-free body mass in lesser snow geese $(n=759)$ by harvest region and harvest type collected during the spring Light Goose Conservation Order in 2015 and 2016. Closed circles are decoyharvested individuals, open circles are jump shot individuals. 

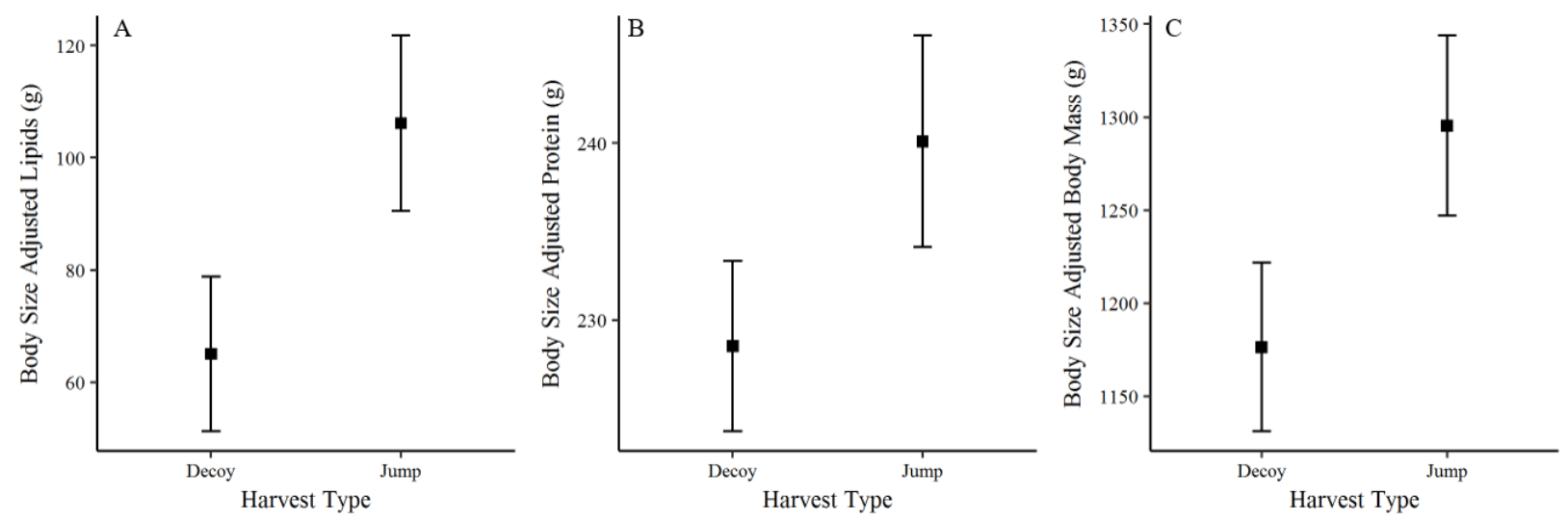

Fig. 2.6 - Least square means and 95\% confidence intervals of lipid content (A), protein content (B), and ingesta-free body mass (C) in Ross's geese $(n=154)$ by harvest type collected during the spring Light Goose Conservation Order in 2015 and 2016. 

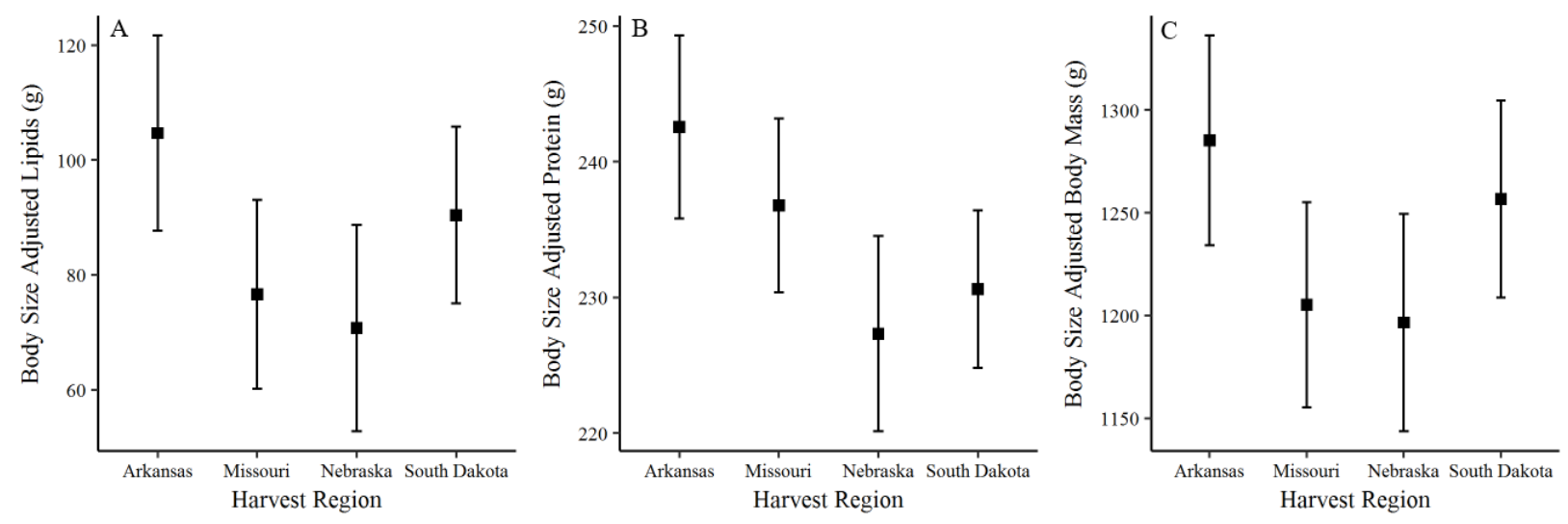

Fig. 2.7- Least square means and 95\% confidence intervals of lipid content (A), protein content $(\mathrm{B})$, and ingesta-free body mass $(\mathrm{C})$ in Ross's geese $(n=154)$ by harvest region collected during the spring Light Goose Conservation Order in 2015 and 2016. 


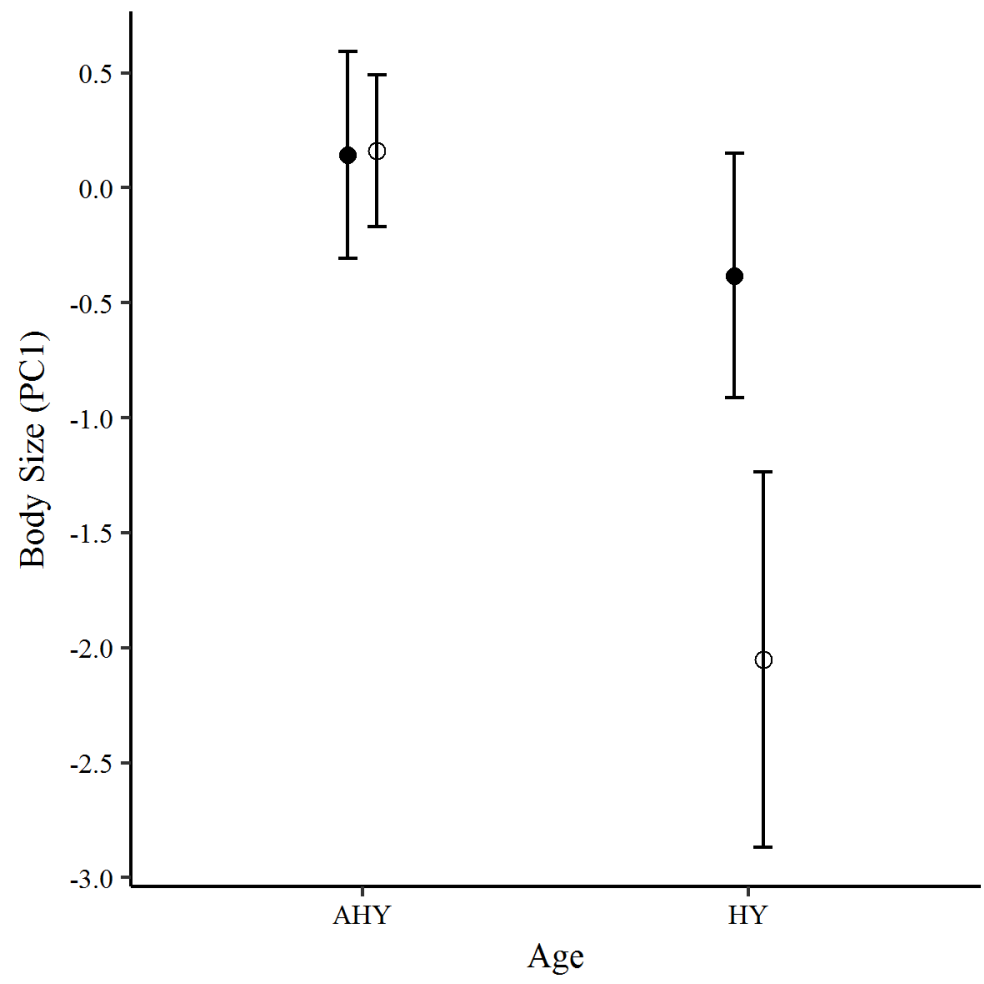

Fig. 2.8 - Least square means and 95\% confidence intervals of body size in Ross's geese $(n=154)$ by age class (after-hatch year and hatch-year) and harvest type collected during the spring Light Goose Conservation Order in 2015 and 2016. Closed circles are decoyharvested individuals, open circles are jump shot individuals. 


\section{CHAPTER 3 - ESTIMATING INDIVIDUAL VARIATION IN SURVIVAL OF LESSER SNOW GEESE USING MARK-RECOVERY DATA: POSSIBILITIES AND LIMITATIONS}

\section{INTRODUCTION}

Animal demography frequently requires observing marked individuals across time to estimate vital rates (i.e. survival, fecundity, immigration, emigration) and among species, these vital rates provide a framework for informed management decisions. Animal demography techniques for estimating survival rates are varied and can include multiple observations of a single individual (capture-mark-recapture) or only record when a marked individual is harvested and reported (mark-recovery). For the majority of managed waterfowl species, band recoveries from hunter shot birds are the primary source to estimate survival and assess population response to hunter harvest (Alisauskas et al. 2011, Koons et al. 2014). However, inherent to commonly used models that estimate survival rates are a series of assumed conditions, that when violated, could result in biased estimates (see Brownie et al. 1985 and Williams et al. 2002 for a review). One condition in band-recovery models is the assumption of homogeneity among the banded sample (Pollock and Raveling 1982), stipulating that all marked individuals within the same cohort (i.e. sex, age class, etc.) have the same annual survival probability. Implications of violating this assumption in terms of biased rate estimation has received considerable attention (Pollock and Raveling 1982, Nichols et al. 1982, Barker 1992, White et al. 2013), given that fitness variation among individuals is an inherent required condition for natural selection (Ender 1986, Newton 1989, Cam et al. 2002). Indeed, individual heterogeneity across diverse population taxa has been observed in survival 
(Lindberg et al. 2013), breeding propensity (Souchay et al. 2014), emigration (Chambert et al. 2015), and cause specific senescence (Koons et al. 2014b). A detailed review of the mechanisms behind individual heterogeneity in animal populations and methodological developments for detecting individual heterogeneity was provided in a special issue of the journal Oikos described by Hamel et al. (2018).

In the case of midcontinent lesser snow geese (Anser caerulescens caerulescens), perceived overabundance resulted in an international management plan to sustainably reduce population size via reduced adult survival rates through increased hunter harvest (Ankney 1996, Batt et al. 1997, Alisauskas et al. 2011). Most recent estimates of causespecific mortality (harvest mortality vs. natural mortality) in midcontinent lesser snow geese demonstrate that natural mortality far exceeds that produced by harvest (Calvert et al. 2017). Consequently, conservation measures that allow for increased harvest currently only operates in a way that compensates for natural mortality and thus could support greater rates of harvest without affecting current rates of adult survival (Calvert et al. 2017). Compensatory harvest of midcontinent snow geese is a unique phenomenon. While harvest is generally presumed to be additive in long-lived species, such as geese (Rexstad et al. 1992), a large contribution to the current compensatory nature of harvest in midcontinent snow geese is likely a nominal amount of harvest relative to the overall population size. Still, the consideration of heterogeneous survival rates in those removed from the population via harvest is important because individual variation is a mechanism that can reduce the strength of additivity if less fit individuals are disproportionately harvested (Lebreton 2005, Cooch et al. 2014, Caudill et al. 2017). 
Recently, Fowler et al. (Chapter 2) reported decoy harvested lesser snow geese had lower body condition (primarily lower lipid reserves) compared to a sample of jumpshot individuals, which were presumed to represent the overall population. Thus, a large contribution of hunter harvested geese may be individuals with reduced body condition who have a higher probability of natural mortality than the overall population, similar to results found in shorter-lived waterfowl species (e.g., Greenwood et al. 1986, Pace and Afton 1999). The primary removal of these poorer conditioned individuals could reduce the strength of additivity presumed to occur in species like geese who are long-lived and have naturally high survival rates. For example, Iverson et al. (2014) uniquely identified the influence of individual variation on survival rate response to harvest pressure in temperate-breeding Canada geese (Branta canadensis). Harvest of adult non-breeding Canada geese was compensatory to natural mortality, but additive for adults who were successful breeders (Iverson et al. 2014). Additionally, Drake et al. (2018) found a cost of reproduction on survival in successful nesting Ross's geese (Anser rossii), such that successful nesters had lower survival rates than failed breeders. Nonetheless, failed breeders had higher hunter reporting rates, suggesting that the cost of reproduction contributes to differential probabilities of natural mortality (Drake et al. 2018). Thus, quantifying the extent of individual variation within population cohorts can be important when considering inferences on the effect of harvest on population survival rates. Yet at present, the amount of individual variation in adult survival rates of midcontinent lesser snow geese using available banding data has not been assessed.

While some proportion of individual variation in survival rates can be quantified if known or suspected differences are measured (i.e., relating gosling survival to date of 
hatch), it is often the case that hidden individual variation remains and contributes as random error in traditional estimation approaches (Gimenez and Choquet 2010, Gimenez et al 2018). Assessing this hidden individual variation in survival rates is a relatively new analysis, and techniques and approaches continue to evolve for different data types (Gimenez et al. 2018). Burnham and Rexstad (1993) first demonstrated detection of heterogeneity in mark-recovery data by assuming that each individual has an intrinsic survival probability resulting from an infinite beta distribution around a random variable $S$, and that individuals with the lowest survival probabilities tend to leave the population first. Later, Pledger and Schwartz (2002) developed a technique to estimate finitemixtures of survival rates from band recovery data. While this approach identifies heterogeneous survival rates for $g$ groups, inferences regarding the proportions of each group which contributes to the overall population cannot be assessed (S. Pledger, personal communication). More recently, Royle (2008) proposed a Bayesian approach using a continuous random effect within a generalized linear mixed model framework to treat each individual as a separate group, allowing for a mean survival estimate and an estimate of variance based on all individuals (Kéry and Schaub 2012). While various software programs such as Program MARK and JAGS provide the capacity to model individual variation in survival or recovery rates from mark-recovery data, few published studies have demonstrated the above approach in either simulations or real-world data set (but see White et al. 2013). Therefore, our objective was to assess the magnitude of individual variation contributing to adult survival estimates of lesser snow geese using long-term band recovery data. Measuring the variance associated with survival estimates provides a means to indirectly identify heterogeneous survival rates that we expect to 
exist as a result of genotypic / phenotypic variation and life-history tradeoffs.

Additionally, assessing individual variation quantifies a potential mechanism for compensatory harvest via heterogeneous survival rates (Sedinger and Herzog 2012).

\section{METHODS}

Midcontinent lesser snow geese are subdivided into two breeding subpopulations, those nesting north of $60^{\circ}$ latitude (Arctic subpopulation) and those breeding in colonies south of $60^{\circ}$ latitude (subarctic subpopulation) (Leafloor et al. 2012). Because adult survival rates tend to be greater in the Arctic subpopulation relative to the subarctic (Alisauskas et al. 2011), we choose to partition estimates of individual variation in adult survival between the two subpopulations for our analysis. We used data from bandings and band recoveries by hunters initiated from long-term monitoring efforts at Karrak Lake $\left(67^{\circ} 14^{\prime} \mathrm{N}, 100^{\circ} 15^{\prime} \mathrm{W}\right)$ and La Pérouse Bay $\left(58^{\circ} 4^{\prime} \mathrm{N}, 90^{\circ} 4^{\prime} \mathrm{W}\right)$ from 1999-2016. At both colonies, breeding adults and goslings were captured during remigal molt and marked with a standard aluminum U.S. Geological Survey leg band. While juvenile individuals are expected to exhibit greater individual variation in survival (Saether and Bakke 2000, Caswell 2001), we restricted our analysis to individuals marked as adults because population change is more sensitive to variation in adult demographic rates (Rockwell et al.1997, Leafloor et al. 2012) and adults have been the primary target of increased harvest initiatives (Leafloor et al. 2012). We defined each recovery year as beginning at the time of banding (Jul-Aug) and ending before the next banding season. To reduce model run time, we subset the data by selecting every $4^{\text {th }}$ marked individual for analysis. Our data set consisted of 26,215 banded birds and 2,833 recoveries, including 
13,262 marked individuals and 1,364 recoveries from Karrak Lake and, 12,953 marked individuals and 1,469 recoveries from La Pérouse Bay.

We developed three unique models to analyze band recovery data using a Bayesian state-space framework (Kéry and Schaub 2012). Briefly, the models are formulated using a state and observation process. The state process is the possible states of a marked individual over time: dead or alive, and is treated as the latent variable $z_{i, t}$, which reflects the true state of individual $i$ at time $t$, ( 1 if alive, 0 if dead). Therefore, the state process is a Bernoulli trial described as:

$$
z_{i, t+1} \mid z_{t} \sim \operatorname{Bernoulli}\left(z_{i, t} * S_{i, t}\right)
$$

where $S$ is the survival probability of individual $i$ at time $t$. The observation process describes the probability of recovery $\left(r_{i, t}\right)$, given mortality, and is modeled as:

$$
y_{i, t} \mid z_{i, t} * z_{i, t-1} \sim \text { Bernoulli }\left(\left(z_{i, t-1}-z_{i, t}\right) * r_{i, t}\right)
$$

where $y$ is the matrix of observed data from individual capture histories.

We developed models using JAGS version 4.3.0 (Plummer 2017), derived from examples provided in Kéry and Schaub (2012). We ran models using the jagsUI package (Kellner 2017) in R Studio, version 3.3.3 (R Development Core Team 2017). Our posterior summaries were based on three Markov Chain Monte Carlo chains of 50,000 iterations after a burn-in of 20,000 and thinning interval of 10 . We assessed model convergence using the Gelman-Rubin statistic (Rhat <1.2) (Gelman and Rubin 1992) and graphical observations of chain mixing in trace plots. 
To establish a baseline for comparison, we developed a time constant survival and recovery model (Model 1) without accounting for individual variation in survival. We choose to model time constant adult survival based on previous studies that demonstrated relatively stable survival rates across years (Calvert et al. 2017) and our overall interest in detecting the extent of individual variation within the population. In our second model, we added a continuous random variable $\left(\varepsilon_{i}\right)$ for individuals, such that individual variation among band recoveries was normally distributed around a mean and variance $\left(\sigma^{2}\right)$. In this model (Model 2), we used vague priors for the random effect but used mean and precision (where precision $=1 /\left(\sqrt{ } \sigma^{2}\right)$ estimates of survival from our first model as informative priors on survival to facilitate in model convergence. Our third model was built upon Model 2 and additionally included informative priors on the precision parameter (variance component) of the random effect for individuals. We provided an informative prior distribution for the variance of the random effect to promote model convergence. We were not aware of any literature that provided an estimate of variance in individual survival on lesser snow geese so we employed a mean of 0.60 (on the logit scale) for $\sigma^{2}$ as a reasonable expectation of variance in adult survival. In all models, we modeled the logits of adult survival and recovery. For each model, we plotted the probability density distribution of time constant estimates of survival, recovery, and individual variation in survival rates $\left(\sigma^{2}\right)$ for each subpopulation.

\section{RESULTS}

Our baseline model estimating time constant group survival and recovery probabilities, without accounting for individual variation in survival (Model 1), ran for 1,057 minutes and successfully converged on all parameter estimates (Fig. 3.1, Table 
3.1). Adult survival was greater in the Karrak Lake colony (Karrak Lake mean: 0.90, 95\% CRI 0.88, 0.91; La Pérouse Bay mean: 0.85, 95\% CRI 0.83, 0.86, Fig. 3.2A) as were recovery rates (Karrak Lake mean: 0.18, 95\% CRI 0.16, 0.19; La Pérouse Bay mean: $0.16,95 \%$ CRI 0.15, 0.17, Figure 2B).

Including the random effect for individuals, Model 2 ran for 1,253 minutes but failed to converge as insufficient chain mixing occurred for the variance parameter of survival $\left(\sigma^{2}\right)$ (Fig. 3.3, Table 3.1). In this model, survival and recovery estimates for Karrak Lake and La Pérouse Bay colonies were similar to Model 1 (Karrak Lake mean survival: 0.90, 95\% CRI 0.89, 0.91; La Pérouse Bay mean survival: 0.85, 95\% CRI 0.84, 0.86, Karrak Lake mean recovery: 0.19, 95\% CRI 0.17, 0.20; La Pérouse Bay mean recovery: $0.16,95 \%$ CRI $0.15,0.17$, Fig. 3.4 ). Estimates for $\sigma^{2}$ (on the logit scale) were similar for each colony (Karrak $\sigma_{s}^{2}: 0.12,95 \%$ CRI 0.04, 0.28; La Pérouse Bay $\sigma_{s}^{2}: 0.10$, 95\% CRI 0.01, 0.25, Fig. 3.4), however, because complete model convergence did not occur, we caution inferences made from all parameter estimates in this model, especially in estimates of $\sigma^{2}$.

When informative priors were used to parameterize the random effect for individuals, model convergence was achieved (Fig. 3.5, Table 3.1). Model 3 ran for 1275 minutes. In this model, adult survival was greater in the Karrak Lake colony (Karrak Lake mean: 0.91, 95\% CRI 0.90, 0.92; La Pérouse Bay mean: 0.85, 95\% CRI 0.84, 0.87, Fig. 3.4) as were recovery rates (Karrak Lake mean: 0.20, 95\% CRI 0.18, 0.21; La Pérouse Bay mean: 0.17, 95\% CRI 0.16, 0.18, Fig. 3.4). For both colonies, posterior probabilities of $\sigma^{2}$ (on the logit scale) were the same but below the mean value provide in 
the prior distribution (Karrak Lake $\sigma^{2}$ s: 0.36, 95\% CRI 0.23, 0.36; La Pérouse Bay $\sigma^{2}$ s: 0.36, 95\% CRI 0.23, 0.36, Fig. 3.4).

Based on the $\sigma^{2}{ }_{s}$ estimates derived from Model 3, we estimated the extent and density of individual variation in adult survival. We drew 10,000 simulated individuals from a normal distribution with group specific mean and variance derived from Model 3 estimates. Accordingly, we plotted probability density plots to depict the range and magnitude of individual survival probabilities and calculated the $2.57 \%$ and $97.5 \%$ quantiles. Based on a $\sigma_{s}^{2}$ of $0.36,95 \%$ of individuals from La Pérouse Bay would experience an annual survival probability between 0.62 and 0.95 (Fig. 3.6) while $95 \%$ of individuals for Karrak Lake would experience an annual survival probability between 0.73 and 0.97 (Fig. 3.6).

\section{DISCUSSION}

Our objective was to use band recoveries of marked adult lesser snow geese to estimate the extent of individual variation in survival probabilities. We expected to detect variation in survival among individuals resulting from multiple influences known to affect adult survival in avian populations such as differential genetic and environmental conditions at birth (Nussey et al. 2005, Senner et al. 2015), variable body condition (Morrison et al. 2007), heterogeneous environmental pressures (Van der Juegd and Larsson 1998), and downstream carry-over effects resulting from breeding success (Aubry et al. 2009, Harrison et al. 2011). However, we were unable to estimate this variation using a state-space modeling approach that included a random effect for individuals, unless we provided the model additional information through the use of an 
informative prior on $\sigma^{2}$ (discussed further below). Our attempt was based on select demonstrations that highlighted a similar approach. For example, White et al. (2013) modeled individual variation in recovery rates from simulated mark-recovery data to estimate potential biases on survival estimates using a random effect for individuals and numerical integration using Program MARK. Similarly, Kéry and Schaub (2012) demonstrated a model to measure individual variation in recovery rates using the Bayesian state-space approach we used in our analysis (Kéry and Schaub 2012, pg. 262). Nonetheless, we were unable to derive a similar estimate for heterogeneous survival from individual capture histories. The inconsistencies between our inability to estimate individual variation and the success of others using similar approaches suggests that individual variation in survival or recovery parameters from mark-recovery data may be identifiable in certain circumstance and not in others. Limited research exists on estimating individual variation in survival or recovery from mark-recovery data and our initial findings warrant further exploration (White et al. 2013).

A likely explanation for failed convergence around an estimate of $\sigma^{2}{ }_{s}$ is that markrecovery data do not afford repeated observations of individuals that would facilitate the identification of variable survival among individuals (D. Koons, personal communication). The premise for including a random effect for marked individuals in our Bayesian models is that individual survival probability is distributed by its own mean and variance. However, marked-recovery data only provide a single recovery event at death. Therefore, the ability for the model to estimate $\sigma^{2}$ is likely severely limited because survival probabilities are estimated only from recovered individuals, and all recovered individuals are by nature recovered only once. Interestingly, when we 
provided an informative prior for the mean and precision of $\sigma_{s}^{2}$, model convergence was achieved, and this finding raises a few noteworthy observations. First, our choice of an informative prior, normally distributed with $\mu=0.6$ and $\mathrm{SD}=0.1$, was only informed by our personal opinion as to what might be a reasonable expectation. In doing so, the $\sigma^{2} \mathrm{~s}$ parameter converged but the posterior distribution was lower than the specified prior value. Consequently, it is not entirely clear the extent to which the posterior distribution is driven by the prior. In principle, if a parameter that is unidentifiable because of model constraints is given an informative prior, the posterior should be a close reflection of the prior distribution (Kéry and Schaub 2012). An alternative explanation for the lower estimate of $\sigma^{2}$ shan the provided prior value is that $\sigma^{2}$ may be "weakly identifiable" and the provision of a prior distribution aides model convergence and parameter estimation.

Given the uncertainty of the informative prior to influence posterior probability estimates of $\sigma^{2}$, we conducted a small set of post hoc analyses on simulated markrecovery data to 1) confirm the inability to identify $\sigma^{2}{ }_{s}$ without an informative prior given known data and 2) examine the influence of informative priors on posterior estimates. We simulated mark-recovery data based on 500 individuals marked annually for 10 years with a mean survival of 0.85 and variance of 0.6 (on the logit scale), and a fixed recovery rate of 0.20 . We analyzed these data using the same Bayesian state-space approach and ran models with and without the use of informative priors. For models using informative priors we provided mean values of $\sigma_{\mathrm{s}}^{2}$ above, equal to, and below the true simulated value. Results from our simulations confirmed that despite known heterogeneous survival in the data, $\sigma^{2}$ was incorrectly estimated and model convergence did not occur 
when using uninformative priors (Appendix, Supplementary Figures 1 - 2). Further, when informative priors where used the posterior probability estimates more closely tracked the value of the prior, rather than the true value (Appendix, Supplementary Figures 3-10). Therefore, we are fairly certain that posterior estimates of $\sigma^{2}$ are closely linked to the prior value, and thus, confident inferences about $\sigma^{2}{ }_{s}$ should be related to confidence in provided priors. Nonetheless, we still observed some deviation in posterior estimates of $\sigma^{2}$ from the given prior so repeated iterations of simulations would be beneficial to better approximate this effect. In addition, further iterative simulations are necessary to describe any potential bias on other parameters (such as survival) dependent on the use of the prior value.

Detecting individual variation in survival or an observation process has been more successful through the use of capture-mark-recapture data collection and analysis (Cam et al. 2002, Gimenez and Choquet 2010, Gimenez et al. 2018). In this framework, the potential for live recapture of individuals provides repeated observations of the survival and recapture process that better allows for the detection of individual variation. Using capture-mark-recapture data offers a utility to estimate $\sigma^{2}$ s that could be incorporated into mark-recovery models to better account for individual variation. For example, in the specific case of lesser snow goose mark-recovery data we analyzed, an identifiable posterior estimate of $\sigma_{s}^{2}$ was achieved through the use of an informative prior. As a result of having both mean and variance estimates for survival, we were able to approximate the distribution of individual survival probabilities that could be expected within the population (Fig. 3.6). Yet, our estimate for $\sigma_{s}^{2}$ is likely driven strongly by our 
provided prior, as discussed above, and therefore should not be taken as an estimate of current biological reality. Rather, the current most straightforward approach to estimating individual variation in survival of lesser snow geese would be through the use of a capture-mark-recapture data set derived from previously marked individuals that are recaptured during summer banding drives. However, these recapture events occur much more infrequently relative to dead recoveries, and sufficient sample sizes of recaptures are limited in availability. Although if sufficient recapture data are available, a worthwhile exploration would be to estimate $\sigma^{2}$ s from lesser snow goose capture-markrecapture data and then use the estimate as an informative prior in a mark-recovery model that accounts for individual variation using a continuous random effect. The comparison of posterior estimates for survival from the heterogeneous model to a traditional model (no random effect) could demonstrate potential biases in traditional estimates that result from an inability to account for heterogeneity (Barker 1992). Inclusion of a random effect alone is not likely to result in different estimates of survival for mark-recovery data, but rather identify the potential extent to which the estimate is biased given the magnitude of individual variation. However, Gimenez et al. (2018) demonstrates the potential of capture-mark-recapture models that account for individual variation through the use of random effects to correct for estimate biases resulting from individual heterogeneity. Here, Gimenez et al. (2018) simulated capture-mark-recapture data of two quality classes (frail and robust) on individuals with two breeding states (breeding or non-breeding). In models that did not account for simulated heterogeneous survival, survival rates of robust breeders were underestimated, while survival of frail breeders was overestimated. In contrast, a model that accounted for individual heterogeneity 
through the use of random effects correctly captured the simulated variation (Gimenez et al. 2018).

\section{MANAGEMENT IMPLICATIONS}

Our inability to estimate individual variation in survival from mark-recovery data highlights an important finding, in that while mark-recovery models are widely used for estimating survival and recovery rates, current advanced modeling techniques cannot use recoveries alone to validate long-standing model assumptions of homogeneity among the marked sample. As a result, this leaves a large number of long-term data sets vulnerable to biases in two major ways. First, use of mark-recovery data alone leaves uncertainty to the accuracy and precision of parameter estimates resulting from an inability to discern if an estimate bias exists due to heterogeneity (Pollock and Raveling 1982, Barker 1992). In the case of lesser snow geese, a long-lived species, individual variation in adult survival is expected to be reduced relative to shorter lived species (Peron 2016) through a process of evolutionary canalization that minimizes variations in fitness parameter important for population growth (i.e., adult survival) in the presence of environmental stochasticity (Gaillard and Yoccoz 2003, Souchay et al. 2014). Nonetheless, not all individuals are the same and each is differentially positioned for maximizing fitness through carry-over effects or silver / lead spoon effects (Cooke et al. 1984, Aubry et al. 2009, Harrison et al. 2011). If poorer conditioned lesser snow geese are more susceptible to harvest, as demonstrated by Fowler et al. (Chapter 2), then their harvest could be considered an indication of poorer fitness relative to the general population and contribute to a second vulnerability for bias in estimates derived from mark-recovery data. Here, additional uncertainty results when survival estimates with unaccounted for 
heterogeneity are used to evaluate demographic responses to harvest. If survival estimates are derived from a heterogeneous sample, and frailer individuals are more susceptible to harvest, then biases in survival estimates can obscure the strength of compensatory or additive effects resulting from harvest pressure (Lebreton 2005, Caudill et al. 2017).

A gap remains in our understanding regarding the means in which individual variation in survival (or recovery) could be estimated using mark-recovery data through current advancement in the use of random effects. Given that a majority of population vital rates in waterfowl are derived from mark-recovery programs, further research should explore the circumstances required in which mark-recovery data can provide estimates of individual variation. For example, it is reasonable to consider that heterogeneous survival may be highly correlated with heterogeneous recovery rates (White et al. 2013). Under these circumstances, identifying heterogeneity in survival may be confounded by individual variation in recovery. We did not consider this situation in our study, but simulated trials would provide a means to explore the identifiability of individual variation in survival given these circumstances. Additionally, certain covariates available for measurement at the time of marking may potentially assist in providing the necessary variation to identify heterogeneous survival through markrecovery data. Hierarchical modeling that parameterizes individuals as a random effect and includes additional covariates (such as body size metrics or condition indices) may provide sufficient additional information to capture variation and promote parameter convergence. In light of the potential inferences that could be made resulting from an understanding of individual variation in parameters derived from mark-recovery data and 
the limited work performed to date, further work is warranted and we suggest exploration through simulated data. 


\section{LITERATURE CITED}

Alisauskas, R. T., R. F. Rockwell, K. W. Dufour, E. G. Cooch, G. Zimmerman, K. L. Drake, J. O. Leafloor, T. J. Moser, and E. T. Reed. 2011. Harvest, survival, and abundance of midcontinent lesser snow geese relative to population reduction efforts. Wildlife Monographs 179:1-42.

Ankney, C. D. 1996. An embarrassment of riches : Too many geese. Journal of Wildlife Management 60:217-223.

Aubry, L. M., D. N. Koons, J. Y. Monnat, and C. Emmanuelle. 2009. Consequences of recruitment decisions and heterogeneity on age-specific breeding success in a long-lived seabird. Ecology 90:2491-2502.

Barker, R. J. 1992. Effect of heterogeneous survival on bird-banding model confidence interval coverage rates. Journal of Wildlife Management 56:111-116.

Batt, B. 1997. Arctic ecosystems in peril: Report of the arctic goose habitat working group. U.S. Fish and Wildlife Service, Washington, D.C. and Canadian Wildlife Service, Ottawa, Ontario.

Brownie, C., D. R. Anderson, K. P. Burnham, and D. S. Robson. 1985. Statistical inference from band recovery data. US Fish and Wildlife Service Resource Publication 156.

Burnham, K. P., and E. A. Rexstad. 1993. Modeling heterogeneity in survival rates of banded waterfowl. Biometrics 49:1194-1208.

Calvert, A. M., R. T. Alisauskas, and G. C. White. 2017. Annual survival and seasonal hunting mortality of midcontinent snow geese. Journal of Wildlife Management 81:1009-1020. 
Cam, E., W. A. Link, E. G. Cooch, J. Monnat, and E. Danchin. 2002. Individual covariation in life-history traits: Seeing the trees despite the forest. American Naturalist 159:96-105.

Caswell, H. 2001. Matrix population models. Sunderland, MA, USA.

Caudill, D., M. R. Guttery, T. M. Terhune, J. A. Martin, G. Caudill, D. K. Dahlgren, and T. A. Messmer. 2017. Individual heterogeneity and effects of harvest on greater sage-grouse populations. Journal of Wildlife Management 81:754-765.

Chambert, T., J. J. Rotella, and R. A. Garrott. 2015. Female Weddell seals show flexible strategies of colony attendance related to varying environmental conditions. Ecology 96:479-488.

Cooch, E. G., M. Guillemain, G. S. Boomer, J.-D. Lebreton, and J. D. Nichols. 2014. The effects of harvest on waterfowl populations. Wildfowl Special Issue No. 4:220276.

Cooke, F., C. S. Findlay, and R. F. Rockwell. 1984. Recruitment and the timing of reproduction in Lesser Snow Geese (Chen caerulescens caerulescens). Auk $101: 451-458$.

Drake, K. L., R. T. Alisauskas, and A. M. Calvert. 2018. Experimental test for a trade-off between successful nesting and survival in capital breeders with precocial offspring. Auk 135:637-646.

Endler, J. A. 1986. Natural selection in the wild. Princeton University Press, Princeton, NJ, USA.

Gaillard, J.-M., and N. G. Yoccoz. 2003. Temporal variation in survival of mammals: a case of environmental canalization? Ecology 84:3294-3306. 
Gelman, A., and D. B. Rubin. 1992. Inference from iterative simulation using multiple sequences. Statistical Science 7:457-472.

Gimenez, O., and R. Choquet. 2010. Individual heterogeneity in studies on marked animals using numerical integration: capture-recapture mixed models. Ecology 91:951-957.

Gimenez, O., E. Cam, and J. M. Gaillard. 2018. Individual heterogeneity and capturerecapture models: What, why and how? Oikos 127:664-686.

Greenwood, H., R. G. Clark, and J. P. Weatherhead. 1986. Condition bias of hunter-shot mallards. Canadian Journal of Zoology 64:599-601.

Hamel, S., J. M. Gaillard, M. Douhard, M. Festa-Bianchet, F. Pelletier, and N. G. Yoccoz. 2018. Quantifying individual heterogeneity and its influence on lifehistory trajectories: different methods for different questions and contexts. Oikos 127:687-704.

Harrison, X. A., J. D. Blount, R. Inger, D. R. Norris, and S. Bearhop. 2011. Carry-over effects as drivers of fitness differences in animals. Journal of Animal Ecology 80:4-18.

Iverson, S. A., E. T. Reed, R. John Hughes, and M. R. Forbes. 2014. Age and breeding stage-related variation in the survival and harvest of temperate-breeding Canada geese in Ontario. Journal of Wildlife Management 78:24-34.

Kellner, K. 2017. jagsUI: A wrapper around 'rjags' to streamline 'JAGS' analyses. R package version 1.4.9.

Kéry, M., and M. Schaub. 2011. Bayesian population analysis using WinBUGS: a hierarchical perspective. Academic Press, Amsterdam, The Netherlands. 
Koons, D. N., G. Gunnarsson, J. M. Schmutz, and J. J. Rotella. 2014. Drivers of waterfowl population dynamics: from teal to swans. Wildfowl Special Issue No. 4:169-191.

Koons, D. N., M. Gamelon, J.-M. Gaillard, L. M. Aubry, R. F. Rockwell, F. Klein, R. Choquet, and O. Gimenez. 2014. Methods for studying cause-specific senescence in the wild. Methods in Ecology and Evolution 5:924-933.

Lebreton, J.-D. 2005. Dynamic and statistical models for exploited populations. Australian and New Zealand Journal of Statistics 47:49-63.

Lindberg, M. S., J. S. Sedinger, and J. Lebreton. 2013. Individual heterogeneity in black brant survival and recruitment with implications for harvest dynamics. Ecology and Evolution 3:4045-4056.

Morrison, R. I., N. C. Davidson, and J. R. Wilson. 2007. Survival of the fattest: Body stores on migration and survival in red knots Calidris canutus islandica. Journal of Avian Biology 38:479-487.

Newton, I. 1989. Lifetime reproduction in birds. Academic Press, London, United Kingdom.

Nichols, J. D., S. L. Stokes, J. E. Hines, and M. J. Conroy. 1982. Additional comments on the assumption of homogeneous survival rates in modern bird banding estimation models. Journal of Wildlife Management 46:953-962.

Nussey, D. H., E. Postma, P. Gienapp, and M. E. Visser. 2005. Selection on heritable phenotypic plasticity in a wild bird population. Science 310:304-306. 
Pace III, R. M., and A. D. Afton. 1999. Direct recovery rates of lesser scaup banded in northwest Minnesota: sources of heterogeneity. Journal of Wildlife Management 63:389-395.

Pledger, S., and C. J. Schwarz. 2002. Modelling heterogeneity of survival in bandrecovery data using mixtures. Journal of Applied Statistics 29:315-327.

Plummer, M. 2017. JAGS: A program for analysis of Bayesian graphical modeling using Gibbs sampling [computer program].

Pollock, K., and D. Raveling. 1982. Assumptions of modern band-recovery models, with emphasis on heterogeneous survival rates. Journal of Wildlife Management 46:88-98.

Rexstad, E. A. 1992. Effect of hunting on annual survival of Canada geese in Utah. Journal of Wildlife Management 56:297-305.

Rockwell, R. F., E. G. Cooch, and S. Brault. 1997. Dynamics of the mid-continent population of lesser snow geese: projected impacts of reductions in survival and fertility on population growth rates. Arctic ecosystems in peril: report of the Arctic Goose Habitat Working Group 73-100. Arctic Goose Joint Venture Special Publication. U.S. Wildlife Service: Washington DC and Canadian Wildlife Service: Ottawa, Ontario.

Royle, J. A. 2008. Modeling individual effects in the Cormack-Jolly-Seber model: A state-space formulation. Biometrics 64:364-370.

Sæther, B., and Ø. Bakke. 2000. Avian life history variation and contribution of demographic traits to the population growth rate. Ecology 81:642-653. 
Sedinger, J. S., and M. P. Herzog. 2012. Harvest and dynamics of duck populations. Journal of Wildlife Management 76:1108-1116.

Senner, N. R., J. R. Conklin, and T. Piersma. 2015. An ontogenetic perspective on individual differences. Proc. R. Soc. B 282:20151050.

Souchay, S. G., and G. G. Gauthier. 2014. To breed or not : a novel approach to estimate breeding propensity and potential trade-offs in an Arctic-nesting species. Ecology 95:2745-2756.

van der Jeugd, H. P., and K. Larsson. 1998. Pre-breeding survival of barnacle geese Branta leucopsis in relation to fledgling characteristics. Journal of Animal Ecology 67:953-966.

White, G. C., L. S. Cordes, and T. W. Arnold. 2013. Band reporting rates of waterfowl: Does individual heterogeneity bias estimated survival rates? Ecology and Evolution 3:4215-4220.

Williams, B. K., J. D. Nichols, and M. J. Conroy. 2002. Analysis and management of wildlife populations. Academic Press, San Diego, CA, USA. 


\section{TABLES}

Table 3.1 - Posterior estimates of time constant survival and recovery probabilities, and individual survival variance, of midcontinent lesser snow geese analyzed from marked and hunter recovered individuals from 1999-2016 using a state-space Bayesian modeling approach. Marked individuals were analyzed separately between an Arctic breeding colony (Karrak Lake) and a subarctic breeding colony (La Pérouse Bay). Model 1 does not estimate individual variation in survival, while Model 2 and Model 3 estimate individual variation as a random effect using uninformative and informative priors, respectively.

\begin{tabular}{|c|c|c|c|c|c|c|}
\hline & Mean & $\begin{array}{l}\text { Standard } \\
\text { Deviation }\end{array}$ & $2.50 \%$ & $97.50 \%$ & Rhat $^{+}$ & n.eff \\
\hline \multicolumn{7}{|l|}{ Model 1} \\
\hline $\mathrm{LPB}^{1}$ survival & 0.85 & 0.51 & 0.83 & 0.86 & 1.020 & 135 \\
\hline $\mathrm{KrK}^{2}$ survival & 0.90 & 0.52 & 0.88 & 0.91 & 1.019 & 172 \\
\hline LPB recovery & 0.16 & 0.51 & 0.15 & 0.17 & 1.006 & 361 \\
\hline KrK recovery & 0.18 & 0.52 & 0.17 & 0.20 & 1.014 & 218 \\
\hline deviance & 15133.6 & 144.9 & 14837.3 & 15383.8 & 1.026 & 91 \\
\hline \multicolumn{7}{|l|}{ Model 2} \\
\hline LPB survival & 0.85 & 0.51 & 0.84 & 0.86 & 1.042 & 57 \\
\hline KrK survival & 0.90 & 0.52 & 0.89 & 0.91 & 1.014 & 267 \\
\hline LPB recovery & 0.16 & 0.51 & 0.15 & 0.17 & 1.039 & 57 \\
\hline KrK recovery & 0.19 & 0.51 & 0.17 & 0.20 & 1.009 & 428 \\
\hline LPB $\sigma_{s}^{2 \dagger}$ & 0.10 & 0.07 & 0.01 & 0.25 & 1.625 & 7 \\
\hline $\mathrm{KrK} \sigma_{\mathrm{s}}^{2}$ & 0.13 & 0.06 & 0.04 & 0.28 & 1.078 & 42 \\
\hline deviance & 15021.2 & 116.3 & 14787.6 & 15247.2 & 1.057 & 49 \\
\hline \multicolumn{7}{|l|}{ Model 3} \\
\hline LPB survival & 0.85 & 0.51 & 0.84 & 0.87 & 1.022 & 109 \\
\hline KrK survival & 0.91 & 0.52 & 0.90 & 0.92 & 1.055 & 50 \\
\hline LPB recovery & 0.17 & 0.51 & 0.16 & 0.18 & 1.009 & 238 \\
\hline KrK recovery & 0.20 & 0.51 & 0.18 & 0.21 & 1.036 & 69 \\
\hline $\mathrm{LPB} \sigma_{\mathrm{s}}^{2}$ & 0.36 & 0.08 & 0.23 & 0.53 & 1.042 & 53 \\
\hline $\mathrm{KrK} \sigma_{\mathrm{s}}^{2}$ & 0.36 & 0.08 & 0.23 & 0.55 & 1.013 & 427 \\
\hline deviance & 14774.9 & 109.4 & 14572.7 & 14990.8 & 1.018 & 123 \\
\hline \multicolumn{7}{|c|}{${ }^{1}$ La Pérouse Bay colony ${ }^{2}$ Karrak Lake colony } \\
\hline
\end{tabular}




\section{FIGURES}
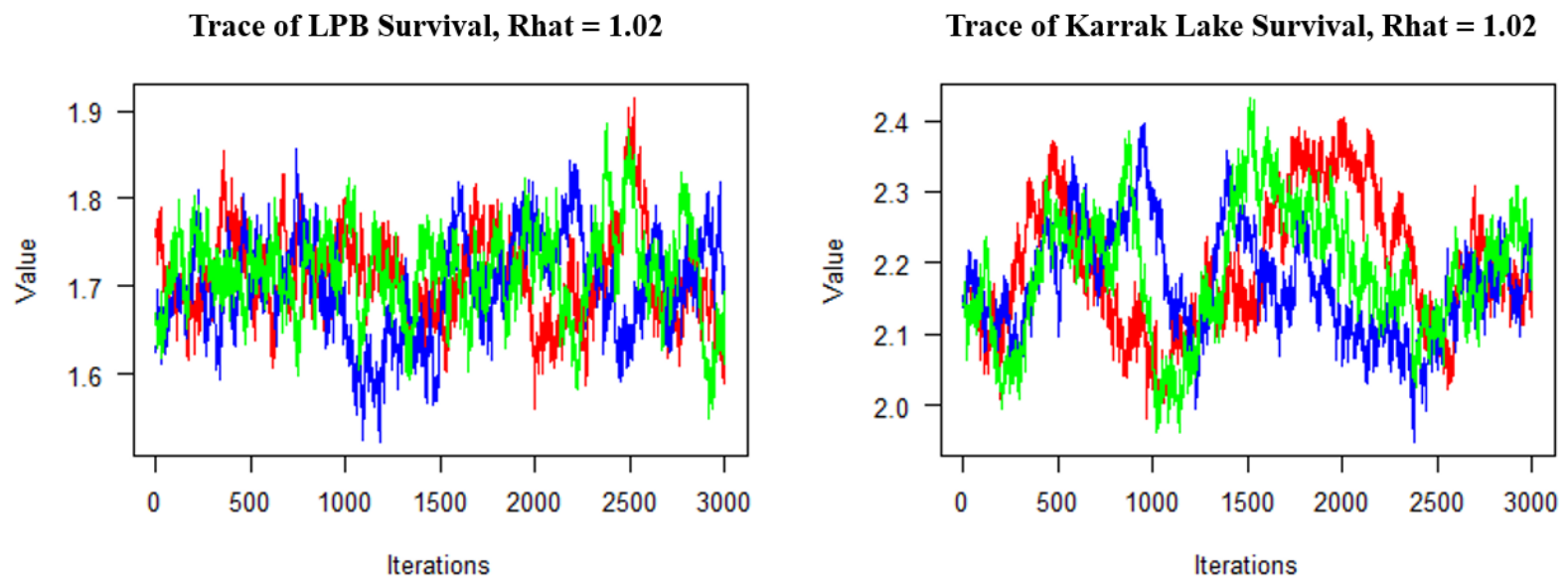

Trace of LPB Recovery, Rhat $=\mathbf{1 . 0 1}$

Trace of Karrak Lake Recovery, Rhat $=\mathbf{1 . 0 1}$
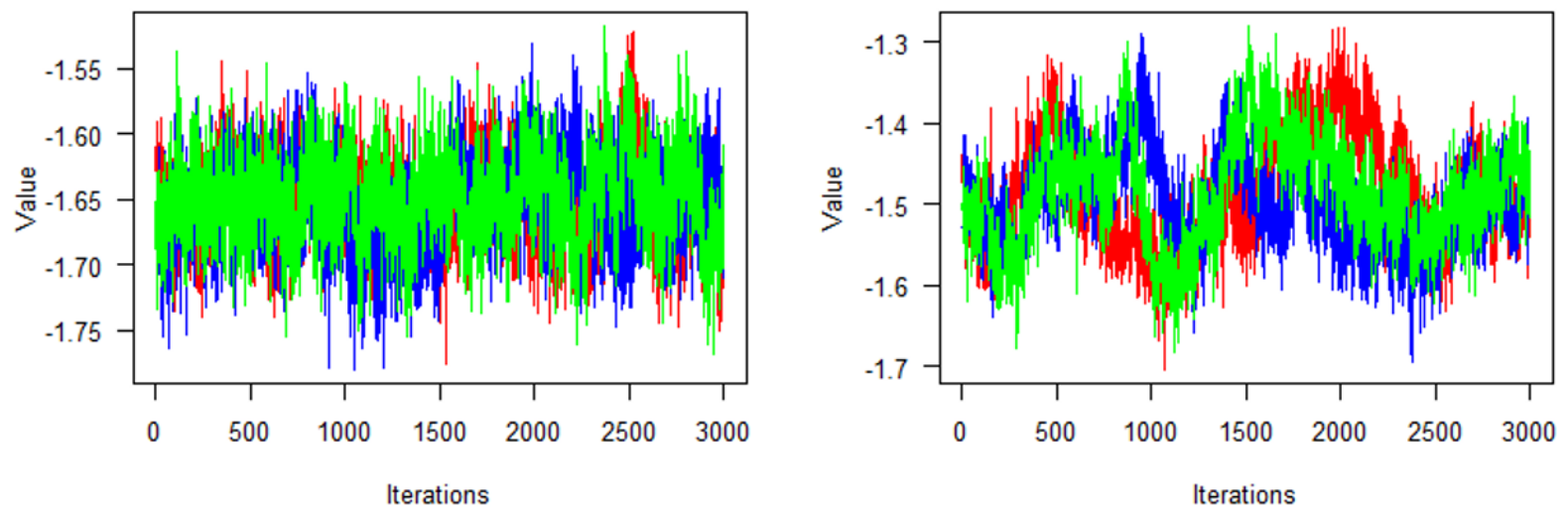

Fig. 3.1 - Trace plot of state-space Bayesian model analyzing time constant survival and recovery probabilities of midcontinent population lesser snow geese at La Pérouse Bay (LPB) and Karrak Lake colonies from 1999 - 2016 based on mark-recovery data reported by hunters. Survival and recovery probabilities are reported on the logit scale. Model was based on three Markov Chain Monte Carlo chains (identified by unique colors) of 50,000 iterations after a burn-in of 20,000 and thinning interval of 10. 

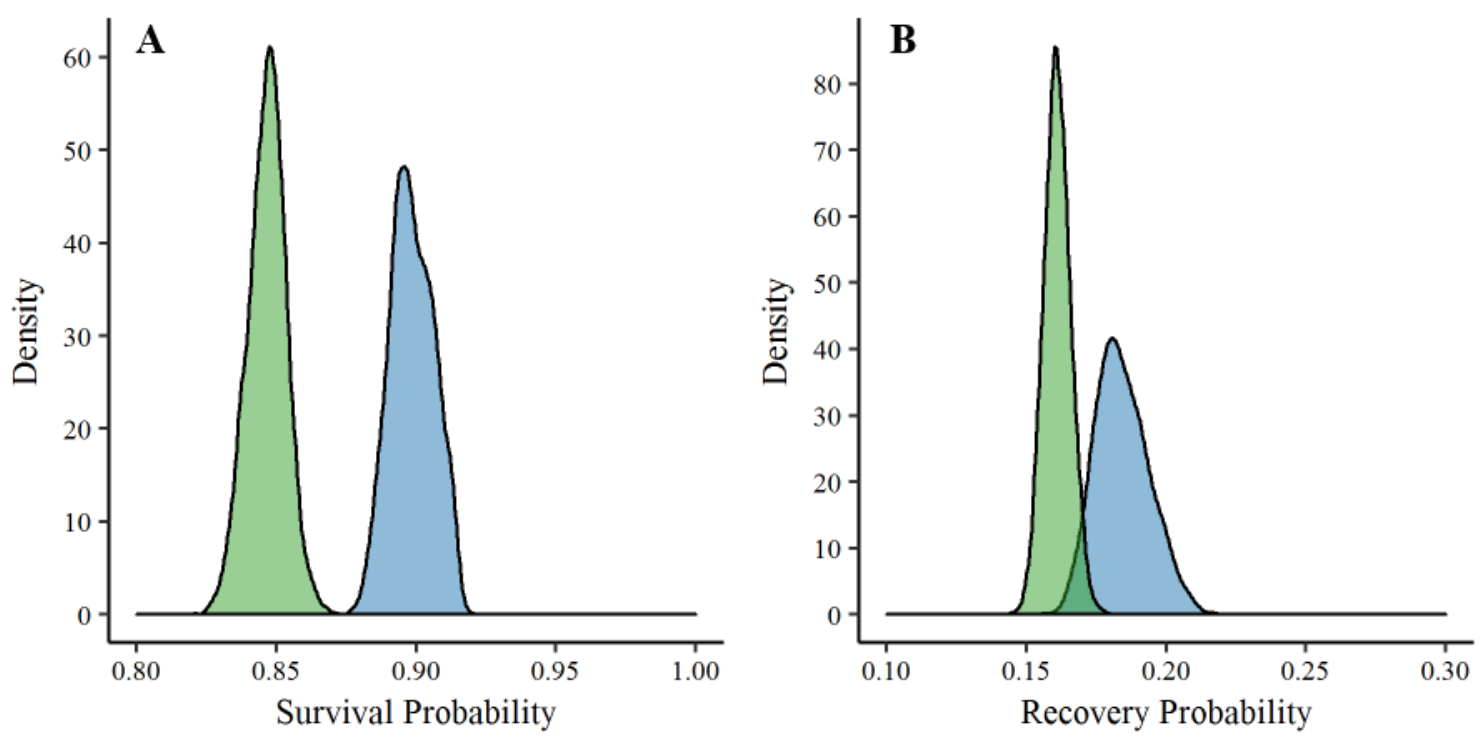

Fig. 3.2 - Posterior density plot of state-space Bayesian model analyzing time constant estimates of survival (A) and recovery (B) probabilities of midcontinent population lesser snow geese at La Pérouse Bay (LPB) (green) and Karrak Lake (blue) colonies from 1999 - 2016 based on mark-recovery data reported by hunters. Survival and recovery probabilities are reported on the logit scale. Model was based on three Markov Chain Monte Carlo chains of 50,000 iterations after a burn-in of 20,000 and thinning interval of 10. 
Trace of LPB Survival, Rhat $=1.04$

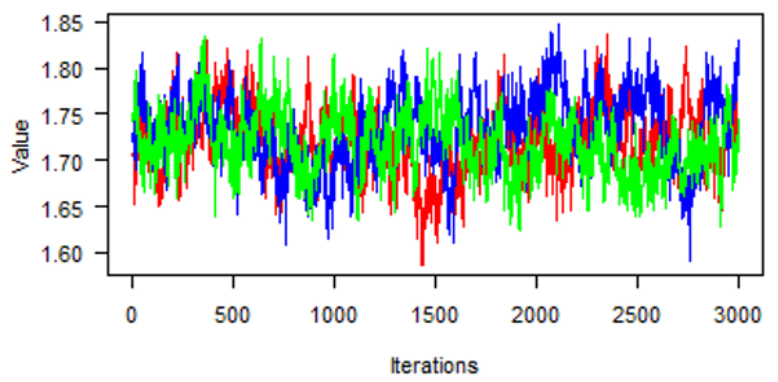

Trace of LPB Recovery, Rhat $=\mathbf{1 . 0 4}$

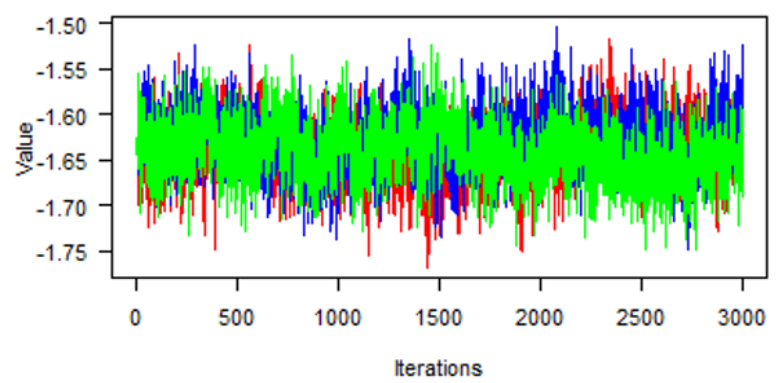

Trace of LPB Survival $\boldsymbol{\sigma}^{2}$, Rhat $=\mathbf{1 . 6 3}$

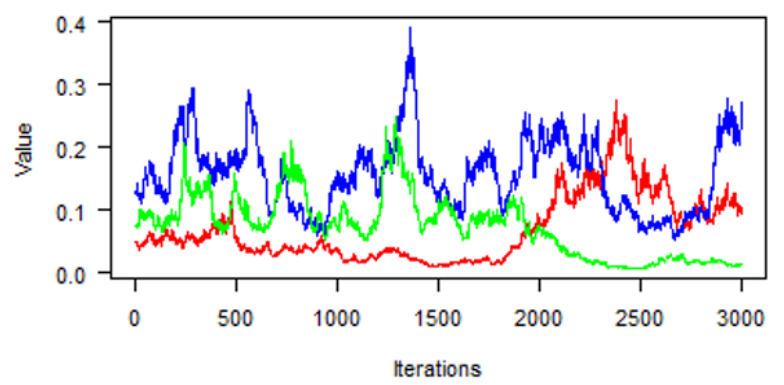

Trace of Karrak Lake Survival, Rhat $=\mathbf{1 . 0 1}$

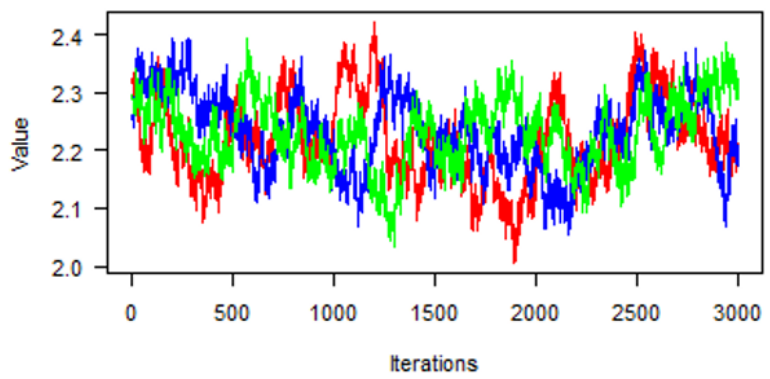

Trace of Karrak Lake Recovery, Rhat $=\mathbf{1 . 0 1}$

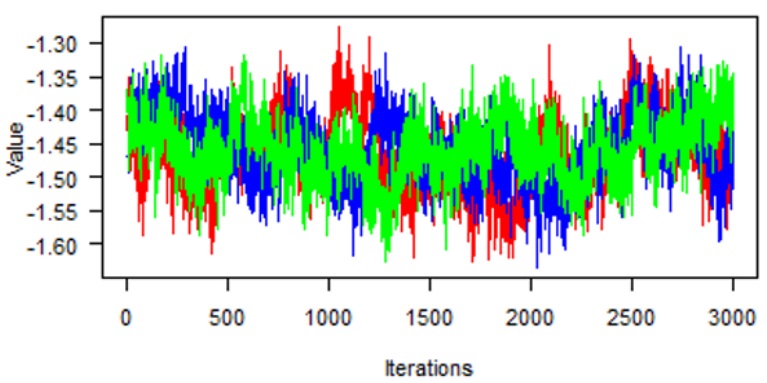

Trace of Karrak Lake Survival $\sigma^{2}$, Rhat $=1.08$

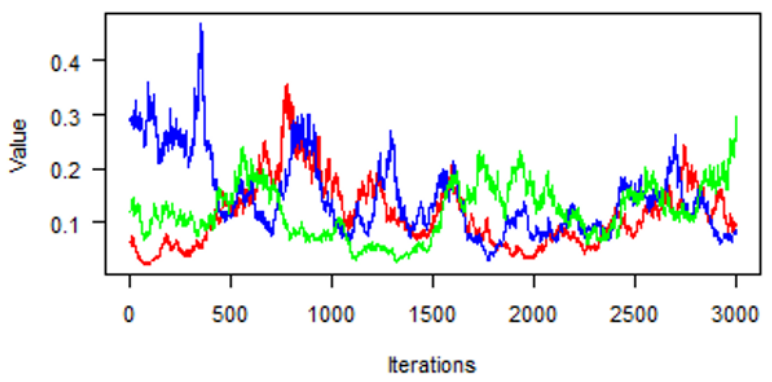

Fig. 3.3 - Trace plot of state-space Bayesian model analyzing time constant survival and recovery probabilities of midcontinent population lesser snow geese at La Pérouse Bay (LPB) and Karrak Lake colonies from 1999 - 2016 based on mark-recovery data reported by hunters. Model includes time constant estimate of survival variance $\left(\sigma^{2}\right)$ among individuals parameterized with uninformative priors. Survival and recovery probabilities as well as $\sigma^{2}$ are reported on the logit scale. Model was based on three Markov Chain Monte Carlo chains (identified by unique colors) of 50,000 iterations after a burn-in of 20,000 and thinning interval of 10. 

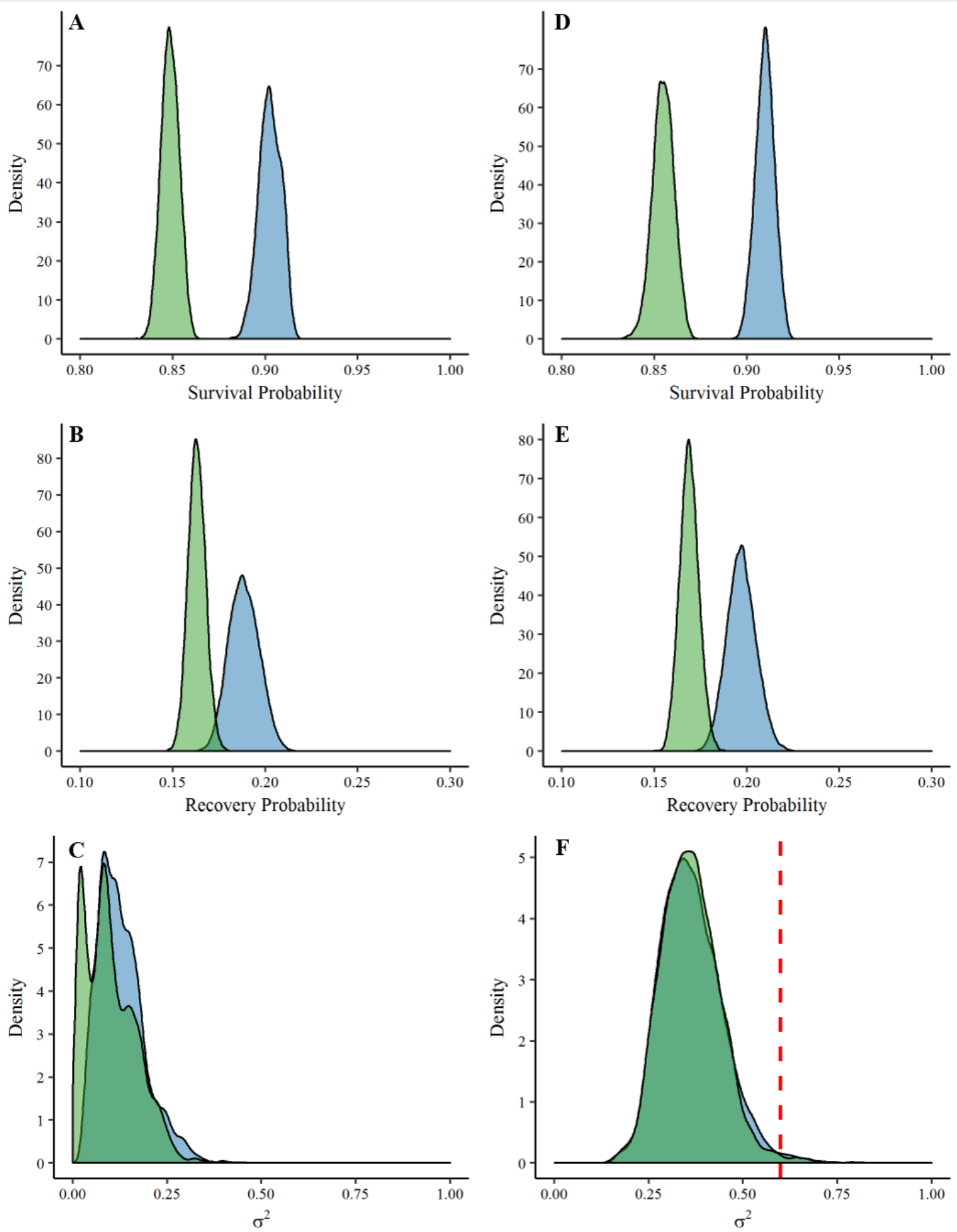

Fig. 3.4 - Posterior density plots of two state-space Bayesian models analyzing time constant survival and recovery probabilities of midcontinent population lesser snow geese at La Pérouse Bay (LPB) (green) and Karrak Lake (blue) colonies from 1999 - 2016 based on mark-recovery data reported by hunters. Model estimates on the left (A-C) 
include time constant estimate of survival variance $\left(\sigma^{2}\right)$ among individuals parameterized with uninformative priors. Model estimates on the right (D-F) include time constant estimate of survival variance $\left(\sigma^{2}\right)$ among individuals parameterized with informative priors (mean of prior denoted by dashed vertical red line). Estimates of individual variance in survival $\left(\sigma^{2}\right)$ are reported on the logit scale. Models were based on three Markov Chain Monte Carlo chains of 50,000 iterations after a burn-in of 20,000 and thinning interval of 10 . 

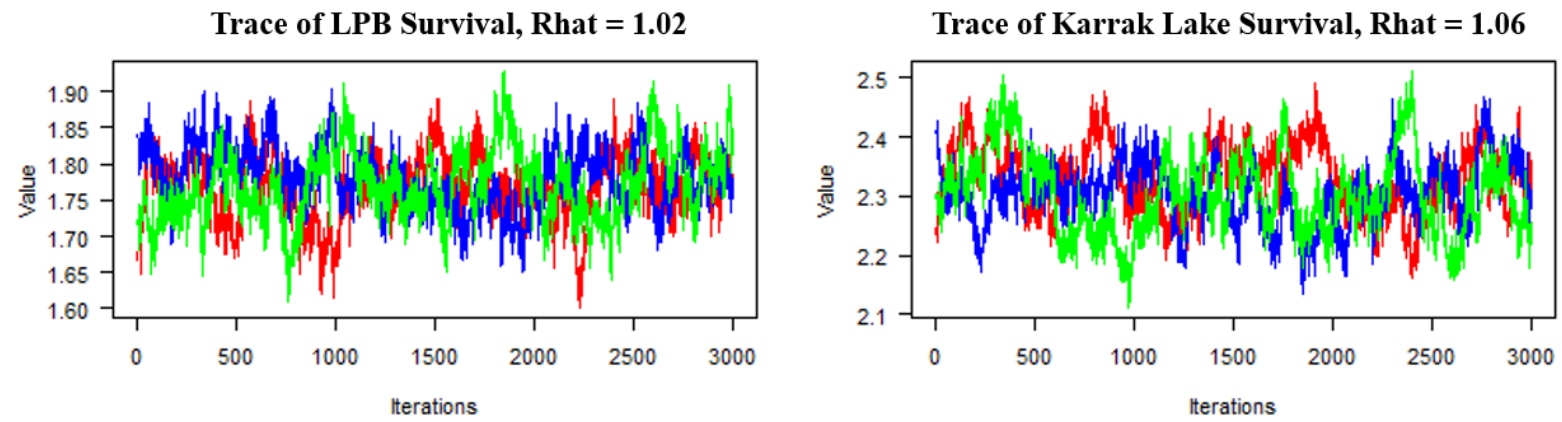

Trace of LPB Recovery Rhat $=\mathbf{1 . 0 1}$

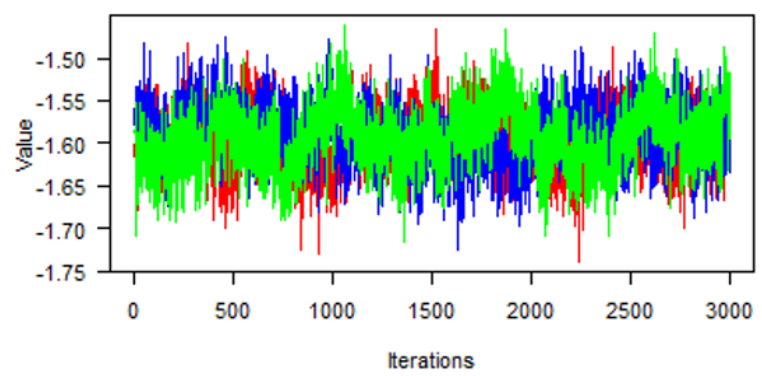

Trace of Karrak Lake Recovery, Rhat $=\mathbf{1 . 0 4}$
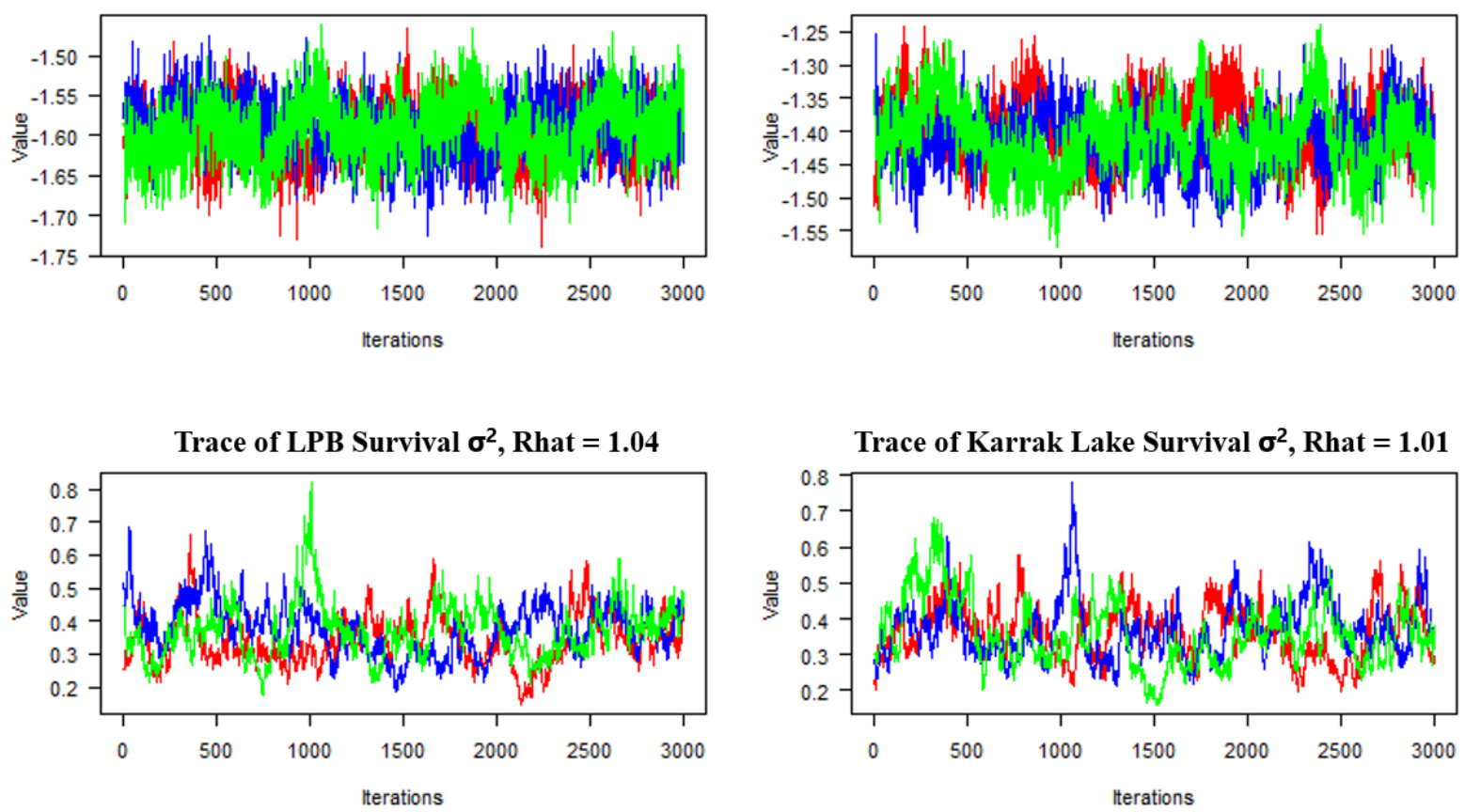

Fig. 3.5 - Trace plot of state-space Bayesian model analyzing time constant survival and recovery probabilities of midcontinent population lesser snow geese at La Pérouse Bay (LPB) and Karrak Lake colonies from 1999 - 2016 based on mark-recovery data reported by hunters. Model includes time constant estimate of survival variance $\left(\sigma^{2}\right)$ among individuals parameterized with informative priors. Survival and recovery probabilities as well as $\sigma^{2}$ are reported on the logit scale. Model was based on three Markov Chain Monte Carlo chains (identified by unique colors) of 50,000 iterations after a burn-in of 20,000 and thinning interval of 10 . 


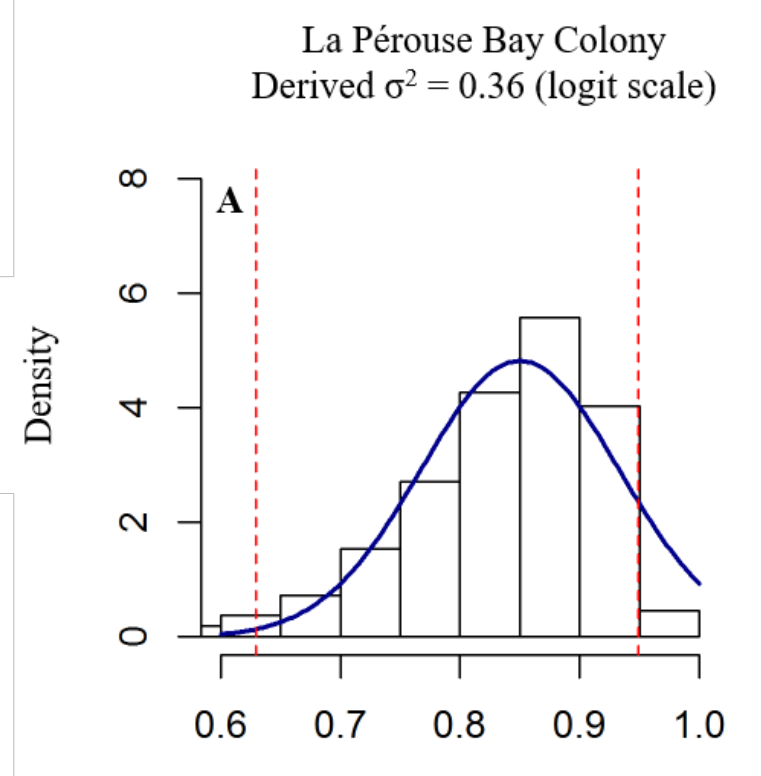

Survival Probability Among Individuals
Karrak Lake Colony

Derived $\sigma^{2}=0.36(\operatorname{logit}$ scale $)$

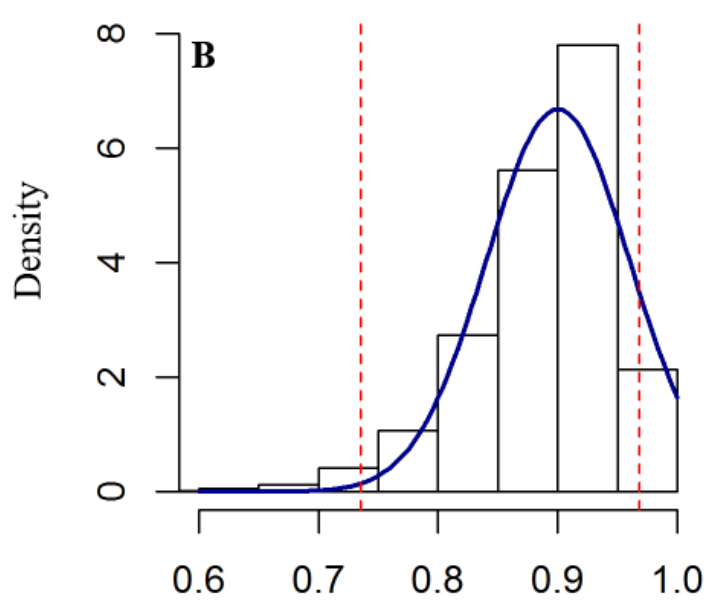

Survival Probability Among Individuals

Fig. 3.6 -Density plots of survival probability among individual lesser snow geese from

La Pérouse Bay (A) and Karrak Lake (B) colonies based on 10,000 simulated individuals drawn from a normal distribution with model derived estimates of mean survival probability and variance $\left(\sigma^{2}\right)$. Dashed red vertical lines represent the $2.5 \%$ and $97.5 \%$ quantiles. Parameter estimates were derived from a state-space Bayesian model analyzing time constant survival and recovery probabilities of midcontinent population lesser snow geese from 1999 - 2016 based on mark-recovery data reported by hunters. Model includes time constant estimate of survival variance $\left(\sigma^{2}\right)$ among individuals parameterized with informative priors. Model was based on three Markov Chain Monte Carlo chains of 50,000 iterations after a burn-in of 20,000 and thinning interval of 10 . 


\section{CHAPTER 4 - THE ROLE OF WINTERING AND BREEDING LOCATIONS ON SPRING BODY CONDITION IN A LONG DISTANT MIGRANT}

\section{INTRODUCTION}

Migratory birds have evolved life history strategies that use and rely on seasonal resources across vast spatial scales in order to maintain fitness (i.e., survival and recruitment) and successfully complete annual life cycle events (Alerstam et al. 2003, Newton 2004). Migration endeavors are not without risk, as they are energetically expensive (McWilliams et al. 2004) and require decisions regarding migration phenology (Marra et al. 1998, Tombre et al. 2008), habitat use (Lindstrom 1991, Schaub and Jenni 2001), and strategies for nutrient accumulation that facilitate successful migration and breeding (Webster et al. 2002, Warnock 2010). Importantly, these processes can be integrally linked to one another, such that events encountered and effects incurred in one season can impact an individual's performance in subsequent seasons (Norris 2005, Harrison et al. 2011, Sedinger and Alisauskas 2014). An individual's performance in one season based on lagged processes during a previous season is thus termed a "carry-over effect" (Sedinger and Alisauskas 2014). For example, Black-tailed Godwits (Limosa limosa islandica) who used high-quality coastal wintering habitats arrived at breeding grounds earlier and had better breeding success compared to individuals that overwintered in poorer-quality inland habitats (Gunnarson et al. 2005). Collectively, individual carry-over effects often scale up to influence population level processes, such as annual recruitment, and are termed "cross-seasonal effects" (Fox et al. 2005, Sedinger and Alisauskas 2014). 
Carry-over effects are often assessed by the relative physical condition of one individual to another, given their respective previous decisions and experiences (Marra et al. 1998, Norris and Marra 2007). For example, red knots (Calidris canutus rufa) with reduced nutrient storage on spring staging habitats arrived later to the breeding grounds and had reduced survival and recruitment compared with individuals with heavier body mass (Baker et al. 2004). Therefore, the phenomenon of carry-over and cross-seasonal effects results from inherent variation among individuals in their ability to access or use resources (Harrison et al. 2011) and thus serves as one mechanism contributing to heterogeneous fitness within a population.

The positive relationship between spring body condition and breeding fitness is also well established among waterfowl (Heitmeyer and Fredrickson 1981, Ankney et al. 1991, Devries et al. 2008), but factors influencing life history decisions that affect body condition and potentially carry-over into subsequent seasons are widely variable. In larger-bodied migratory birds, such as waterfowl, larger body size increases an individual's ability to store endogenous nutrients (Ankney et al. 1991). Therefore, heterogeneity in body size among individuals may allow larger bodied individuals an advantage for greater fitness. Additionally, body size in waterfowl can influence social status (Black and Owen 1987) such that larger individuals may be more dominant over certain habitats or resources by aggressively excluding smaller bodied individuals from preferred resources (Raveling 1970). Consequently, variation in access and use by individuals to winter habitats that provide substantial food resources can result in differential breeding propensities or success (Sedinger et al. 2011). Alternatively, spring body condition may be influenced from a preceding years breeding efforts such that the 
energetic expenditure of breeding is costly enough to forego a breeding attempt in the subsequent year (Prince et al. 1994, Souchay et al. 2014).

While it is clear that carry-over effects incurred from breeding and overwintering experiences can have subsequent impacts on spring body condition and ultimately, fitness, the role of preemptive strategies related to migration phenology and distance on body condition are not as well understood. Fundamentally, long-distant migrants face tradeoffs regarding allocation of spring nutrients for migration versus reproduction (Witter and Cuthill 1993). Spring body condition and refueling strategies can be dependent upon migration strategies related to migration length (Warnock 2010, Alerstam 2011) and influence the degree to which an individual relies on exogenous or endogenous reserves for reproduction (Klassen et al. 2006). For long-distant migrants, increased body size paired with higher latitude breeding destinations generally increase propensity for an individual to rely on endogenous reserves for breeding, due to increased capacity for nutrient storage and shorter growing season at respective breeding destinations (Klassen et al. 2006). However, some species implement flexible nutrient accumulation strategies that may rely on both endogenous and exogenous sources for breeding, possibly influenced by interannual environmental conditions and variable migration lengths (Wypkema and Ankney 1979, Gauthier et al. 2003, Sedinger et al. 2006).

Given that spring body condition can be influenced by complex life history strategy interactions based on both previous experiences (carry-over effects) and nutrient allocation strategies associated with migration and breeding, we sought to evaluate the influence of prior habitat use and future breeding destination on spring body condition 
using lesser snow geese (Anser caerulescens caerulescens) as a study organism. The North American midcontinent population of lesser snow geese breeds across approximately fifteen degrees of latitude and thirty-six degrees longitude throughout the Canadian subarctic and arctic (Alisauskas et al. 2011). Additionally, population size has responded positively after expansion into additional winter habitats made accessible by the late $20^{\text {th }}$ century conversion of coastal prairies and floodplain forests into agricultural landscapes, primarily in the form of rice (Oryza sativa) production (Abraham et al. 2005). While a large proportion of lesser snow geese now overwinter in these agricultural habitats, lesser snow geese also continue to winter in coastal marsh habitats (Jónsson et al. 2014).

In this study, we used stable isotope techniques to determine likely breeding season destination, assessed by $\delta^{2} \mathrm{H}$ values in newly grown feathers following summer molting (Fowler et al. 2018a), and prior winter habitat use (Hénaux et al. 2012) among lesser snow geese collected during spring migration. We assessed the ability of seasonal origins data to explain variations in spring body condition and body size of collected individuals. Historically, lesser snow geese solely used coastal marshes in Texas and Louisiana up until the 1960s, which was thought to regulate population size due to high mortality associated with the energetic expenditure of foraging in this habitat type (Alisauskas 1988, Francis et al. 1992, Ankney 1996). After lesser snow geese expanded into additional winter habitat types, Alisauskas (1988) reported lower true metabolizable energy values in coastal marsh diet items, relative to agricultural diet items such as rice and corn (Zea mays), suggesting that body condition of individuals using different habitat types may vary prior to spring migration. Therefore, if carry-over effects are incurred 
due to decisions associated with winter habitat use, we hypothesized that individuals using coastal marsh habitats would have reduced spring body condition (primarily lower lipids) compared to those using agricultural habitats. Further, geese overwintering in coastal marshes have previously been documented as being larger bodied compared to individuals overwintering in rice or corn predominant landscapes (Alisauskas 1998, Jónsson 2005). Hence, we expected to find similar trends in body size among spring collected individuals based on winter habitat classification.

Given the propensity of individuals that breed at higher latitudes to rely more on endogenous reserves for reproduction and the positive relationship between "capital" breeding and increased body size (Klassen et al. 2006), we expected to observe larger body sizes for individuals classified to higher latitude breeding regions. However, Hobson et al. (2011) found greater support for endogenous reproductive investment in smaller bodied lesser snow geese breeding in a subarctic colony at La Pérouse Bay than for larger bodied greater snow geese (Anser caerulescens atlantica) breeding at Bylot Island, a high arctic colony. These results suggest that individuals with longer migration distances may invest less of their endogenous reserves for reproduction, as reserves may be diminished before arrival (Hobson et al. 2011). It is therefore possible that individuals within a species rely on different foraging strategies in preparation for nesting at different latitudes. Agricultural production in southern Manitoba has facilitated a significant late spring (late April and May) staging area for lesser snow geese before departing for arctic and subarctic breeding colonies, and refueling there is important for future recruitment (Alisauskas 2002). Thus, we tested for potential differences in foraging strategies during early spring migration (February and March) by evaluating differences in nutrient 
reserves among individuals classified to different molting destinations and prior winter habitat use.

\section{METHODS}

\section{Collection of spring individuals to assess body condition and seasonal origins}

We collected lesser snow geese across east-central Arkansas and southeast Missouri (Region 1), northwest Missouri (Region 2), southeastern Nebraska (Region 3), and east-central South Dakota (Region 4), USA, during spring migration from 2 February - 31 March $2015(n=357)$ and 11 February - 7 March $2016(n=405)$. These regions were characterized by intensive agricultural production of rice, corn, and winter wheat (Triticum aestivum) and typify landscape characteristics that lesser snow geese use during spring migration (Abraham et al. 2005). Collection areas were considered key lesser snow goose staging areas during spring migration and band recovery and harvest estimates indicate a greater proportion of lesser snow geese harvested in these states compared to other states in the Mississippi and Central flyways (Webb et al. 2010, Alisauskas et al. 2011, Kruse and Fronzcak 2013). Therefore, we collected birds in these states to ensure a heterogeneous sample range of nutrient reserves among sex and age classes representative of lesser snow goose populations during spring migration. We obtained individuals harvested over decoys from participants in the Light Goose Conservation Order as well as those that were randomly collected using jump shooting techniques (Fowler et al. 2018b). All lesser snow geese collected were labeled and frozen until processing, and were collected in accordance with the United States Fish and Wildlife Service scientific collection permit number MB47969B-1, Arkansas state permit number 102320141, Missouri state permit number 16217, Nebraska state permit number 
535, South Dakota state permit numbers 1 and 5, and University of Missouri Animal Care and Use Committee permit number 8191.

For individuals collected during spring, we aged snow geese as hatch-year or after hatch-year (HY or AHY, respectively) using plumage characteristics and foot color and recorded sex based on reproductive organs during dissections (Baldassare 2014). We weighed thawed individuals to the nearest $0.5 \mathrm{~g}$ with an electronic scale. To assess body size, we measured head, culmen, and total tarsus length with digital calipers to the nearest $0.1 \mathrm{~mm}$, and measured body length and un-flattened wing chord to the nearest $\mathrm{mm}$ using a measuring board (Dzubin and Cooch 1993, Fowler et al. 2018b). We used these five morphometrics to develop a univariate index of body size based on loadings from the first principle component of a principle components analysis (described in Chapter 2).

\section{Dissection and chemical analyses of geese}

A complete description on methods for dissection and chemical analyses of geese are detailed in Fowler et al. (2018b), but in brief, we shaved individuals of their feathers to remove potential biases in protein estimates, and weighed and removed ingestacontents to achieve an ingesta-free body mass (g). We ground individual carcasses through an industrial meat grinder and then dried a subsample to a constant mass. Subsequently, we submitted pulverized homogenates samples to the University of Missouri Agricultural Experiment Station Chemical Laboratory for proximate analysis of crude lipid and protein following standardized procedures (Alisauskas 2002, Horwitz 2006). Total body lipids and protein were then scaled to body described, as described in Chapter 1. 
Additionally, to determine presumed breeding origin, we removed the first primary feather (P1) from each individual as a source material to determine presumed molting origin via a linear discriminant function using known feather stable isotope values (details below). In 2016, we removed bicep muscle tissue in a subset of spring collected adult and juvenile individuals $(n=173)$ to identify likely winter habitat use. This subset constrained the sample to those individuals who were collected in Arkansas, Missouri, or Nebraska to ensure that the stage of an individual's migration chronology did not extend beyond the metabolic turnover of their bicep muscle to represent their winter habitat, per Hénaux et al. (2012) (details below).

\section{Determination of summer molting origin}

To determine likely geographic origins of summer molting in lesser snow geese collected during spring migration, we followed the approach outlined in Fowler et al. (2018a) that used a linear discriminant function derived from newly grown feathers collected from known geographic breeding colony locations to make probability based assignments to reference colonies from sampled feathers of unknown origin. We used newly grown flight feathers (primary or coverts) of adult and juvenile lesser snow geese collected by participating researchers during routine mid-summer banding operations at three arctic and two subarctic breeding colonies (Fig. 4.1) in July 2014 and 2016. Arctic breeding colonies included Southampton Island (63 $\left.48^{\prime} 30.67^{\prime \prime},-85^{\circ} 41^{\prime} 50.71^{\prime \prime}\right)$, Baffin Island (66 $\left.42^{\prime} 46.04^{\prime \prime},-72^{\circ} 33^{\prime} 26.32^{\prime \prime}\right)$ and Karrak Lake (67' $15^{\prime} 37.30^{\prime \prime},-100^{\circ} 16^{\prime}$

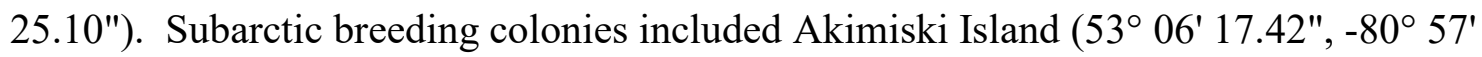
28.73") and La Pérouse Bay (58 43' 5.62", -93 53' 21.54") (Fig. 1). Upon removal, feathers were stored dry in paper envelopes until processing. All feathers from breeding 
colonies were collected in accordance with Environment Canada Animal Care Committee permit number \#16JL01. Collected feathers were cleaned of surface oils in chloroform:methanol $(2: 1 v / v)$ solvent rinse and analyzed for stable hydrogen $\left(\delta^{2} \mathrm{H}\right)$ isotope measurements as described in detail by Fowler et al. (2018a). Fowler et al. (2018a) assessed utility of $\delta^{2} \mathrm{H}, \delta^{13} \mathrm{C}, \delta^{15} \mathrm{~N}$, and $\delta^{34} \mathrm{~S}$ adult feather values from known colonies to distinguish among discrete sampled colonies and found the best predictive function that retained an interpretable level of spatial precision and accuracy was one using $\delta^{2} \mathrm{H}_{\mathrm{f}}$ alone to classify individuals among subgroups rather than among colonies or subpopulations. Subgroups grouped signatures from Baffin and Southampton Island (hereafter referred to as BISI) into one category and signatures from La Pérouse Bay and Akimiski Island into another category (hereafter referred to as subarctic), leaving Karrak Lake as an independent colony.

In preliminary analyses, we found differences in $\delta^{2} \mathrm{H}_{\mathrm{f}}$ between adult and juvenile feathers of known geographic molting origin $\left(F_{1,128}=31.54, P<0.0001\right)$, suggesting that a discriminant function based only on adults may increase the propensity to misclassify juveniles from unknown origins unless a juvenile specific discriminate function can be separately derived from additional known reference samples. However, known feather samples for juveniles were only collected in subarctic colonies in one year (2016), which limited our ability to develop a discriminate function across the larger geographic range of lesser snow geese. Therefore, we derived a discriminant function (hereafter referred to as "Summer Origins LDF"), similar to Fowler et al. (2018a), from a larger data set of known adult reference feather samples using the "lda" function in the MASS package in Program R (Venables and Ripley 2002). 
We assessed the performance of this linear discriminate function in two ways. First, we assessed the overall model accuracy of assignment for the discriminant function based on $\mathrm{K}$-fold cross validation $(K=10)$. Secondly, we assessed the discrete group accuracy, precision, and recall of the discriminant function based on a confusion matrix of the true class and predicted class of the individuals resulting from cross validation. Here, accuracy, precision, and recall were defined, respectively, as follows:

$$
\begin{gathered}
\text { Accuracy }=\frac{T N+T P}{T N+T P+F N+F P} \\
\text { Precision }=\frac{T P}{(T P+F P)} \\
\text { Recall }=\frac{T P}{(T P+F N)}
\end{gathered}
$$

where $T N$ were number of true negatives, $T P$ the number of true positives, $F N$ the number of false negatives, and FP the number of false positives (James et al. 2013). We determined the strength of the individual model based on the collective metrics of accuracy, precision, and recall.

\section{Determination of winter habitat use}

To determine likely winter habitat use (and by proxy, broad geographic wintering origin) in spring migratory geese, we followed a similar approach described by Hénaux et al. (2012) where stable isotopes were analyzed in bicep muscle tissue of geese collected at known reference winter habitat types. While no direct experimental studies have been conducted on the elemental turnover of bicep muscle tissue in snow geese, Hénaux et al. (2012) predicted that isotopic measurements in muscle tissue of snow geese represented a 
dietary integration over the previous month. Hénaux et al. (2012) analyzed $\delta^{2} \mathrm{H}, \delta^{13} \mathrm{C}$, and $\delta^{15} \mathrm{~N}$ values in bicep muscle tissue and found strong predictive power based on the combined use of all three isotopes for classification. Additionally, Hénaux et al. (2012) suggested future work to assess the use of $\delta^{34} \mathrm{~S}$ as a fourth possible isotope to distinguish between coastal and non-coastal habitats. Therefore, we collected bicep muscle tissue from wings of lesser snow geese harvested during winter at known discrete geographic locations and habitat types and analyzed each sample for $\delta^{2} \mathrm{H}, \delta^{13} \mathrm{C}, \delta^{15} \mathrm{~N}$, and $\delta^{34} \mathrm{~S}$ values. We collected adult and juvenile wings of lesser snow geese shot in coastal marshes (or close proximity) of Texas (Brazoria County; $29^{\circ} 06^{\prime} \mathrm{N} 95^{\circ} 19^{\prime} \mathrm{W}$ ) and Louisiana (Cameron Parish; 29 $44^{\prime} \mathrm{N} 92^{\circ} 50^{\prime} \mathrm{W}$ ) and rice agriculture in Arkansas (Dumas County; 33 $47^{\prime} \mathrm{N} 91^{\circ} 22^{\prime} \mathrm{W}$ ) in January 2016 and 2017 . Because snow geese were present in coastal and agricultural habitats from November to January (Jónsson and Afton 2006), we expected individuals collected as references were in equilibrium with local food resources (Hénaux et al. 2012). Unfortunately, samples collected in 2016 were lost due to spoiling from an undetected freezer outage during storage.

We used the same procedure for preparing and analyzing stable isotope values from the remaining bicep muscle tissue as described in Hénaux et al. (2012). To determine whether muscle tissues from different collection areas were isotopically distinct, we calculated mean muscle stable isotope values from each collection state and ran a multiple analysis of variance (MANOVA; $\alpha<0.05$ ). Muscle values for all four isotopes were normally distributed (Shapiro test: all $P$ 's $>0.05$ ) and homoscedastic (Levene's test: all $P$ 's $>0.05$ ). We initially tested for differences in tissue stable isotope values between adult and juvenile individuals using a MANOVA and found no effect of 
age on stable isotope values $\left(F_{4,39}=1.06, P=0.392\right)$. Therefore, we used both adult and juvenile reference samples to build linear discriminant functions. Because we had less certainty regarding the utility of all four stable isotope values to accurately classify winter habitat use, we assessed the performance of a suite of linear discriminant functions that used a combination of distinct isotopes to classify individuals to either the three collection geographic regions or two habitat types grouped as coastal marsh or agricultural rice habitats.

\section{Summer molt origin and winter habitat use assignment}

We classified the likely geographic molting origins of spring collected individuals using the Summer Molt LDF based on known reference samples. As described above, we limited our prediction of geographic molting origins to adults only $(n=497)$. Following prediction for adults, we retained only those individuals whose posterior probability of assignment was $\geq 0.70$ based on visual assessment of the probability density function of classified individuals. The determination for this cutoff is partially subjective but provides a means to retain the majority of individuals, based on natural breaks in the density function (Beatty et al. 2014), classified with high probabilities while removing individuals who had lower origin probability certainty despite classification. Similarly, we classified likely winter habitat use of spring collected individuals using the best performing linear discriminant function (hereafter referred to as "Winter Habitat LDF") and retained individuals whose posterior probability of assignment was $\geq 0.80$, based on observed natural breaks in the density function. 


\section{Model Fitting}

To determine the influence of winter habitat use and summer geographic molting origin on spring body condition and body size, we built an individual general linear mixed model to separately describe variation in size adjusted total body lipids, total body protein, and body size based on selected explanatory variables of interest. We analyzed individuals who provided summer geographic molting origin separately from those individuals providing winter habitat use data for two primary reasons. First, the subset of adult and juvenile individuals sampled for bicep muscle tissue occurred in only one of the two sample years and resulted in a comparatively smaller sample size $(n=173)$. Secondly, because we choose to only retain adult individuals for analysis who had a strong posterior probability of assignment for both summer geographic molting origins and winter habitat use, the number of individuals who had both high molting classification and winter habitat use probabilities was even smaller $(n=98)$. Therefore, we analyzed individuals with high likelihoods of summer geographic molting origin data $(n=324)$ and winter habitat use data $(n=137)$ separately in order to maximize available data for each model.

For adult individuals containing summer geographic molting data, we formulated body condition models as:

$$
\begin{aligned}
\text { Condition }= & \beta_{0}+\beta_{1} *[\mathrm{Sex}]+\beta_{2} *[\text { Summer Molt }]+\beta_{3} *[\text { Sex } * \text { Summer Molt }] \\
& +\varepsilon_{D * M}+\varepsilon_{H}
\end{aligned}
$$

where $\beta_{0}$ was the intercept, $\beta_{1}, \beta_{2}$, and $\beta_{3}$ were regression coefficients describing the linear relationship between size adjusted body condition (lipids or protein) and sex, classified origin of summer molt, the respective interaction, and $\varepsilon_{D}{ }^{*} M$ was the random interactive 
effect between date of collection (Julian) and classified molting origin, and $\varepsilon_{H}$ was the random effect of harvest collection method (hunter decoy shot or jump shot).

Similarly, we modeled variation in body size as:

$$
\begin{aligned}
\text { Body Size }= & \beta_{0}+\beta_{1} *[\text { Sex }]+\beta_{2} *[\text { Summer Molt }]+\beta_{3} *[\text { Sex } * \text { Summer Molt }] \\
& +\varepsilon_{D}
\end{aligned}
$$

where $\beta_{0}$ was the intercept, $\beta_{1}, \beta_{2}$, and $\beta_{3}$, were regression coefficients describing the linear relationship between body size (univariate PC1) and sex, classified molt origin, the respective interaction, and $\varepsilon_{D}$ was the random effect of collection date.

For individuals containing winter habitat use data, we formulated body condition models as:

$$
\begin{aligned}
\text { Condition }= & \beta_{0}+\beta_{1} *[\mathrm{Sex}]+\beta_{2} *[\text { Age }]+\beta_{3} *[\text { Habitat Use }]+\varepsilon_{\text {Date } * \text { Habitat Use }} \\
& +\varepsilon_{\text {Harvest Type }}
\end{aligned}
$$

where $\beta_{0}$ was the intercept, $\beta_{1}, \beta_{2}$, and $\beta_{3}$ were regression coefficients describing the linear relationship between size adjusted body condition (lipids or protein) and sex, age, and classified winter habitat use, and $\varepsilon_{D * M}$ was the random interactive effect between collection date and classified winter habitat use, and $\varepsilon_{H}$ was the random effect of collection method of harvest (hunter decoy shot or jump shot).

To evaluate if body size differed among individuals classified to different wintering habitats, we modeled variation in body size as:

$$
\text { Body Size }=\beta_{0}+\beta_{1} *[\text { Sex }]+\beta_{2} *[\text { Age }]+\beta_{3} *[\text { Winter Habitat }]+\varepsilon_{D}
$$


where $\beta_{0}$ was the intercept, $\beta_{1}, \beta_{2}$, and $\beta_{3}$, are regression coefficients describing the linear relationship between body size (univariate PC1) and sex, age, and classified winter habitat, and $\varepsilon_{D}$ was the random effect of collection date.

We analyzed general linear models using the base package of Program $\mathrm{R}$ (Version, 3.3.3, R Core Team 2018) and used the lme4 package for Program R (Bates et al. 2014) to formulate mixed-effects models, deriving coefficient estimates using restricted maximum likelihood. We assessed goodness of fit by calculating conditional and marginal $\mathrm{R}^{2}$ values (Nakagawa and Schielzeth 2013) with the r.squaredGLMM function in the MuMIn package for Program R (Barton 2017). We considered covariates significant when $95 \%$ confidence intervals did not overlap zero $(\alpha=0.05)$. To estimate least square means for factor levels of interest and calculate differences in least square means, we used the lmerTest package for Program R (Kuznetsova et al. 2017).

\section{RESULTS}

Stable isotope values of snow goose feathers collected from reference breeding colonies and classification model performance

Stable isotope values $\left(\delta^{2} \mathrm{H}\right)$ of known adult flight feathers collected in 2014 and 2016 differed between Akimiski Island, La Pérouse Bay, and Karrak Lake. However, feather deuterium values did not differ between Southampton Island and Baffin Island but were different from remaining colonies (Table 4.1). Grouping these five colonies into three geographic subgroups (defined in Methods) resulted in distinct $\delta^{2} \mathrm{H}$ values, similar to Fowler et al. (2018a) (Table 4.1). K-fold cross validation $(k=10)$ of our Summer Origins LDF resulted in an overall accuracy rate of $91.8 \%$, and measured recall was $>$ $85 \%$ for all three classification levels (Karrak Lake, BISI, and Subarctic) (Table 4.2). 
We used the Summer Origin LDF to classify summer molting origins on 497 adult lesser snow geese containing $\delta^{2} \mathrm{H}_{\mathrm{f}}$ data. Based on the distribution of probability frequency of posterior probabilities of summer origin classification (Fig. 4.2), we elected to retain only those individuals who had a $70 \%$, or greater, posterior probability. Using this threshold, we classified 161 individuals to Karrak Lake, 158 to the BISI complex, and 5 as Subarctic, resulting in a total of 324 individuals with summer molt origin for general linear mixed model analysis.

\section{Body condition of spring migrants classified to summer origin categories}

Lipid content (adjusted for body size) of the 324 adults analyzed for summer origins averaged $129.6 \mathrm{~g}$ [standard deviation $(\mathrm{SD})=64.4 \mathrm{~g}$ ) and ranged $312.3 \mathrm{~g}$ across the sample with a minimum value of $16.1 \mathrm{~g}$ to a maximum of $328.5 \mathrm{~g}$. Protein content (adjusted for body size) averaged $374.2 \mathrm{~g}(\mathrm{SD}=28.9 \mathrm{~g})$ and ranged $174.8 \mathrm{~g}$ across the sample with a minimum value of $286.2 \mathrm{~g}$ to a maximum of $460.9 \mathrm{~g}$. PC1 for selected adults averaged 0.39 units $(\mathrm{SD}=1.77)$ and loadings ranged from -4.7 to 5.9 .

Lipid content in adult lesser snow geese was not influenced by sex, classified summer molt origin, or by the interaction between the two fixed effects (Table 4.3). However, our model explained approximately $52 \%$ of the overall variation in the data, with the random interactive effect of Julian date of collection and classified molt origin as well the random effect of harvest collection type accounting for $96 \%$ of the explained variation $($ marginal $\mathrm{R}$-squared $=0.02 ;$ conditional $\mathrm{R}$-squared $=0.52 ;$ Table 4.3$)$.

Similarly, protein content in adult lesser snow geese was not influenced by sex, classified summer molt origin, or by the interaction between the two selected fixed effects (Table 4.3). This model explained approximately $17 \%$ of the overall variation in the data, with 
the random interactive effect of Julian date of collection and classified molt origin as well the random effect of harvest collection type accounting for $88 \%$ of the explained variation $($ marginal $\mathrm{R}$-squared $=0.02 ;$ conditional $\mathrm{R}$-squared $=0.17$; Table 4.3$)$.

Body size for adult lesser snow geese was influenced by the interaction between classified summer molt origin and sex (Fig. 4.3). This model explained approximately $33 \%$ of the overall variation in the data, with the random interactive effect of collection date accounting for $10 \%$ of the explained variation (marginal R-squared $=0.30$; conditional R-squared $=0.33$; Table 4.3 ). Adult males classified to the three breeding regions did not differ from one another in body size (Fig. 4.3). However, adult females from the BISI complex were 1.44 loading units $(95 \%$ CI: $0.98,1.90)$ smaller than females assigned to Karrak Lake, but were not different from females assigned to subarctic breeding regions (Difference estimate: 0.01; 95\% CI: -1.50, 1.50) (Fig. 4.3).

Stable isotope values of snow goose muscle tissue collected from reference winter habitats and classification model performance

Results from our MANOVA indicated overall differences $\left(F_{8,76}=7.10, P<\right.$ 0.0001) in reference bicep muscle tissue isotope values among states collected in 2017 (Table 4.4). While $\delta^{2} \mathrm{H}_{m}, \delta^{13} \mathrm{C}_{m}$, and $\delta^{34} \mathrm{~S}_{m}$ differed among collection states $\left(\delta^{2} \mathrm{H}_{\mathrm{m}}: F_{2,43}=\right.$ 14.08, $\left.P<0.0001 ; \delta^{13} \mathrm{C}_{m}: F_{2,43}=12.35, P<0.0001 ; \delta^{34} \mathrm{~S}_{m}: F_{2,43}=34.05, P<0.0001\right)$, $\delta^{15} \mathrm{~N}_{m} \operatorname{did} \operatorname{not}\left(F_{2,43}=2.77, P=0.0734\right)$. Similarly, when reference tissues where grouped by habitat type (coastal marsh or rice agriculture), $\delta^{2} \mathrm{H}_{m}, \delta^{13} \mathrm{C}_{m}$, and $\delta^{34} \mathrm{~S}_{m}$ differed between habitat types $\left(\delta^{2} \mathrm{H}_{\mathrm{m}}: F_{1,44}=28.8, P<0.0001 ; \delta^{13} \mathrm{C}_{m}: F_{1,44}=18.87, P<\right.$ $\left.0.0001 ; \delta^{34} \mathrm{~S}_{m}: F 1_{, 44}=51.8, P<0.0001\right)$, but $\delta^{15} \mathrm{~N}_{m}$ values did not differ $\left(F_{1,44}=0.00, P=\right.$ 0.984) (Table 4.5). 
We evaluated predictive performance of ten candidate linear discriminant functions derived from our reference bicep muscle tissue samples. Six candidate models discretely classified individuals to their state of collection, while four models classified individuals to the respective habitat types. Discriminant functions that classified individuals to habitat type were more accurate than those classifying individuals to the state of collection, as frequent misclassification occurred between Louisiana and Texas (Table 4.6). Our most accurate function used $\delta^{13} \mathrm{C}_{m}, \delta^{15} \mathrm{~N}_{m}$, and $\delta^{34} \mathrm{~S}_{m}$ to discriminate between habitat types and had an overall model accuracy of $93.5 \%$, which was $19.6 \%$ more accurate than the top discriminant function classifying individuals to state origins (Table 4.7).

Because of the strong performance of our top classification model (containing $\delta^{13} \mathrm{C}_{m}, \delta^{15} \mathrm{~N}_{m}$, and $\delta^{34} \mathrm{~S}_{m}$ ), we used this discriminant function as our Winter Habitat LDF to classify adult and juvenile individuals $(n=137)$ to winter habitat use collected during spring migration. Based on the distribution of probability frequency in posterior probabilities of winter habitat origin classification (Fig. 4.4), we retained only those individuals with an $80 \%$, or greater, posterior probability. Using this threshold, we classified 61 individuals to coastal marsh habitat and 76 to rice dominant agriculture, resulting in 137 individuals with winter habitat use for general linear mixed model analysis (Fig. 4.5).

Body condition of spring migrants classified to winter habitat categories

Lipid content (adjusted for body size) of the 137 adults and juveniles averaged $130.5 \mathrm{~g}$ [standard deviation $(\mathrm{SD})=59.6 \mathrm{~g}$ ) and ranged $267.3 \mathrm{~g}$ across the sample with a minimum value of $19.3 \mathrm{~g}$ to a maximum of $286.5 \mathrm{~g}$. Protein content (adjusted for body 
size) averaged $367.1 \mathrm{~g}(\mathrm{SD}=27.3 \mathrm{~g})$ and ranged $121.2 \mathrm{~g}$ across the sample with a minimum value of $309.1 \mathrm{~g}$ to a maximum of $430.2 \mathrm{~g}$. PC1 for selected individuals averaged -0.22 units $(\mathrm{SD}=1.67)$ and loadings ranged from -6.2 to 5.9 .

Lipid content in lesser snow geese was influenced by winter habitat use and age classes, but not by sex (Table 4.8). Individuals classified as overwintering in coastal marsh habitats had $33.4 \mathrm{~g}(95 \% \mathrm{CI}: 0.38 \mathrm{~g}, 66.4 \mathrm{~g})$ less lipids at the time of collection during spring migration compared to individuals classified as overwintering in rice based habitats (Fig. 4.6). Additionally, juveniles had 53.4 g (95\% CI: 30.4 g, 76.4 g) more lipids than adults (Fig. 4.6). Our model explained approximately $43 \%$ of the overall variation in the data, with the random interactive effect of Julian date of collection and classified winter habitat use and the random effect of harvest collection type accounting for $53.5 \%$ of the explained variation (marginal R-squared $=0.20$; conditional R-squared $=0.43 ;$ Table 4.8).

Winter habitat use did not influence protein content, but protein content differed by age and sex (Table 4.8). Adult individuals had $13.2 \mathrm{~g}$ (95\% CI: $2.6 \mathrm{~g}, 23.8 \mathrm{~g}$ ) more protein relative to juveniles (Fig. 4.7), while females had $11.5 \mathrm{~g}(1.9 \mathrm{~g}, 21.2 \mathrm{~g})$ less protein compared to males (Fig. 4.7). This model explained approximately $11 \%$ of the overall variation in the data, with the random interactive effect of collection date and classified molt origin as well the random effect of harvest collection type accounting for approximately $82 \%$ of the explained variation (marginal R-squared $=0.09$; conditional Rsquared $=0.11 ;$ Table 4.8).

Similarly, snow geese who used coastal marsh or rice habitat types was not influenced by body size. Rather, sex and age alone were important predictors to explain 
variation in body size data (Table 4.8). Adult geese were 1.10 loading units (95\% CI: 0.49, 1.71) larger than juveniles (Fig. 4.8), while females were 1.15 loading units (95\% CI: $0.60,1.72$ ) smaller than males (Fig. 4.8). This model explained approximately $18 \%$ of the overall variation in the data, with the random interactive effect of Julian date of collection accounting for $0 \%$ of the explained variation (marginal R-squared $=0.18$; conditional R-squared $=0.18$; Table 4.8).

\section{DISCUSSION}

Our study evaluated the influence of winter habitat use and presumed breeding season destination on spring body condition during migration, as well as variation in individual body size, of a long distance migrant waterfowl species. We found that spring body condition was better explained as a carry-over effect from winter habitat use, rather than inferences regarding strategies associated with different summer destinations. However, our ability to detect nutrient accumulation strategies associated with breeding season destination was likely limited based on collecting birds only in early stages of migration. Alisauskas (1988) suggested that individuals using different winter habitats enter into spring migration with differential body condition. Our research demonstrates that this likely still occurs, and that further, geese using coastal marsh habitats during winter maintain lower overall lipid reserves during spring migration, at least during the sampling period of our study. As a result, differences in lipid reserves between individuals using distinct winter habitats could in part explain heterogeneous body condition among individuals during spring migration. Further, the impact of these individual carry-over effects likely translates to cross-seasonal population effects that may explain individual variation in natural mortality or harvest susceptibility (Chapter 2), 
or influence heterogeneous reproductive potential (Ankney and MacInnes 1978, Sedinger et al. 2011, Sedinger and Alisauskas 2014).

Lipid reserves are an important fuel source for waterfowl during overwintering and spring migration, and are primarily catabolized through carbohydrate rich diet items (Jenni and Jenni 1998, McWilliams et al. 2004). Alisauskas (1988) found that coastal marsh diet items such as tubers and rhizomes had lower true metabolizable energy (TME) estimates compared to rice or corn habitats, meaning that marsh diet items provide less gross energy available to produce lipids. Waterfowl foods found in marshes typically have low TME values as a consequence of their high fiber content, which requires increased daily consumption rates by waterfowl and likely results in a greater proportion of time activity budgets allocated to foraging (Alisauskas 1988, Gauthier et al. 1988). Increased energy expenditure related to greater time spent foraging, paired with lower energetic diet items, may result in lower lipid reserves among geese using coastal marsh habitats compared to birds using landscapes containing rice or other diet items found in agricultural landscapes (Jónsson and Afton 2006). Relative body condition during the transition between winter and spring migration has implications for condition throughout migration and into breeding, even for "income" strategy waterfowl species (Tamisier et al. 1995, Guillemain et al. 2008). In our study, geese associated with coastal marsh habitats in winter had lower lipid reserves during early spring migration, suggesting that the ecological consequences of winter foraging habitats and subsequent body condition carry over into spring migration.

Indeed, Sedinger et al. (2011) found that black brant (Branta bernicla nigricans) stratified across winter habitat types of different foraging quality resulted in differential 
breeding propensities, suggesting that use of high quality winter habitat facilitates body condition beneficial for expeditious migration and successful breeding. In contrast, individuals using habitats of lower foraging quality, or habitats that require greater energy expenditure, may result in individuals with lower fitness (Bearhop et al. 2004, Gunnarsson et al. 2006). Our study design was not equipped to evaluate if breeding productivity was related to differential winter habitat quality. Yet, if coastal marsh habitats facilitates reduced body condition into spring migration then it is likely that these individuals continue to remain in reduced body condition leading up to rapid follicular development and nesting (Ankney and MacInnes 1978, Alisauskas 2002), resulting in lower breeding propensity or fecundity. Thus, future studies should consider evaluating the impacts on the complete life-history of individuals who use different winter habitats.

We did not observe differences in total body protein between individuals classified to marsh or rice based winter habitat types. Interestingly, rice based habitat types provide a substantially greater fraction of available protein compared to marsh habitats, although marsh habitats still provide sufficient protein resources to meet daily existence demands (Alisauskas 1988). While protein reserves are an essential component of structural function in migration, carrying excess protein is an energetic cost to migration (Jenni and Jenni 1998) so similarities in protein levels among individuals that overwintered in different habitat types may be a shared strategy in protein accumulation.

We did not observe differences in body size, inferred by a univariate index (PC1), between individuals associated with coastal marsh and rice based agricultural habitats. Previous studies found individuals wintering in traditional coastal marshes to be generally larger bodied, particularly in bill morphology (Alisauskas 1998, Jónsson 2005). 
It is unclear why body size differences of geese associated with different habitat types were not detected in our study. Alisauskas (1998) proposed multiple working hypotheses regarding segregation of larger bodied geese found in marshes relative to rice and corn based agricultural habitats. Most notably, Alisauskas (1998) suggested winter range expansion beyond coastal marsh systems facilitated phenotypic selection towards smaller size morphs that could maintain comparable survival rates by implementing grazing or pecking strategies compared to grubbing strategies observed in geese foraging in marshes. Jónsson (2005) and Jónsson and Afton (2014) assessed whether snow geese using coastal marshes in Louisiana were a distinct subpopulation that differed from snow geese utilizing agricultural habitats, such as rice, in adjacent lands that previously were coastal prairie. Jónsson (2005) found that although geese using rice habitats were generally smaller than coastal marsh geese, there was notable intraseasonal movement of individuals between the two habitats, leading Jónsson and Afton (2014) to conclude that geese using coastal marshes were not a distinct subpopulation. One possible explanation for our finding of similar body size could come from our methodological approach to classifying spring migrants to either coastal marsh or rice based habitat types. Our Winter Habitat LDF function relied on distinct differences in sulfur isotope values $\left(\delta^{34} \mathrm{~S}_{m}\right)$ found between reference samples collected in the two habitat types. $\delta^{34} \mathrm{~S}_{m}$ values were more enriched for birds collected either in or within close proximity to coastal marshes in Texas and Louisiana. Given movement of individuals between habitat types reported by Jónsson and Afton (2014), it is possible that a significant proportion of our spring migrants classified to coastal marsh systems where individuals who were in close proximity to coastal systems (resulting in more enriched $\delta^{34} \mathrm{~S}_{m}$ ) but moved frequently into 
adjacent rice agricultural systems. If this were the case, it is more reasonable to expect these individuals to be of similar body size as those classified to rice habitats (referenced by samples collected in Arkansas) which would allow greater flexibility to exploit both habitat types. An alternative explanation, not mutually exclusive, is related to decline in overall body size (Alisauskas et al. 2011) of the midcontinent population since the time of study conducted by Alisauskas (1998) and Jónsson (2005), where geese were collected in 1983-84 and 2002-04, respectively. As the primary wintering grounds have shifted more northwards into Arkansas (Alisauskas et al. 2011), phenotypic selection may favor smaller bodied individuals (Alisauskas 1998) and reduce variation in body size among the population. However, we were not able to make morphometric measurements on geese collected as reference samples in distinct coastal marsh and rice habitats, thus, we did not have any morphometrics to assess whether or not individuals collected at known winter habitats differed in body size.

The identification of carry-over effects across diverse taxa on body condition has been widely explored (Harrison et al. 2011, Sedinger and Alisauskas 2014), yet fewer studies have looked for evidence of differential body condition on individuals anticipating unique future life-histories. We evaluated whether different breeding season destinations influenced lipid or protein reserves during early spring migration, given that previous work demonstrated variable investments of endogenous reserves to reproduction related to migration length in arctic nesting geese (Hobson et al. 2011). However, we did not detect differences in lipid or protein reserves among sampled individuals classified to one of the three discrete geographic subgroups predicted by our Summer Origins LDF. As referenced earlier, our study was unlikely to detect differences in nutrient 
accumulation strategies among breeding season destinations, given that we collected birds only in early stages of migration and not throughout the entire migratory event (i.e., as birds approached breeding grounds). Two considerations are important in interpreting our results; one methodological and the other ecological. First, while our Summer Origins LDF had high probability of accurately predicting an individual to one of three discrete subgroups, these subgroups each represented a large geographical extent and therefore likely masked a relatively large amount of variability in destinations of any given individual. Reference feather samples used to derive Summer Origins LDF were from the six most logistically accessible colonies where birds are routinely banded for population monitoring. However, at least 43 known lesser snow goose nesting colonies are distributed throughout the Canadian arctic and subarctic (Kerbes et al. 2014). While $\delta^{2} \mathrm{H}_{f}$ values are strongly correlated with latitude (Hobson et al. 2012, Fowler et al. 2018a), a more precise spatially explicit map of expected $\delta^{2} \mathrm{H}_{f}$ values across the Canadian arctic and subarctic has not yet been developed for geese. Therefore, although our Summer Origins LDF is the most readily available predictive function for establishing geographic origins of lesser snow geese during the breeding season, it should be considered an approximate location relative to the large distribution of potential breeding colonies. Additionally, assignments of geographic destination assume fidelity to the location in which $\delta^{2} \mathrm{H}_{f}$ were derived the previous year, which may not be consistent across years (Souchay et al. 2014). If a spring migrant deferred breeding in the previous summer, and instead participated in a molt-migration, then $\delta^{2} \mathrm{H}_{f}$ may not be a reliable indicator of breeding season destination in the current year as that individual was likely headed to an established colony (Souchay et al. 2014, Wilson et al. 2016). Therefore, our broad 
classification approach cannot account for all life-history events that would influence decisions regarding nutrient accumulation strategies.

The second consideration regarding lack of support for the influence of breeding season destination on spring body condition is that our study may have collected birds too early in spring migration to detect nutrient accumulation strategies related to breeding. We assessed $\delta^{2} \mathrm{H}_{f}$ from individuals collected early February to the last day in March, with the most northern collection location in South Dakota. Individuals in our study generally exhibited greater lipid content at more northern collection sites (Chapter 2), indicating a latitudinal nutrient accumulation strategy rather than simply maintaining existence energy during migration. However, our collection sites represent a relatively early portion of spring migration and exclude other key final staging areas important for refueling before departing for breeding colonies (Alisasukas 2002). We were particularly interested in how nutrient reserves differed during migration between arctic and subarctic nesting individuals given their different migration lengths. It was challenging to properly assess these differences because we classified only 5 subarctic individuals out of 324 individuals in the data set. However, if individuals from arctic and subarctic colonies rely on different nutrient accumulation strategies, they could demonstrate those strategies at later points in migration as they approach more terminal staging areas and initiate rapid follicular development brought on by increased photoperiod (Alisauskas and Ankney 1992). Given the geographic shift of food availability from carbohydrate rich foraging landscapes (such as residual corn) to protein-dominant cereal grain landscapes with increasing latitude (Abraham et al. 2005), and the increasing need for nutrient reserves concurrent with decreasing availability on the landscape beyond the Canadian prairie, 
differences in nutrient accumulation strategies related to breeding season destination would likely be better assessed at locations closer to the breeding grounds.

In addition to sex and age differences, we also observed differences in female body size among individuals classified to Karrak Lake and the BISI complex, with smaller body size for BISI females than those from Karrak Lake. Reasons for this size difference could be variable. Larger body size may be associated with high latitude breeding grounds (Klassen et al. 2006) where selection favors larger bodied individuals who can transport greater quantities of reserves (Ankney and MacInnes 1978). Karrak Lake was the most northern colony sampled in our study and had a distinct $\delta^{2} \mathrm{H}_{f}$ value from the BISI complex. While Baffin Island is similar in latitude to Karrak Lake, Southampton Island is lower by approximately 3 degrees of latitude. Our sample size for individuals classified to the subarctic was low and resulted in too large a standard error to detect significant differences, but mean estimates of subarctic female body size were similar to that of the BISI complex and not Karrak Lake. These results suggest a general trend of smaller body size with decreasing latitude. An alternative to this explanation could instead be related to environmental characteristics specifically occurring in the BISI complex that influence growth rates, similar to conditions experienced by subarctic lesser snow geese in previous decades (Francis et al. 1992). However, we do not have specific evidence to suggest that environmental conditions are deteriorating and indeed, immigrations rates to the BISI complex may be increasing (R. Alisauskas, unpublished data). Regardless of the mechanism behind differences in body size between individuals classified to Karrak Lake and the BISI complex, smaller body size in BISI birds may regulate the quantity of endogenous nutrients brought to breeding grounds, or even 
fitness (Calder 1996, Hill et al. 2003). In a comparison of lesser snow geese to Ross's geese (A. rossii), Traylor et al. (2012) posited that smaller body size of Ross's geese result in a more frequent feeding in order to meet nutrient demands because of a higher mass-specific metabolic rate. Intraspecific variation of body size among snow geese distributed throughout the arctic may have a similar result.

\section{Additional Methodological Considerations}

Our ability to classify individuals to two winter habitat types relied on a suite of three stable isotope values $\left(\delta^{13} \mathrm{C}, \delta^{15} \mathrm{~N}\right.$, and $\left.\delta^{34} \mathrm{~S}\right)$ assessed in bicep muscle tissue of migrant snow geese. This particular combination of stable isotopes performed best in model cross-validation among 9 other candidate models. While $\delta^{2} \mathrm{H}_{m}$ values were distinct between state collection sites representing different habitat types, we elected not to use $\delta^{2} \mathrm{H}_{m}$ in our Winter Habitat LDF. This decision resulted from the inability to develop a discriminant function based on reference samples collected in the same year as spring migrants due to a freezer outage (referenced in Methods). $\delta^{2} \mathrm{H}$ values have potential for inter-annual variability associated with annual variation in amounts and timing of precipitation that influence $\delta^{2} \mathrm{H}$ values (Hénaux et al. 2012). Therefore, we used only $\delta^{13} \mathrm{C}, \delta^{15} \mathrm{~N}$, and $\delta^{34} \mathrm{~S}$ because the mechanisms that influence differences in values are less variable across years (Hénaux et al. 2012). However, our Winter Habitat LDF classified individuals discretely between only two habitat types due to the limited scope of available reference samples. These two categories alone may be too narrow to encompass the full range of potential winter habitats available to lesser snow geese. Primarily, some lesser snow geese may overwinter exclusively in corn agricultural habitats (Alisauskas 1998). We suspect that some individuals in our study classified to 
rice habitat may have alternatively overwintered in corn habitat, as some $\delta^{13} \mathrm{C}$ values were more enriched than expected for $\mathrm{C} 3$ photosynthetic plants, such as rice (Alisauskas and Hobson 1993, Hobson 1999). Nonetheless, individuals classified to coastal marsh and rice habitats were distinct in their isotopic distribution (Fig. 4.5), particularly because of the inclusion of $\delta^{34} \mathrm{~S}_{m}$ which is a unique signature indicating the proximity to coastal marsh systems (Peterson and Fry 1987, Hobson 1999, Hénaux et al. 2012). Therefore, our Winter Habitat LDF still allowed for assessment of potential carry-over effects on body condition associated with overwintering in proximity to coastal marsh systems relative to more inland agricultural landscapes.

\section{CONCLUSIONS AND MANAGEMENT IMPLICATIONS}

Our study indicates that lesser snow goose body condition during spring migration is more likely influenced by previous winter habitat use rather than by differences in migration strategy associated with breeding season destination. Specifically, we demonstrated that lesser snow geese using traditional winter habitats in coastal marshes have lower lipid reserves in early spring migration. This finding is consistent with previous studies and reviews that identify the carry-over impact of relative habitat quality on later life history events (Sedinger et al. 2011, Harrison et al. 2011, Sedinger and Alisauskas 2014). Thus, lesser snow geese who primarily use coastal marsh habitat types may have a greater probability of natural mortality (Morrison et al. 2007) or harvest susceptibility (see Chapter 2) from reduced body condition during spring migration.

Since 1997, lesser snow geese have been designated as an overabundant species (Batt et al. 1997) in large part to explosive population growth associated with winter 
range expansion outside of the historical coastal marsh habitats (Hobaugh 1985, Abraham et al. 2005). The spring Light Goose Conservation Order has allowed unlimited spring take of lesser snow geese since 1999 via liberal hunting regulations and accommodations. However, this initiative to reduce population size via reductions in overall adult survival rates has not been successful, largely due to an insufficient ability to reach impactful harvest rates (Alisauskas et al. 2011, Calvert et al. 2017) and potentially, harvest bias towards poorer conditioned individuals (See Chapter 2). Attempts to actively manage the midcontinent population of lesser snow geese have proven challenging (Leafloor et al. 2012) and our study indicates that the population continues to benefit from agricultural subsidies in wintering habitats and that these benefits transcend winter into spring migrations, potentially through cross-seasonal effects. While coastal marsh habitats provide micronutrients not found in agricultural systems (Alisauskas 1988), the abundance of agricultural habitats distributed throughout the migration corridor has facilitated improved energetics through increased availability of food items readily catabolized into lipids. The wide scale availability of agricultural resources throughout major portions of the spring migratory flyway may contribute to the observed increase in survival rates of light geese (Wilson et al. 2016).

Finally, this study contributes applications for the use of stable isotope ecology in assessing migratory connectivity and carry-over effects in avian species. While our discrete classifications of individuals to both winter habitat and summer geographic origin were broad, they provide a framework that can be improved upon through more precise and frequent sampling. In particular, an interannual spatially explicit distribution of $\delta^{2} \mathrm{H}_{m}$ could prove useful in delineating latitudes of overwintering in individual lesser 
snow geese. Additionally, alternative use for assessing $\delta^{2} \mathrm{H}_{f}$ from flight feathers could be used as a secondary means of monitoring proportions of harvest from discrete geographic areas (Fowler et al. 2018a). 


\section{LITERATURE CITED}

Abraham, K. F., R. L. Jefferies, and R. T. Alisauskas. 2005. The dynamics of landscape change and snow geese in mid-continent North America. Global Change Biology $11: 841-855$.

Alerstam, T. 2011. Optimal bird migration revisited. Journal of Ornithology 152:5-23.

Alerstam, T., A. Hedenström, and S. Åkesson. 2003. Long-distance migration: evolution and determinants. Oikos 103:247-260.

Alisauskas, R. A. Y. T. 1998. Winter range expansion and relationships between landscape and morphometrics of midcontinent lesser snow geese. Auk 115:851862.

Alisauskas, R. T. 2002. Arctic climate, spring nutrition, and recruitment in midcontinent lesser snow geese. Journal of Wildlife Management 66:181-193.

Alisauskas, R. T., and C. D. Ankney. 1992. The cost of egg laying and its relationship to nutrient reserves in waterfowl. Ecology and management of breeding waterfowl. University of Minnesota Press, Minneapolis 30-61.

Alisauskas, R. T., C. D. Ankney, and E. E. Klaas. 1988. Winter diets and nutrition of midcontinental lesser snow geese. Journal of Wildlife Management 52:403-414.

Alisauskas, R. T., R. F. Rockwell, K. W. Dufour, E. G. Cooch, G. Zimmerman, K. L. Drake, J. O. Leafloor, T. J. Moser, and E. T. Reed. 2011. Harvest, survival, and abundance of midcontinent lesser snow geese relative to population reduction efforts. Wildlife Monographs 179:1-42. 
Ankney, C. D. 1996. An embarrassment of riches : Too many geese: Invited paper: Journal of Wildlife Management 60:217-223.

Ankney, C. D., A. D. Afton, and R. T. Alisauskas. 1991. The role of nutrient reserves in limiting waterfowl reproduction. Condor 93:1029-1032.

Ankney, C. D., and C. D. MacInnes. 1978. Nutrient reserves and reproductive performance of female lesser snow geese. Auk 95:459-471.

Baker, A. J., P. M. Gonzalez, T. Piersma, L. J. Niles, I. de L. S. do Nascimento, P. W. Atkinson, N. A. Clark, C. D. T. Minton, M. K. Peck, and G. Aarts. 2004. Rapid population decline in Red Knots: Fitness consequences of decreased refueling rates and late arrival in Delaware Bay. Proceedings of the Royal Society B: Biological Sciences 271:875.

Baldassarre, G. A. 2014. Ducks, geese, and swans of North America. Volume 1. John Hopkins University Press, Baltimore, Maryland, USA.

Batt, B. 1997. Arctic ecosystems in peril: report of the arctic goose habitat working group. U.S Fish and Wildlife Service, Washington, D.C. and Canadian Wildlife Service, Ottawa, Ontario.

Bates, D., M. Mächler, B. Bolker, and S. Walker. 2014. Fitting linear mixed-effects models using lme4. arXiv preprint arXiv:1406.5823.

Bearhop, S., G. M. Hilton, S. C. Votier, and S. Waldron. 2004. Stable isotope ratios indicate that body condition in migrating passerines is influenced by winter habitat. Proceedings of the Royal Society of London B: Biological Sciences 271:S215-S218. 
Black, J. M., and M. Owen. 1987. Determinants of social rank in goose flocks: acquisition of social rank in young geese. Behaviour 102:129-145.

Calder, W. A. 1996. Size, function, and life history. Courier Corporation.

Calvert, A. M., R. T. Alisauskas, and G. C. White. 2017. Annual survival and seasonal hunting mortality of midcontinent snow geese. Journal of Wildlife Management 81:1009-1020.

Devries, J. H., R. W. Brook, D. W. Howerter, and M. G. Anderson. 2008. Effects of spring body condition and age on reproduction in mallards (Anas platyrhynchos). Auk 125:618-628.

Dzubin, A., and E. G. Cooch. 1992. Measurements of geese: general field methods. California Waterfowl Association, Sacramento, California, USA.

Fowler, D. N., E. B. Webb, F. B. Baldwin, M. P. Vrtiska, and K. A. Hobson. 2018a. A multi-isotope $\left(\delta^{13} \mathrm{C}, \delta^{15} \mathrm{~N}, \delta^{34} \mathrm{~S}, \delta^{2} \mathrm{H}\right)$ approach to establishing migratory connectivity in lesser snow geese: Tracking an overabundant species. PloS One 13:e0203077.

Fowler, D. N., K. J. Kuechle, B. A. Woodall, M. P. Vrtiska, and E. B. Webb. 2018b. Evaluating indices of lipid and protein content in lesser snow and Ross's geese during spring migration. Wildlife Society Bulletin 42:295-303.

Fox, A. D., J. Madsen, H. Boyd, E. Kuijken, D. W. Norriss, I. M. Tombre, and D. A. Stroud. 2005. Effects of agricultural change on abundance, fitness components and distribution of two arctic-nesting goose populations. Global Change Biology $11: 881-893$. 
Francis, C., M. Richards, F. Cooke, and R. Rockwell. 1992. Long-term changes in survival rates of lesser snow geese. Ecology 73:1346-1362.

Gauthier, G., J. Bêty, and K. A. Hobson. 2003. Are greater snow geese capital breeders? New evidence from a stable-isotope model. Ecology 84:3250-3264.

Gauthier, G., Y. Bédard, and J. Bédard. 1988. Habitat use and activity budgets of greater snow geese in spring. Journal of Wildlife Management 52:191-201.

Guillemain, M., J. Elmberg, C. Arzel, A. R. Johnson, and G. Simon. 2008. The incomecapital breeding dichotomy revisited: late winter body condition is related to breeding success in an income breeder. Ibis 150:172-176.

Gunnarsson, T. G., J. A. Gill, J. Newton, P. M. Potts, and W. J. Sutherland. 2005. Seasonal matching of habitat quality and fitness in a migratory bird. Proceedings of the Royal Society of London B: Biological Sciences 272:2319-2323.

Gunnarsson, T. G., J. A. Gill, P. W. Atkinson, G. Gelinaud, P. M. Potts, R. E. Croger, G. A. Gudmundsson, G. F. Appleton, and W. J. Sutherland. 2006. Population-scale drivers of individual arrival times in migratory birds. Journal of Animal Ecology 75:1119-1127.

Harrison, X. A., J. D. Blount, R. Inger, D. R. Norris, and S. Bearhop. 2011. Carry-over effects as drivers of fitness differences in animals. Journal of Animal Ecology 80:4-18. 
Heitmeyer, M. E., and L. H. Fredrickson. 1981. Do wetland conditions in the Mississippi Delta hardwoods influence mallard recruitment? Transactions of the North American Wildlife and Natural Resources Conferences 46:44-57.

Hénaux, V., L. A. Powell, M. P. Vrtiska, and K. A. Hobson. 2012. Establishing winter origins of migrating lesser snow geese using stable isotopes. Avian Conservation and Ecology 7:5.

Hill, R. J., T. Alisauskas, and C. Davison. 2003. Influence of body size and condition on harvest and survival of juvenile Canada geese. Journal of Wildlife Management $67: 530-541$.

Hobaugh, W. C. 1985. Body condition and nutrition of snow geese wintering in southeastern Texas. Journal of Wildlife Management 49:1028-1037.

Hobson, K. A. 1999. Tracing origins and migration of wildlife using stable isotopes: A review. Oecologia 120:314-326.

Hobson, K. a., C. M. Sharp, R. L. Jefferies, R. F. Rockwell, and K. F. Abraham. 2011. Nutrient allocation strategies to eggs by lesser snow geese (Chen caerulescens) at a sub-Arctic colony. Auk 128:156-165.

Hobson, K. A., S. L. Van Wilgenburg, L. I. Wassenaar, and K. Larson. 2012. Linking hydrogen $\left(\delta^{2} \mathrm{H}\right)$ isotopes in feathers and precipitation : Sources of variance and consequences for assignment to isoscapes. PLoS ONE 7:1-9.

Horwitz, W. 2006. Official methods of analysis of AOAC International. Gaithersburg, Maryland, USA. 
James, G., D. Witten, T. Hastie, and R. Tibshirani. 2013. An introduction to statistical learning. Volume 112. Springer, New York, New York.

Jenni, L., and S. Jenni-Eiermann. 1998. Fuel supply and metabolic constraints in migrating birds. Journal of Avian Biology 29:521-528.

Jónsson, J. E., and A. D. Afton. 2006. Different time and energy budgets of lesser snow geese in rice-prairies and coastal marshes in southwest Louisiana. Waterbirds 29:451-458.

Jónsson, J. E., M. Frederiksen, and A. D. Afton. 2014. Movements and survival of lesser snow geese (Chen caerulescens caerulescens) wintering in two habitats along the Gulf Coast, Louisiana. Wildfowl 64:54-74.

Jónsson, J.E. 2005. Effects of body size and habitat use on goose behavior: Lesser snow goose and Ross's goose. Ph.D. thesis, School of Renewable Natural Resources, Louisiana State University, Baton Rouge, Louisiana, USA.

Kerbes, R. H., K. M. Meeres, and R. T. Alisauskas. 2014. Surveys of nesting lesser snow geese and Ross's geese in Arctic Canada, 2002-2009. U.S. Fish and Wildlife Service Washington, D.C., USA.

Klaassen, M., K. F. Abraham, R. L. Jefferies, and M. P. Vrtiska. 2006. Factors affecting the site of investment, and the reliance on savings for arctic breeders : the capitalincome dichotomy revisited. Ardea 94:371-384.

Kruse, K. L., and D. Fronczack. 2013. Light geese in the Central and Mississippi Flyways. U.S. Fish and Wildlife Service, Denver, Colorado, USA. 
Kuznetsova, A., P. B. Brockhoff, and R. H. B. Christensen. 2017. ImerTest Package: Tests in linear mixed effects models. Journal of Statistical Software 82.

Leafloor, J. O., T. J. Moser, and B. Batt. 2012. Evaluation of special management measures for midcontinent lesser snow geese and Ross's geese. Arctic Goose Joint Venture Special Publication. Washington, D.C, Ottawa, Ontario.

Lindström, Å. 1991. Maximum fat deposition rates in migrating birds. Ornis Scandinavica $12-19$.

Marra, P. P., K. A. Hobson, and R. T. Holmes. 1998. Linking winter and summer events in a migratory bird by using stable-carbon isotopes. Science 282:1884-1886.

McWilliams, S. R., C. Guglielmo, B. Pierce, and M. Klaassen. 2004. Flying, fasting, and feeding in birds during migration: A nutritional and physiological ecology perspective. Journal of Avian Biology 35:377-393.

Morrison, R. I., N. C. Davidson, and J. R. Wilson. 2007. Survival of the fattest: Body stores on migration and survival in red knots (Calidris canutus islandica). Journal of Avian Biology 38:479-487.

Nakagawa, S., and H. Schielzeth. 2013. A general and simple method for obtaining $\mathrm{R}^{2}$ from generalized linear mixed-effects models. Methods in Ecology and Evolution $4: 133-142$.

Newton, I. 2004. Population limitation in migrants. Ibis 146:197-226.

Norris, D. R. 2005. Carry-over effects and habitat quality in migratory populations. Oikos 109:178-186. 
Norris, D.R., and P. P. Marra. 2007. Seasonal interactions, habitat quality, and population dynamics in migratory birds. Condor 109:535-547.

Peterson, B. J., and B. Fry. 1987. Stable isotopes in ecosystem studies. Annual review of ecology and systematics 18:293-320. Annual Reviews 4139 El Camino Way, PO Box 10139, Palo Alto, CA 94303-0139, USA.

Prince, P. A., P. Rothery, J. P. Croxall, and A. G. Wood. 1994. Population dynamics of Black-browed and Grey-headed Albatrosses Diomedea melanophris and D. chrysostoma at Bird Island, South Georgia. Ibis 136:50-71.

Raveling, D. G. 1970. Dominance relationships and agonistic behavior of Canada geese in winter. Behaviour 37:291-318.

Schaub, M., L. Jenni, and F. Bairlein. 2008. Fuel stores, fuel accumulation, and the decision to depart from a migration stopover site. Behavioral Ecology 19:657666.

Sedinger, J. S., and R. T. Alisauskas. 2014. Cross-seasonal effects and the dynamics of waterfowl populations. Wildfowl Special Issue No. 4:277-304.

Sedinger, J. S., D. H. Ward, J. L. Schamber, W. I. Butler, D. William, B. Conant, J. F. Voelzer, N. D. Chelgren, M. P. Herzog, H. Ward, F. Voelzer, and P. Herzog. 2006. Effects of El Nino on distribution and reproductive performance of black brant. 87:151-159.

Sedinger, J. S., J. L. Schamber, D. H. Ward, C. A. Nicolai, and B. Conant. 2011. Carryover effects associated with winter location affect fitness, social status, and 
population dynamics in a long-distance migrant. American Naturalist 178:E110E123.

Souchay, G., G. Gauthier, and R. Pradel. 2014. To breed or not: a novel approach to estimate breeding propensity. Ecology 95:2745-2756.

Tamisier, A., L. Allouche, F. Aubry, and O. Dehorter. 1995. Wintering strategies and breeding success: hypothesis for a trade-off in some waterfowl species. Wildfowl 46:76-88.

Tombre, I. M., K. A. Høgda, J. Madsen, L. R. Griffin, E. Kuijken, P. Shimmings, E. Rees, and C. Verscheure. 2008. The onset of spring and timing of migration in two arctic nesting goose populations: the pink-footed goose (Anser bachyrhynchus) and the barnacle goose (Branta leucopsis). Journal of Avian Biology 39:691-703.

Traylor, J. J., R. T. Alisauskas, S. M. Slattery, and K. L. Drake. 2012. Comparative survival and recovery of Ross's and lesser snow geese from Canada's central arctic. Journal of Wildlife Management 76:1135-1144.

Venables, W. N., and B. D. Ripley. 2002. Random and mixed effects. Pages 271-300 in. Modern applied statistics with S. Fourth. Springer, New York, New York, USA.

Warnock, N. 2010. Stopping vs. staging: the difference between a hop and a jump. Journal of Avian Biology 41:621-626.

Webb, E. B., L. M. Smith, M. P. Vrtiska, and T. G. Lagrange. 2010. Effects of local and landscape variables on wetland bird habitat use during migration through the Rainwater Basin. Journal of Wildlife Management 74:109-119. 
Webster, M. S., P. P. Marra, S. M. Haig, S. Bensch, and R. T. Holmes. 2002. Links between worlds: unraveling migratory connectivity. Trends in Ecology and Evolution 17:76-83.

Wilson, S., R. T. Alisauskas, and D. K. Kellett. 2016. Factors influencing emigration of Ross's and snow geese from an Arctic breeding area. Journal of Wildlife Management 80:117-126.

Witter, M. S., and I. C. Cuthill. 1993. The ecological costs of avian fat storage. Philosophical Transactions of the Royal Society Bulletin 340:73-92.

Wypkema, R. C. P., and C. D. Ankney. 1979. Nutrient reserve dynamics of lesser snow geese staging at James Bay, Ontario. Canadian Journal of Zoology 57:213-219. 


\section{TABLES}

Table 4.2 - Mean and standard error of stable hydrogen $\left(\delta^{2} \mathrm{H}\right)$ isotope values in flight feathers collected from adult lesser snow geese at Arctic and subarctic colonies during summer banding in 2014 and 2016.

\begin{tabular}{lcccc}
\hline \multicolumn{1}{c}{ Sampled Colonies } & Location & $\boldsymbol{\delta}^{\mathbf{2}} \mathbf{H}(\%)$ & Subgroups & $\boldsymbol{\delta}^{\mathbf{2}} \mathbf{H}(\% \mathbf{)})$ \\
\hline Akimiski Island $(n=20)$ & $53.10484,-80.95798$ & $-110.27(2.69) \mathrm{A}$ & Subarctic & $-121.64(1.91) \mathrm{A}$ \\
La Pérouse Bay $(n=28)$ & $58.71823,-93.88931$ & $-129.77(1.19) \mathrm{B}$ & & \\
Southampton Island $(n=$ & $63.80852,-85.69742$ & $-157.42(1.70) \mathrm{C}$ & Baffin / & $-160.65(1.59) \mathrm{B}$ \\
27) & $66.71279,-72.55731$ & $-166.11(2.73) \mathrm{C}$ & Southampton & \\
Baffin Island $(n=16)$ & $67.26036,-100.27364$ & $-185.54(4.98) \mathrm{D}$ & Arctic & $-185.54(4.98) \mathrm{C}$ \\
Karrak Lake $(n=7)$ &
\end{tabular}

${ }^{a}$ Means with the same letters within a column are not different $(P>0.05)$. 
Table 4.3 - Model performance of linear discriminant function derived to classify summer molt origin of adult lesser snow geese using stable hydrogen $\left(\delta^{2} \mathrm{H}\right)$ isotope values. Discriminant function was built using known reference samples from three subregions (“Subarctic”, "Karrak Lake”, and "BISI Complex”). Model performance was assessed using $\mathrm{k}$-fold cross-validation $(\mathrm{k}=10)$.

\begin{tabular}{lccc}
\hline & \multicolumn{3}{c}{ Summer Origin LDF Model Performance } \\
\hline & Subarctic $^{1}(n=48)$ & Karrak Lake $^{2}(n=7)$ & BISI Complex $^{3}(n=43)$ \\
Recall & $97.9 \%$ & $85.7 \%$ & $86.0 \%$ \\
Precision & $97.9 \%$ & $54.5 \%$ & $94.9 \%$ \\
Accuracy & $98.0 \%$ & $93.9 \%$ & $91.8 \%$ \\
\hline
\end{tabular}
${ }^{1}$ individuals collected at Akimiski Island and La Perouse Bay; ${ }^{2}$ individuals collected at Karrak Lake; ${ }^{3}$ individuals collected at Baffin and Southampton Islands 
Table 4.4 - Results of general linear mixed models explaining variation in lipid content $(\mathrm{g})$, protein content (g), and univariate index of body size of lesser snow geese $(n=324)$ with predicted summer molt origin collected in Arkansas, Missouri, Nebraska, and South

Dakota during spring migration in 2015 and 2016. Predictor variables included sex (male or female), summer molting origin

("Subarctic""; "Karrak Lake"”; "BISI complex"), the random effect for harvest type (decoy or jump shot), and the random effect for Julian date of collection.

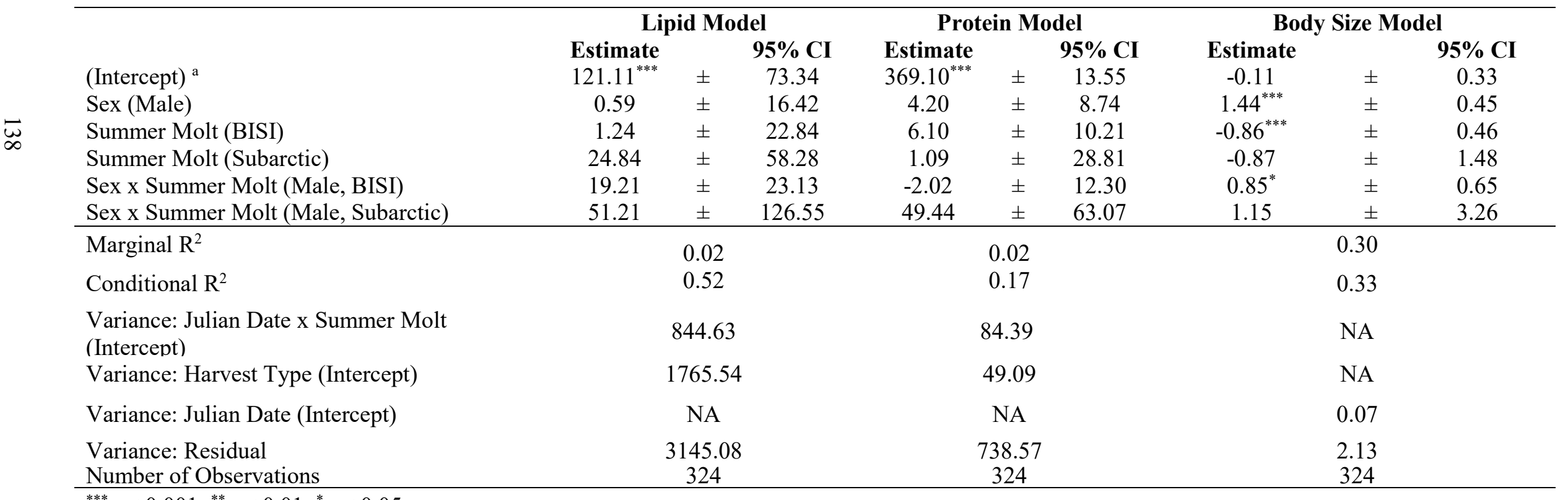

${ }^{* * *} \mathrm{p}<0.001,{ }^{* *} \mathrm{p}<0.01,{ }^{*} \mathrm{p}<0.05$

${ }^{a}$ Intercept referenced on adult female geese classified as molting at Karrak Lake

${ }^{1}$ individuals collected at Akimiski Island and La Pérouse Bay; ${ }^{2}$ individuals collected at Karrak Lake; ${ }^{3}$ individuals collected at Baffin and Southampton Islands 
Table 4.4 - Mean and standard error of stable hydrogen $\left(\delta^{2} \mathrm{H}\right)$, carbon $\left(\delta^{13} \mathrm{C}\right)$, nitrogen $\left(\delta^{15} \mathrm{~N}\right)$, and sulfur $\left(\delta^{34} \mathrm{~S}\right)$ isotope values in bicep muscle tissue from adult and juvenile lesser snow geese collected in 2017 coastal marsh ("Texas Coast"; Louisiana Coast") and rice based agricultural habitat ("Arkansas MAV").

\begin{tabular}{cccccc}
\hline $\begin{array}{c}\text { Sampling } \\
\text { Region }\end{array}$ & Sampling Dates & $\boldsymbol{\delta}^{\mathbf{2}} \mathbf{H}(\mathbf{\% o})$ & $\boldsymbol{\delta}^{\mathbf{1 3}} \mathbf{C}(\mathbf{\% o})$ & $\boldsymbol{\delta}^{\mathbf{1 5}} \mathbf{N}(\% \mathbf{\%})$ & $\boldsymbol{\delta}^{\mathbf{3 4}} \mathbf{S}(\mathbf{\% o})$ \\
\hline Arkansas & 3-5 January 2017 \\
MAV & $\begin{array}{c}(n=13) \\
\text { 1-5 January 2017 } \\
(n=13)\end{array}$ & $-159.98(2.46) \mathrm{A}$ & $-21.45(0.52) \mathrm{A}$ & $7.32(0.19) \mathrm{A}$ & $-2.46(0.35) \mathrm{A}$ \\
$\begin{array}{c}\text { Texas Coast } \\
\text { Louisiana } \\
\text { Coast }\end{array}$ & $\begin{array}{c}\text { 18 January }-8 \\
\text { February }(n=20)\end{array}$ & $-144.72(2.01) \mathrm{B}$ & $-23.90(0.24) \mathrm{B}$ & $7.02(0.26) \mathrm{A}$ & $3.33(0.49) \mathrm{C}$ \\
\hline
\end{tabular}

${ }^{a}$ Means with the same letters within a column are not different $(P>0.05)$. 
Table 4.5 - Mean and standard error of stable hydrogen $\left(\delta^{2} H\right)$, carbon $\left(\delta^{13} \mathrm{C}\right)$, nitrogen $\left(\delta^{15} \mathrm{~N}\right)$, and sulfur $\left(\delta^{34} S\right)$ isotope values in bicep muscle tissue collected from adult and juvenile lesser snow geese grouped by habitat type. Reference individuals representing rice agriculture were collected in Arkansas, while individuals representing coastal marsh habitats were collected in Louisiana and Texas, January 2017.

\begin{tabular}{ccccc}
\hline Habitat Grouping & $\boldsymbol{\delta}^{\mathbf{2}} \mathbf{H}(\mathbf{\%})$ & $\boldsymbol{\delta}^{\mathbf{1 3}} \mathbf{C}(\mathbf{\%})$ & $\boldsymbol{\delta}^{\mathbf{1 5}} \mathbf{N}(\mathbf{\%})$ & $\boldsymbol{\delta}^{\mathbf{3 4}} \mathbf{S}(\mathbf{\%})$ \\
\hline Rice Agriculture $(n=13)$ & $-159.98(2.46) \mathrm{A}$ & $-21.45(0.52) \mathrm{A}$ & $7.32(0.19) \mathrm{A}$ & $-2.46(0.35) \mathrm{A}$ \\
Coastal Marsh $(n=33)$ & $-144.95(2.26) \mathrm{B}$ & $-23.49(0.21) \mathrm{B}$ & $7.32(0.18) \mathrm{A}$ & $2.55(0.41) \mathrm{B}$ \\
\hline
\end{tabular}

${ }^{\mathrm{a}}$ Means with the same letters within a column are not different $(P>0.05)$. 
Table 4.6 - Candidate linear discriminant models built for classifying state level winter geographic origins, or habitat type, based on stable isotope values from bicep muscle tissue in lesser snow geese $(n=60)$ collected from known locations in January 2017. Model accuracy was assessed using $\mathrm{k}$-fold $(\mathrm{k}=10)$ cross validation.

\begin{tabular}{cclc}
\hline Model & $\begin{array}{c}\text { Discrete } \\
\text { Group }\end{array}$ & \multicolumn{1}{|c}{ Function Predictors } & $\begin{array}{c}\text { Overall Model } \\
\text { Accuracy }\end{array}$ \\
\hline 1 & State $^{1}$ & $\sim \delta^{13} \mathrm{C}+\delta^{34} \mathrm{~S}$ & $56.5 \%$ \\
2 & State & $\sim \delta^{15} \mathrm{~N}$ & $50.0 \%$ \\
3 & State & $\sim \delta^{13} \mathrm{C}+\delta^{15} \mathrm{~N}$ & $54.3 \%$ \\
4 & State & $\sim \delta^{2} \mathrm{H}+\delta^{13} \mathrm{C}+\delta^{15} \mathrm{~N}$ & $65.2 \%$ \\
5 & State & $\sim \delta^{2} \mathrm{H}+\delta^{13} \mathrm{C}+\delta^{15} \mathrm{~N}+\delta^{34} \mathrm{~S}$ & $73.9 \%$ \\
6 & State & $\sim \delta^{13} \mathrm{C}+\delta^{15} \mathrm{~N}+\delta^{34} \mathrm{~S}$ & $73.9 \%$ \\
7 & Habitat Type & $\sim \delta^{2} \mathrm{H}+\delta^{13} \mathrm{C}+\delta^{15} \mathrm{~N}$ & $84.8 \%$ \\
8 & Habitat Type & $\sim \delta^{2} \mathrm{H}+\delta^{13} \mathrm{C}+\delta^{34} \mathrm{~S}$ & $91.3 \%$ \\
9 & Habitat Type & $\sim \delta^{13} \mathrm{C}+\delta^{15} \mathrm{~N}+\delta^{34} \mathrm{~S}$ & $93.5 \%$ \\
10 & Habitat Type & $\sim \delta^{2} \mathrm{H}+\delta^{13} \mathrm{C}+\delta^{15} \mathrm{~N}+\delta^{34} \mathrm{~S}$ & $91.3 \%$ \\
\hline
\end{tabular}

${ }^{1}$ Arkansas, Louisiana, and Texas; ${ }^{2}$ Coastal marsh and rice agriculture 
Table 4.6 - Comparison in model performance between top linear discriminant models when classifying state origins versus habitat types using stable isotope values $\left(\delta^{13} \mathrm{C}, \delta^{15} \mathrm{~N}\right.$, and $\left.\delta^{34} \mathrm{~S}\right)$ derived from bicep muscle tissue of lesser snow geese collected in January 2017.

\begin{tabular}{lccccc}
\hline \multirow{2}{*}{ Full model } & \multicolumn{2}{c}{ State Origins Model } & \multicolumn{2}{c}{ Habitat Type Model } \\
& \multicolumn{2}{c}{ State $\delta^{13} \mathrm{C}+\delta^{15} \mathrm{~N}+\delta^{34} \mathrm{~S}$} & \multicolumn{2}{c}{ Habitat Type $\delta^{13} \mathrm{C}+\delta^{15} \mathrm{~N}+\delta^{34} \mathrm{~S}$} \\
\hline & Arkansas & Louisiana & Texas & Coastal Marsh & Rice Habitat \\
Recall & $(n=13)$ & $(n=20)$ & $(n=20)$ & Habitat $(n=33)$ & $(n=13)$ \\
Precision & $92.3 \%$ & $70.0 \%$ & $61.5 \%$ & $93.9 \%$ & $92.3 \%$ \\
Accuracy & $85.7 \%$ & $82.4 \%$ & $53.3 \%$ & $96.9 \%$ & $85.7 \%$ \\
\hline
\end{tabular}


Table 4.7 - Results of general linear mixed models explaining variation in lipid content (g), protein content (g), and univariate index of body size of lesser snow geese $(n=137)$ with predicted winter habitat origin collected in Arkansas, Missouri, and Nebraska during the spring migration in 2015 and 2016. Predictor variables included sex (male or female), age (juvenile or adult), winter habitat type ("Coastal Marsh"; "Rice"), the random effect for harvest type (decoy or jump shot), and the random effect for Julian date of collection.

\begin{tabular}{|c|c|c|c|c|c|c|c|c|c|}
\hline \multirow[b]{3}{*}{$(\text { Intercept })^{\mathrm{a}}$} & \multicolumn{3}{|c|}{ Lipid Model } & \multicolumn{3}{|c|}{ Protein Model } & \multicolumn{3}{|c|}{ Body Size Model } \\
\hline & Estimate & & $95 \%$ CI & Estimate & & $95 \% \mathrm{CI}$ & Estimate & & $95 \% \mathrm{CI}$ \\
\hline & $106.39^{* * *}$ & \pm & 43.23 & $367.99^{* * *}$ & \pm & 7.60 & $-0.47^{*}$ & \pm & 0.44 \\
\hline Age (Juvenile) & $53.43^{* * *}$ & \pm & 23.44 & $-13.23^{*}$ & \pm & 10.37 & $-1.17^{* * *}$ & \pm & 0.60 \\
\hline Sex (Male) & -6.40 & \pm & 18.62 & $11.56^{*}$ & \pm & 9.52 & $1.14^{* * *}$ & \pm & 0.55 \\
\hline Winter Habitat (Rice) & $33.39^{*}$ & \pm & 30.73 & -3.63 & \pm & 8.86 & 0.31 & \pm & 0.51 \\
\hline Marginal $\mathrm{R}^{2}$ & \multicolumn{3}{|c|}{0.20} & \multicolumn{3}{|c|}{0.09} & \multicolumn{3}{|c|}{0.18} \\
\hline Conditional $\mathrm{R}^{2}$ & \multicolumn{3}{|c|}{0.43} & \multicolumn{3}{|c|}{0.11} & \multicolumn{3}{|c|}{0.18} \\
\hline $\begin{array}{l}\text { Variance: Julian Date x Winter Habitat } \\
\text { (Intercept) }\end{array}$ & \multicolumn{3}{|c|}{554.72} & \multicolumn{3}{|c|}{16.72} & \multicolumn{3}{|c|}{ NA } \\
\hline Variance: Harvest Type (Intercept) & \multicolumn{3}{|c|}{492.22} & \multicolumn{3}{|c|}{0.00} & \multicolumn{3}{|c|}{ NA } \\
\hline Variance: Julian Data (Intercept) & \multicolumn{3}{|c|}{ NA } & \multicolumn{3}{|c|}{ NA } & \multicolumn{3}{|c|}{0.00} \\
\hline $\begin{array}{l}\text { Variance: Residual } \\
\text { Number of Observations }\end{array}$ & \multicolumn{3}{|c|}{$\begin{array}{l}2524.38 \\
137\end{array}$} & \multicolumn{3}{|c|}{$\begin{array}{c}680.37 \\
137\end{array}$} & \multicolumn{3}{|c|}{2.33} \\
\hline
\end{tabular}

${ }^{* * *} \mathrm{p}<0.001,{ }^{* *} \mathrm{p}<0.01,{ }^{*} \mathrm{p}<0.05$

${ }^{a}$ Intercept referenced on adult female geese classified as using coast marsh habitat 


\section{FIGURES}

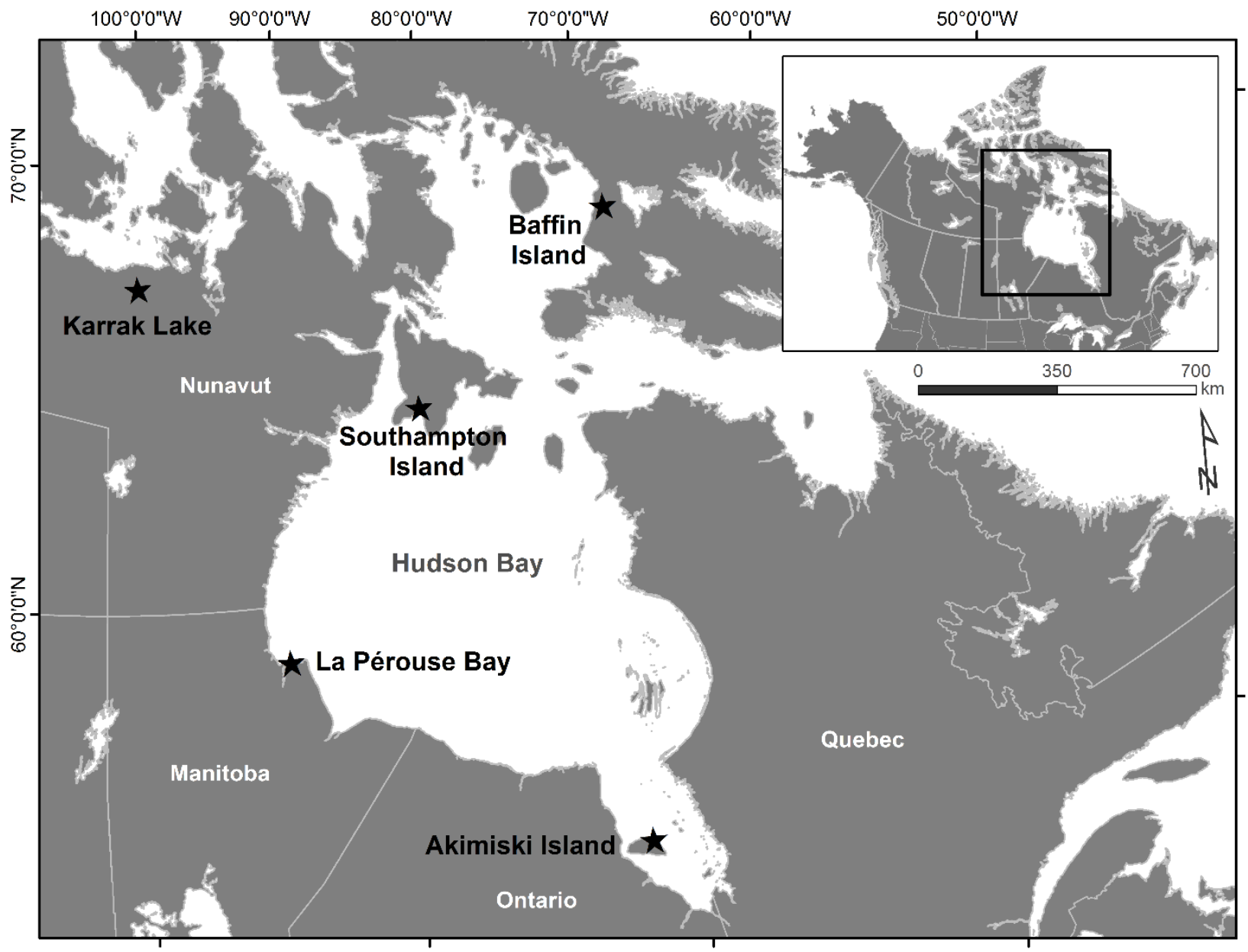

Fig. 4.1 - Location of sampled breeding colonies where newly grown flight feathers of adult midcontinent lesser snow geese were collected for quantification of $\delta^{2} \mathrm{H}$ isotope signatures in July 2014. A second year of collections occurred at all colonies except Karrak Lake in July 2016. 

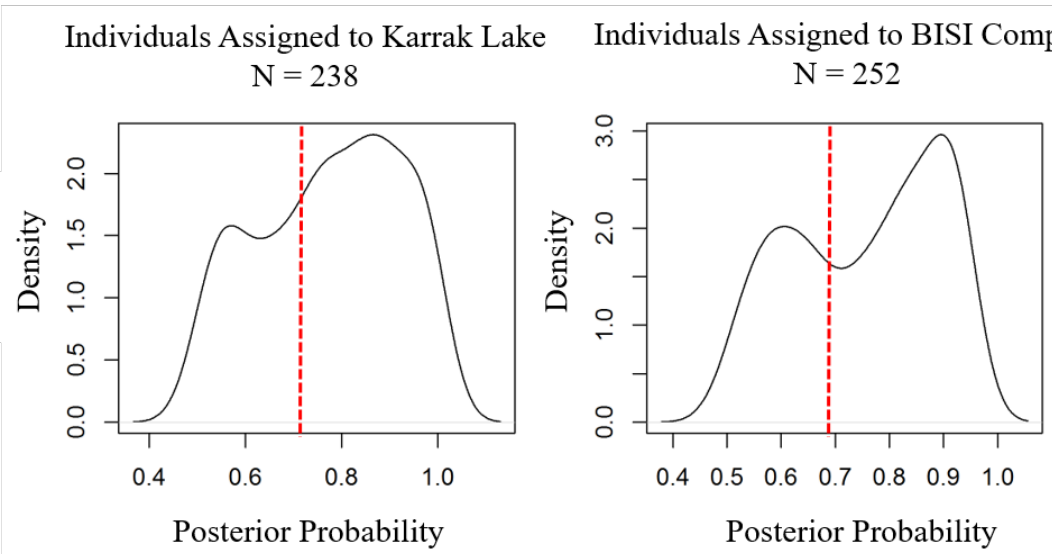

Individuals Assigned to Subarctic $\mathrm{N}=7$

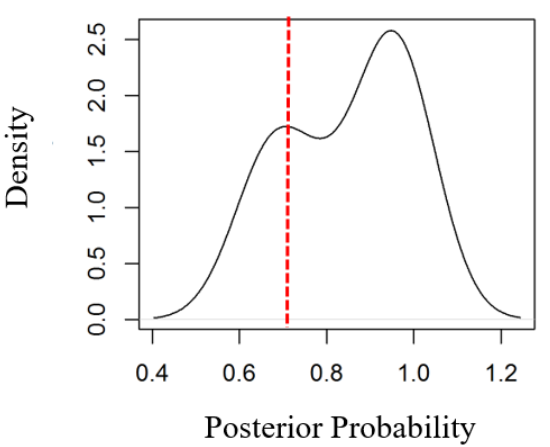

Fig. 4.2 - Probability density functions of lesser snow geese assigned to discrete geographic origins of summer molt using the "Summer Origin LDF" linear discriminant function. Lesser snow geese were collected during spring migration in Arkansas, Missouri, Nebraska, and South Dakota during 2015 and 2016. Individuals with a posterior probability $\geq 0.70$ (red vertical line) were kept for analysis to evaluate the influence of summer geographic location on spring body condition and overall body size. 


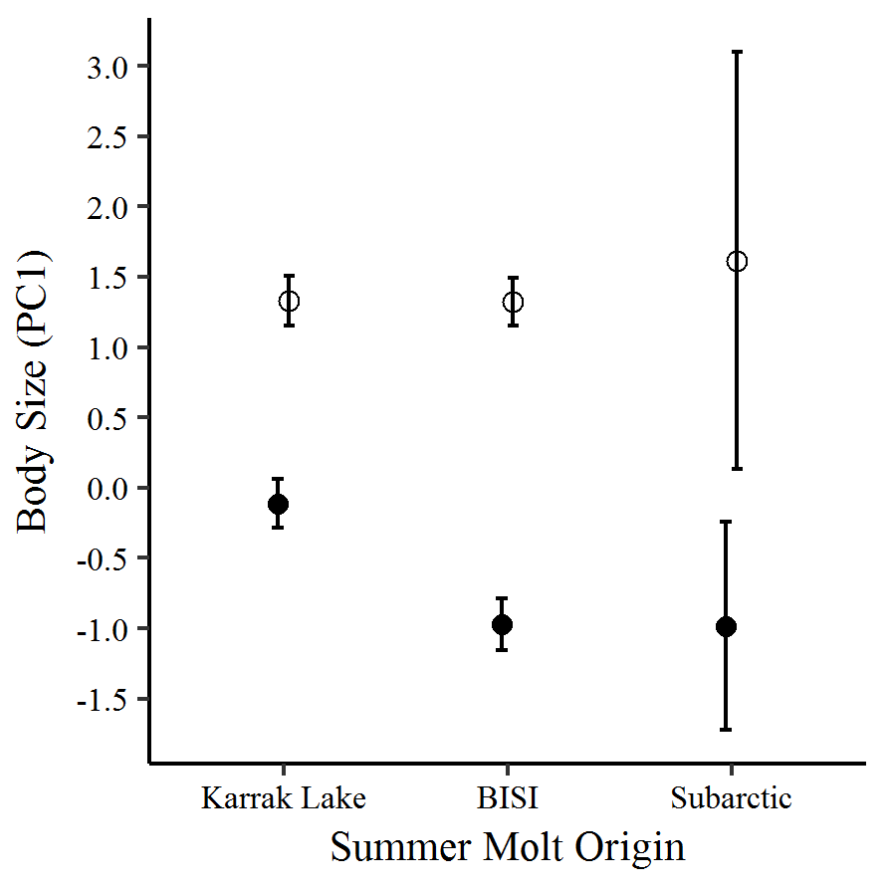

Fig. 4.3 - Model least square means and standard errors of body size among spring migrant male and female lesser snow geese classified to discrete geographic molt origins based on $\delta^{2} \mathrm{H}$ isotope values in flight feathers. Index of body size was derived from the first principal component of length of tarsus, culmen, head, body, and wing chord. "BISI" refers to individuals classified to the Baffin and Southampton Islands complex, and "Subarctic" represents origins south of $60^{\circ} \mathrm{N}$. Open circles represent males. Closed circles represent females. 

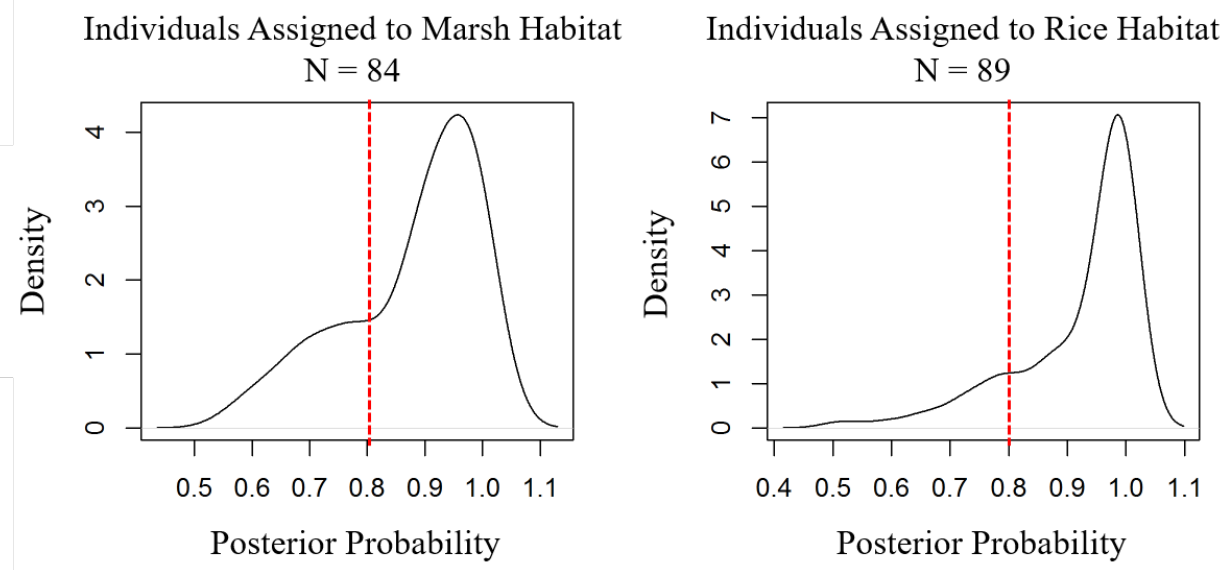

Fig. 4.4 - Probability density functions of lesser snow geese assigned to discrete winter habitat types using the "Winter Habitat LDF" linear discriminant function. Lesser snow geese were collected during spring migration in Arkansas, Missouri, and Nebraska 2016. Individuals with a posterior probability $\geq 0.80$ (red vertical line) were kept for analysis to evaluate the influence of winter habitat type on spring body condition and overall body size. 


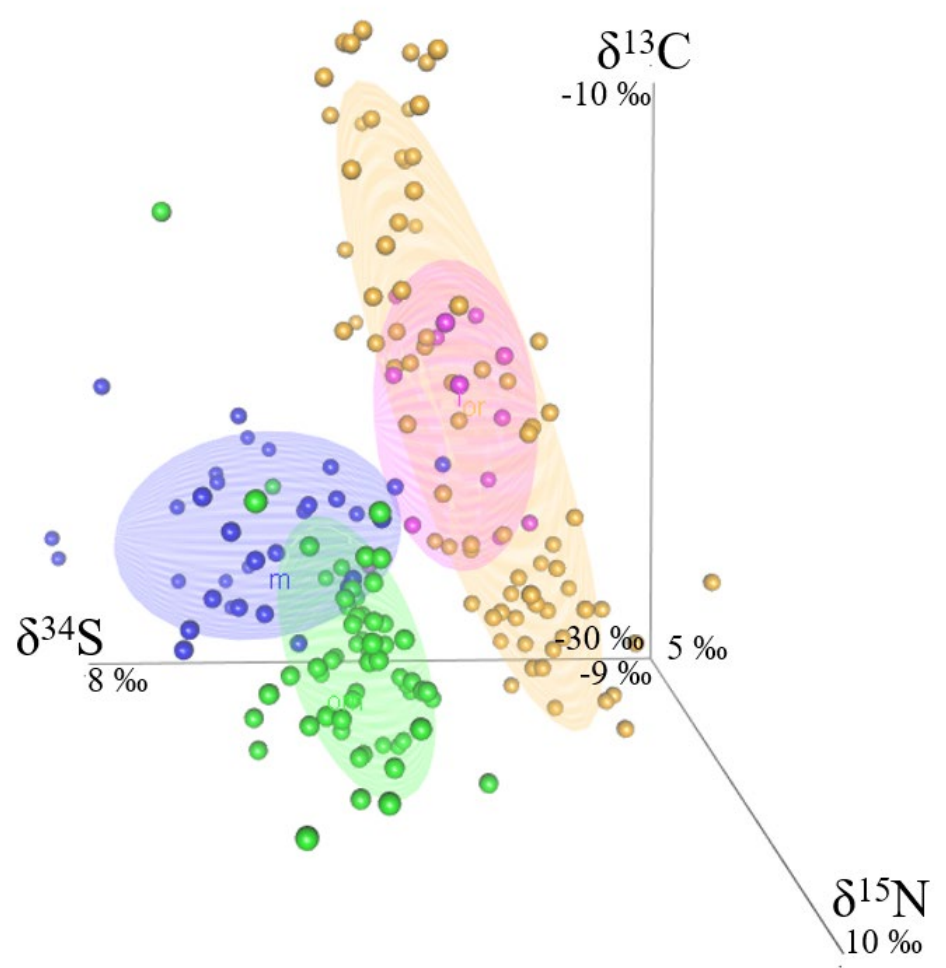

Fig. 4.5 - Stable isotope values of lesser snow goose bicep muscle tissue from individuals serving as reference samples of known coastal marsh habitat (blue) and agricultural rice based habitat (pink). Spring migrants of unknown origin were classified to either coastal marsh habitats (green) or rice habitats (orange) using a linear discriminant function derived from reference samples. 

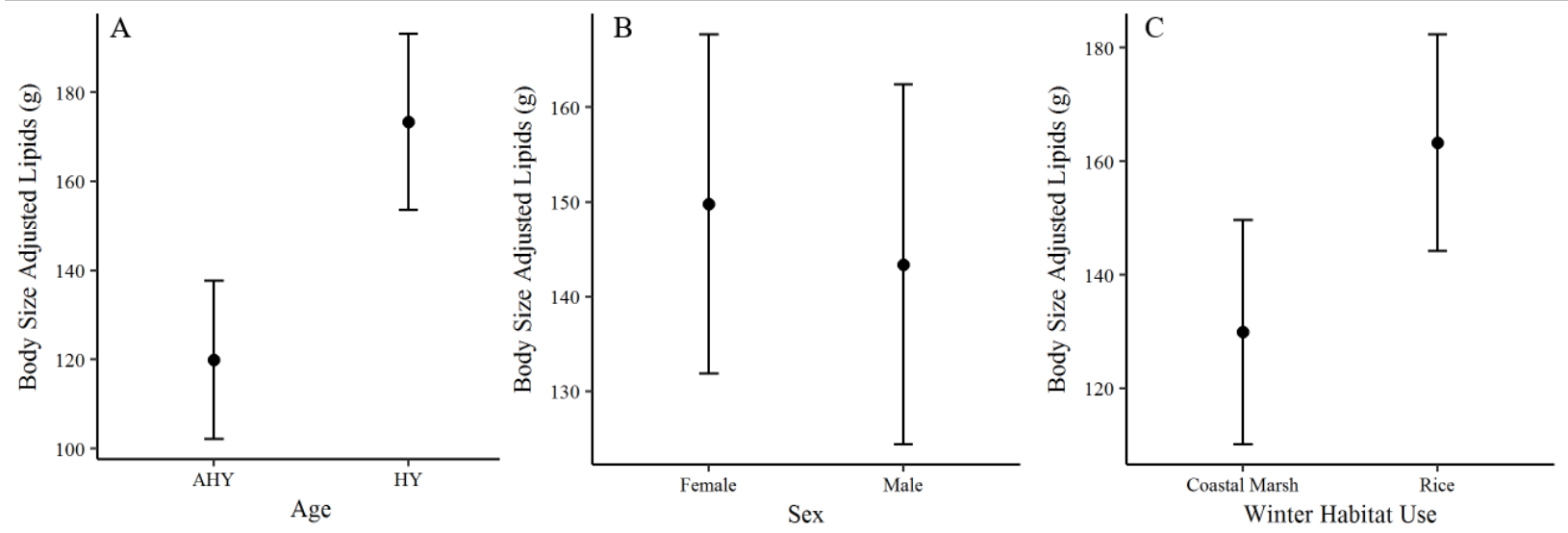

Fig. 4.6 - Model least square means and standard errors of size adjusted lipid content across age (A), sex (B), and winter habitat use (C) in lesser snow geese $(n=137)$ collected during spring migration in 2016 in Arkansas, Missouri, and Nebraska. 

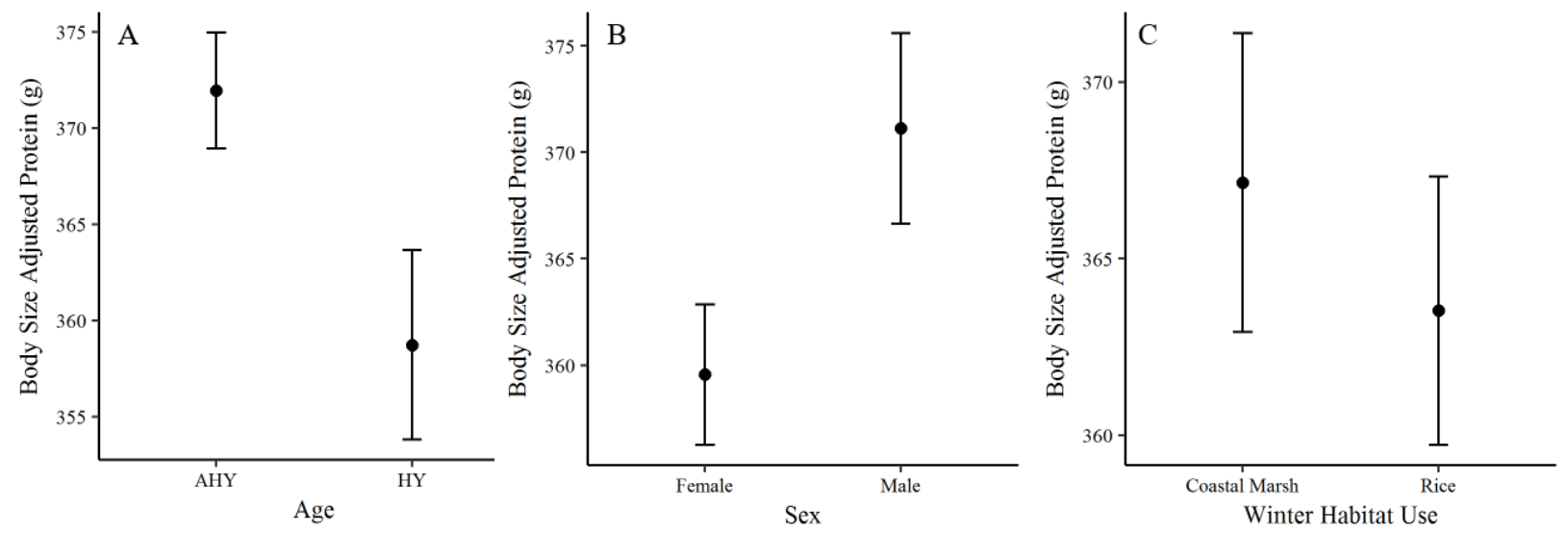

Fig. 4.7 - Model least square means and standard errors of size adjusted protein content across age (A), sex (B), and winter habitat use (C) in lesser snow geese $(n=137)$ collected during spring migration in 2016 in Arkansas, Missouri, and Nebraska. 

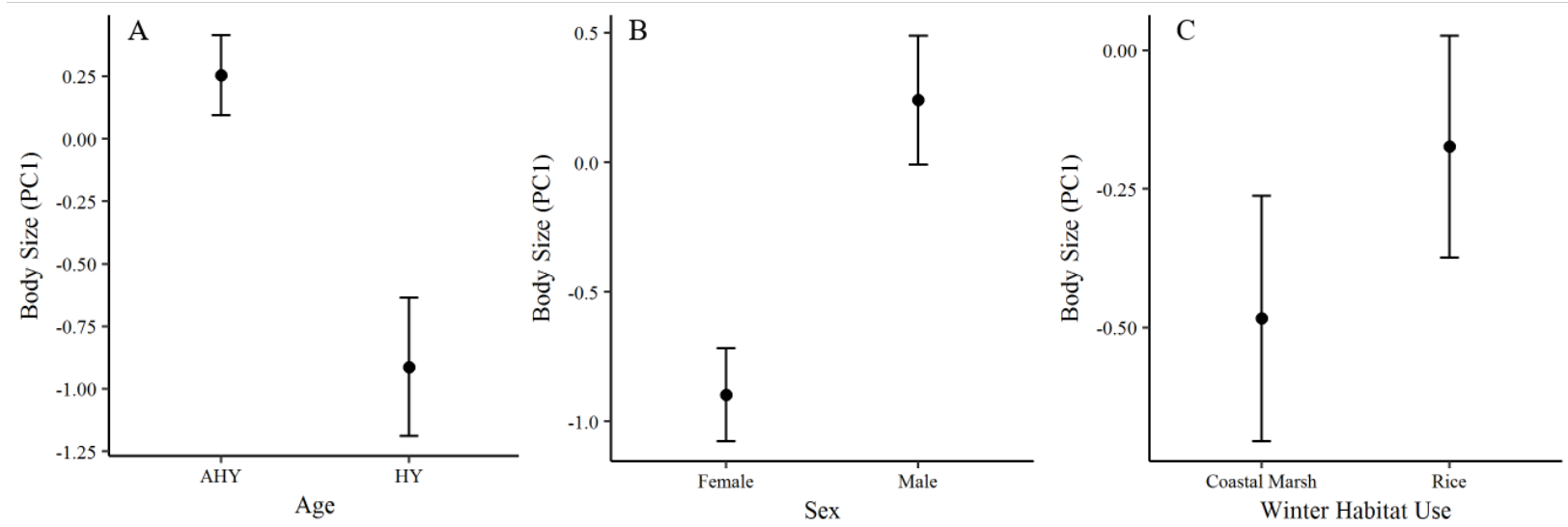

Fig. 4.8 - Model least square means and standard errors of body size across age (A), sex (B), and winter habitat use (C) in lesser snow geese $(n=137)$ collected during spring migration in 2016 in Arkansas, Missouri, and Nebraska. Index of body size was derived from the first principal component of length of tarsus, culmen, head, body, and wing chord. 


\section{CHAPTER 5 - EXECUTIVE SUMMARY}

Individual heterogeneity in fitness within a population is well established (Vaupel et al. 1979, Vindenes and Landangen 2015, Gimenez et al. 2018) and provides the required variability for natural selection to occur (Endler 1986, Hamel et al. 2018). In the case of harvestable waterfowl species, quantifying the extent of individual variation in fitness parameters such as survival, or proxies for survival, such as overall body condition, are important for interpreting effects of harvest on survival rates, and ultimately population growth (Lebreton 2005, Sedinger and Herzog 2012). While density dependence has often been identified as the primary mechanism for compensatory mortality (Boyce et al. 1999), individual heterogeneity within a population can serve as an additional independent mechanism for compensating effects of harvest on survival when harvest is disproportionately biased towards frail individuals (Cooch et al. 2014, Caudill et al. 2017). Compensatory harvest provides a means to maximize optimal harvest opportunities without incurring direct impacts to population size and is often considered a favorable harvest effect from the perspective of hunters and managers who seek to increase hunter recruitment (Burnham and Anderson 1984, Humburg et al. 2018). However, in special cases where desired management actions seek to sustainably reduce population size through harvest regulations (Batt et al. 1997), harvest mortality is required to be additive to that of natural mortality.

The expansion of North American midcontinent lesser snow geese (Anser caerulescens caerulescens) and Ross's geese (Anser rossii) are a classic example of unprecedented population growth in response to anthropogenic ecosystem alterations (Ankney 1996, Jefferies et al. 2003, Abraham et al. 2005). Resulting from concerns of 
increasing population size on breeding habitats (Rockwell et al. 1997) and negative cascading effects to adjacent species (Batt et al. 1997), liberalization of regular season hunting regulations and initiation of a spring conservation order, known as the light goose conservation order (LGCO), in both Canada and the United States in 1999 were implemented in an effort to increase harvest mortality. While harvest mortality is generally presumed to be additive in geese (Rexstad 1992), harvest rates have not increased proportionate to increasing population size (Alisauskas et al. 2011) and annual rates of juvenile and adult natural mortality across midcontinent breeding areas are greater than annual harvest mortality, thus providing the means for continued compensation (Calvert et al. 2017, but see Koons et al. 2014).

In Chapter 2 we evaluated evidence for a condition bias in lesser snow and Ross's geese harvested by participants in the LGCO to identify additional components potentially contributing to the observed compensatory harvest, in addition to low harvest rates. Thus, we examined differences in spring body condition of lesser snow $(n=759)$ and Ross's geese $(n=125)$ harvested both over decoys and from the general population that might provide insight on harvest susceptibility. We opportunistically collected light geese harvested over decoys by LGCO participants and simultaneously collected paired random samples via jump or pass shooting during peak spring migration in Arkansas, Missouri, Nebraska, and South Dakota during the 2015 and 2016 LGCO. Specimens were assessed for body condition using standard lipid and protein proximate analyses and were adjusted for body size based on morphological measurements. We used general linear and mixed models to separately explain variation in total lipid and protein values, ingesta-free body mass, and body size using harvest method, harvest region, sex, and age 
as predictors, while accounting for year as a random effect. In both lesser snow and Ross's geese, our models supported an effect of harvest method on variation in lipids and ingesta-free body mass, but not protein or body size. Averaging across sex and region, juvenile and adult snow geese harvested over decoys had $29.7 \mathrm{~g}(95 \%$ CI: 11.4, 47.9) and 59.9 g (95\% CI: 49.7, 70.2), respectively, less lipids compared to birds sampled randomly through jump shooting. Similarly, averaging across age, sex, and region, mean difference of lipids in decoy harvested Ross's geese was $41.1 \mathrm{~g}(95 \% \mathrm{CI}: 26.2,55.9)$ lower than individuals collected by jump shooting. In both lesser snow and Ross's geese, similar patterns of decreased ingesta-free body mass in decoy harvested individuals existed, following patterns found in lipid values. Lipids are the primary energetic source used during spring migration for long distant migrant birds (Jenni and Jenni-Eirman 1998) and are positively correlated to both recruitment (Ankney and McInnes 1978, Alisauskas 2002) and survival (Bêty et al. 2003, Morrison et al. 2007). Our results indicate management efforts to control population size through the LGCO harvest appears to target individuals of lower intrinsic body condition who exhibit higher risk prone behavior. Thus, at current harvest levels, compensatory mortality is likely facilitated by not only insufficient harvest quantity but also the quality individuals, as harvest seems to contribute to the number of individuals that die annually, but not increase overall annual mortality (Calvert et al. 2017).

In Chapter 3, we sought to estimate the extent and distribution of individual variation in survival of adult midcontinent lesser snow geese, given findings in Chapter 2 that adult individuals harvested by LGCO participants had lower overall body condition. As a result, harvested individuals likely have a lower survival probability compared to the 
overall population. Nonetheless, an assumption of homogeneity among cohorts of marked individuals is a prerequisite of models developed to estimate survival parameters from mark-recovery or capture-mark-recapture (Pollock and Raveling 1982). In cases where individual variation exists in survival, parameter estimates of survival can be biased (Barker 1992). Therefore, our objective was to assess the magnitude of individual variation contributing to estimates of adult survival of lesser snow geese using long-term mark-recovery data. Measuring the variance associated with survival estimates provides a means to indirectly identify heterogeneous survival rates that we expect to exist resulting from genotypic / phenotypic variation and life-history tradeoffs (Souchay et al. 2014, Gimenez et al. 2018, Drake et al. 2018). Additionally, assessing individual variation quantifies a potential mechanism for compensatory harvest via heterogeneous survival rates (Sedinger and Herzog 2012). We used data from adult bandings and band recoveries by hunters initiated from long-term monitoring efforts at an Arctic and subarctic colony, Karrak Lake $\left(67^{\circ} 14^{\prime} \mathrm{N}, 100^{\circ} 15^{\prime} \mathrm{W}\right)$ and La Pérouse Bay $\left(58^{\circ} 4^{\prime} \mathrm{N}, 90^{\circ} 4^{\prime}\right.$ W), respectively, from 1999-2016. We analyzed mark-recovery data using a time constant Bayesian state-space framework (Kéry and Schaub 2012) and estimated the variance in survival $\left(\sigma_{\mathrm{s}}^{2}\right)$ by adding a continuous random variable for all individuals. We experienced failed model convergence when attempting to estimate $\sigma^{2}$ s with only uninformative prior distributions. Rather, model convergence occurred when an informative prior was provided for $\sigma^{2}$. In this model, adult survival was greater in the Karrak Lake colony (Karrak Lake mean: 0.91, 95\% CRI 0.90, 0.92; La Pérouse Bay mean: $0.85,95 \%$ CRI $0.84,0.87$ ) as were recovery rates (Karrak Lake mean: $0.20,95 \%$ CRI 0.18, 0.21; La Pérouse Bay mean: 0.17, 95\% CRI 0.16, 0.18). For both colonies, 
posterior probabilities of $\sigma_{s}^{2}$ (on the logit scale) were the same but below the mean value provide in the prior distribution (Karrak Lake $\sigma^{2} \mathrm{~s}: 0.36,95 \%$ CRI 0.23, 0.36; La Pérouse Bay $\sigma_{\mathrm{s}}^{2}: 0.36,95 \%$ CRI $\left.0.23,0.36\right)$.

A likely explanation for failed convergence around an estimate of $\sigma^{2}$ is that markrecovery data do not afford repeated observations of individuals that would facilitate the identification of variable survival among individuals. The premise for including a random effect for marked individuals in our Bayesian models is that individual survival probability is distributed based on its own mean and variance. However, markedrecovery data only provides a single recovery event at death. Therefore ability for the model to estimate $\sigma^{2}$ s is likely severely limited, as survival probabilities are estimated only from recovered individuals, and all recovered individuals are by nature recovered only once. Our inability to estimate individual variation in survival from mark-recovery data highlights an important finding, in that while mark-recovery models are widely used for estimating survival and recovery rates, current advanced modeling techniques cannot use recoveries alone to validate long-standing model assumptions of homogeneity among the marked sample. A gap remains in our understanding regarding the means in which individual variation in survival (or recovery) could be estimated using mark-recovery data through current advancement in the use of random effects. Given that a majority of population vital rates in waterfowl are derived from mark-recovery programs, further research could explore the circumstances required in which mark-recovery data could provide estimates of individual variation. Hierarchical modeling that parameterizes individuals as a random effect and includes additional covariates (such as body size 
metrics or condition indices) may provide sufficient additional information to capture variation and promote parameter convergence. Further work is warranted and we suggest exploration through simulated data.

In Chapter 4, we evaluated further potential mechanisms for heterogeneous body condition. Given that spring body condition can be influenced by complex life history strategy interactions owing to previous experiences (i.e. carry-over effects) (Harrison et al. 2011, Sedinger and Alisauskas 2014) and nutrient allocation strategies associated with migration and breeding (Klassen et al. 2006, Hobson et al. 2011), we evaluated the influence of prior winter habitat use and future breeding destination on spring body condition using lesser snow geese as a study organism, given intraspecific life history strategies within the species. We used stable isotope techniques to determine likely breeding season destination, assessed by $\delta^{2} \mathrm{H}$ values in newly grown feathers following summer molting (Fowler et al. 2018), and prior winter habitat use (Hénaux et al. 2012) among lesser snow geese collected during spring migration. We assessed the ability of seasonal origins data to explain variation in spring body condition and body size of collected individuals.

We found that previous winter habitat use most immediately influenced early spring body condition, rather than inferences regarding summer destination. Specifically, we found that use of different winter habitat types influenced total body lipid levels in lesser snow geese at collection in early spring migration. Adult and juvenile individuals who used coastal marsh habitats during winter had $33.4 \mathrm{~g}(95 \% \mathrm{CI}: 0.38 \mathrm{~g}, 66.4 \mathrm{~g})$ less lipids than counterparts reliant on a rice based agricultural diet. Winter habitat type did not influence total body protein, and differences in individual body size between winter 
habitats were not detected. Waterfowl foods found in marshes typically have low true metabolizable energy values as a consequence of their high fiber content, which requires increased daily consumption rates by waterfowl and likely results in a greater proportion of time allocated to foraging (Alisauskas 1988, Gauthier et al. 1988). Increased energy expenditure related to greater time spent foraging, paired with lower energetic diet items, may result in lower lipid reserves among geese using coastal marsh habitats compared to birds using landscapes containing rice or other diet items found in agricultural landscapes (Jónsson and Afton 2006). As a result, differences in lipid reserves between individuals using distinct winter habitats could in part explain heterogeneous body condition among individuals and subsequent harvest susceptibility during spring migration. Further, the influence of habitat type use on spring body condition provides an additional mechanism to potentially explain causes in natural mortality or harvest susceptibility.

In conclusion, our study identified important individual variation in spring body condition (Chapter 2) as well as a carry-over effect from winter habitat use that influences spring body condition (Chapter 4) in two overabundant species. The importance of individual variation in body condition, and greater susceptibility of poorer conditioned individuals to harvest mortality, is particularly relevant given current efforts to actively reduce population size by lowering adult survival rates through the spring LGCO. In addition to extremely low harvest rates (Calvert et al. 2017), LGCO participants predominately remove individuals likely to have a greater mortality probability than the general population. Thus, their removal does little to affect population survival rates. Yet, quantifying the extent of individual variation in survival through mark-recovery data proved challenging (Chapter 3) and continued work is 
required to evaluate the conditions necessary to estimate variation in this parameter estimate. Population reduction through the LGCO has not been effective, however recent stabilization of population size may be the realization of carrying-capacity at terminal staging areas that limits recruitment (Ross et al. 2017). Thus, future midcontinent light goose population size is likely to either remain stable or decrease related to reduced recruitment because of density-dependence at important staging areas (Ross et al. 2017). Future work should consider how individual variation in survival may change as the population shifts towards an older age-distribution. 


\section{LITERATURE CITED}

Abraham, K. F., R. L. Jefferies, and R. T. Alisauskas. 2005. The dynamics of landscape change and snow geese in mid-continent North America. Global Change Biology $11: 841-855$.

Alisauskas, R. T., C. D. Ankney, and E. E. Klaas. 1988. Winter diets and nutrition of midcontinental lesser snow geese. Journal of Wildlife Management 52:403-414.

Alisauskas, R. T. 2002. Arctic climate, spring nutrition, and recruitment in midcoontinent lesser snow geese. Journal of Wildlife Management 66:181-193.

Alisauskas, R. T., R. F. Rockwell, K. W. Dufour, E. G. Cooch, G. Zimmerman, K. L. Drake, J. O. Leafloor, T. J. Moser, and E. T. Reed. 2011. Harvest, survival, and abundance of midcontinent lesser snow geese relative to population reduction efforts. Wildlife Monographs 179:1-42.

Ankney, C. D. 1996. An embarrassment of riches : Too many geese. Journal of Wildlife Management 60:217-223.

Ankney, C. D., and C. D. MacInnes. 1978. Nutrient reserves and the reproductive performance of female lesser snow geese. Auk 95:459-471.

Barker, R. J. 1992. Effect of heterogeneous survival on bird-banding model confidence interval coverage rates. Journal of Wildlife Management 56:111-116. 
Batt, B. 1997. Arctic Ecosystems in Peril: Report of the Arctic Goose Habitat Working Group. U.S Fish and Wildlife Service, Washington, D.C. and Canadian Wildlife Service, Ottawa, Ontario.

Bêty, J., G. Gauthier, and J.-F. Giroux. 2003. Body condition, migration, and timing of reproduction in snow geese: a test of the condition-dependent model of optimal clutch size. American Naturalist 162:110-121.

Boyce, M. S., a. R. E. Sinclair, and G. C. White. 1999. Seasonal Compensation of Predation and Harvesting. Oikos 87:419-426.

Burnham, K. P., and D. R. Anderson. 1984. Tests of compensatory vs. additive hypotheses of mortality in mallards. Ecology 65:105-112.

Calvert, A. M., R. T. Alisauskas, and G. C. White. 2017. Annual survival and seasonal hunting mortality of midcontinent snow geese. Journal of Wildlife Management 81:1009-1020.

Caudill, D., M. R. Guttery, T. M. Terhune, J. A. Martin, G. Caudill, D. K. Dahlgren, and T. A. Messmer. 2017. Individual heterogeneity and effects of harvest on greater sage-grouse populations. Journal of Wildlife Management 81:754-765.

Cooch, E. G., M. Guillemain, G. S. Boomer, J.-D. Lebreton, and J. D. Nichols. 2014. The effects of harvest on waterfowl populations. Wildfowl Special Issue No. 4:220276. 
Drake, K. L., R. T. Alisauskas, and A. M. Calvert. 2018. Experimental test for a trade-off between successful nesting and survival in capital breeders with precocial offspring. Auk 135:637-646.

Endler, J. A. 1986. Natural selection in the wild. Princeton University Press, Princeton, NJ, USA.

Fowler, D. N., K. J. Kuechle, B. A. Woodall, M. P. Vrtiska, and E. B. Webb. 2018. Evaluating indices of lipid and protein content in lesser snow and Ross's geese during spring migration. Wildlife Society Bulletin 42:295-303.

Gauthier, G., Y. Bédard, and J. Bédard. 1988. Habitat use and activity budgets of greater snow geese in spring. Journal of Wildlife Management 52:191-201.

Gimenez, O., E. Cam, and J. M. Gaillard. 2018. Individual heterogeneity and capturerecapture models: What, why and how? Oikos 127:664-686.

Hamel, S., J. M. Gaillard, M. Douhard, M. Festa-Bianchet, F. Pelletier, and N. G. Yoccoz. 2018. Quantifying individual heterogeneity and its influence on lifehistory trajectories: different methods for different questions and contexts. Oikos 127:687-704.

Harrison, X. A., J. D. Blount, R. Inger, D. R. Norris, and S. Bearhop. 2011. Carry-over effects as drivers of fitness differences in animals. Journal of Animal Ecology 80:4-18. 
Hénaux, V., L. A. Powell, M. P. Vrtiska, and K. A. Hobson. 2012. Establishing winter origins of migrating lesser snow geese using stable isotopes. Avian Conservation and Ecology 7:5.

Hobson, K. a., C. M. Sharp, R. L. Jefferies, R. F. Rockwell, and K. F. Abraham. 2011. Nutrient allocation strategies to eggs by lesser snow geese (Chen caerulescens) at a sub-arctic colony. Auk 128:156-165.

Humburg, D. D., M. G. Anderson, M. G. Brasher, M. F. Carter, J. M. Eadie, D. C. Fulton, F. A. Johnson, M. C. Runge, and M. P. Vrtiska. 2018. Implementing the 2012 North American waterfowl management plan revision: populations, habitat, and people. Journal of Wildlife Management 82:275-286.

Jefferies, R. L., R. F. Rockwell, and K. F. Abraham. 2003. The embarrassment of riches: agricultural food subsidies, high goose numbers, and loss of Arctic wetlands - a continuing saga. Environmental Reviews 11:193-232.

Jenni, L., and S. Jenni-Eiermann. 1998. Fuel supply and metabolic constraints in migrating birds. Journal of Avian Biology 29:521-528.

Jónsson, J. E., and A. D. Afton. 2006. Different time and energy budgets of lesser snow geese in rice-prairies and coastal marshes in southwest Louisiana. Waterbirds 29:451-458.

Kéry, M., and M. Schaub. 2012. Bayesian population analysis using WinBUGS: a hierarchical perspective. Academic Press, Amsterdam, The Netherlands. 
Klaassen, M., K. F. Abraham, R. L. Jefferies, and M. P. Vrtiska. 2006. Factors affecting the site of investment, and the reliance on savings for arctic breeders : the capitalincome dichotomy revisited. Ardea 94:371-384.

Koons, D. N., R. F. Rockwell, and L. M. Aubry. 2014. Effects of exploitation on an overabundant species: the lesser snow goose predicament. Journal of Animal Ecology 3:365-374.

Lebreton, J.-D. 2005. Dynamic and statistical models for exploited populations. Australian and New Zealand Journal of Statistics 47:49-63.

Morrison, R. I., N. C. Davidson, and J. R. Wilson. 2007. Survival of the fattest: Body stores on migration and survival in red knots (Calidris canutus islandica). Journal of Avian Biology 38:479-487.

Pollock, K., and D. Raveling. 1982. Assumptions of modern band-recovery models, with emphasis on heterogeneous survival rates. Journal of Wildlife Management 46:88-98.

Rexstad, E. A. 1992. Effect of hunting on annual survival of Canada geese in Utah. Journal of Wildlife Management 56:297-305.

Sedinger, J. S., and R. T. Alisauskas. 2014. Cross-seasonal effects and the dynamics of waterfowl populations. Wildfowl Special Issue No. 4:277-304.

Sedinger, J. S., and M. P. Herzog. 2012. Harvest and dynamics of duck populations. The Journal of Wildlife Management 76:1108-1116. 
Souchay, S. G., and G. G. Gauthier. 2014. To breed or not : a novel approach to estimate breeding propensity and potential trade-offs in an Arctic-nesting species. Ecology $95: 2745-2756$.

Vaupel, J. W., K. G. Manton, and E. Stallard. 1979. The impact of heterogeneity in individual frailty on the dynamics of mortality. Demography 16:439-454.

Vindenes, Y., and Ø. Langangen. 2015. Individual heterogeneity in life histories and ecoevolutionary dynamics. Ecology Letters 18:417-432. 


\section{APPENDICES}

Appendix 1 - Data form used during field collections of decoy and jump shot lesser snow and Ross's geese during the spring Light Goose Conservation Order in 2015 and 2016.

\begin{tabular}{|c|c|c|c|c|c|c|c|c|}
\hline $\begin{array}{c}\text { Data } \\
\text { Entered } \\
\text { by } \\
\text { (Name) }\end{array}$ & $\begin{array}{l}\text { Goose ID } \\
\text { (Tag } \\
\text { Number) }\end{array}$ & Date & $\begin{array}{c}\text { Time of } \\
\text { Harvest } \\
\text { (hour of } \\
\text { day) }\end{array}$ & $\begin{array}{c}\text { Location } \\
\text { (WMA or } \\
\text { GPS) }\end{array}$ & $\begin{array}{l}\text { Location } \\
\text { Ownership } \\
\text { (Public or } \\
\text { Private) }\end{array}$ & $\begin{array}{c}\text { Tactic } \\
\text { (decoyed, } \\
\text { jump shot) }\end{array}$ & $\begin{array}{c}\text { Landscape } \\
\text { ( Over } \\
\text { Land or } \\
\text { Water) }\end{array}$ & Additional Comments \\
\hline & & & & & & & & \\
\hline \\
\hline & & & & & & & & \\
\hline & & & & & & & & \\
\hline & & & & & & & & \\
\hline & & & & & & & & \\
\hline & & & & & & & & \\
\hline & & & & & & & & \\
\hline & & & & & & & & \\
\hline & & & & & & & & \\
\hline & & & & & & & & \\
\hline & & & & & & & & \\
\hline & & & & & & & & \\
\hline & & & & & & & & \\
\hline
\end{tabular}


Appendix 2 - Number of lesser snow geese $(n=759)$ and Ross' geese $(n=154)$ collected in Arkansas, Missouri, Nebraska, and South Dakota by harvest type, sex, and age, during the spring Light Goose Conservation Order in 2015 and 2016.

\begin{tabular}{|c|c|c|c|c|c|c|c|c|c|c|c|c|c|c|c|c|}
\hline \multirow[b]{3}{*}{ Region } & \multicolumn{8}{|c|}{2015} & \multicolumn{8}{|c|}{2016} \\
\hline & \multicolumn{4}{|c|}{ Decoy Shot } & \multicolumn{4}{|c|}{ Jump Shot } & \multicolumn{4}{|c|}{ Decoy Shot } & \multicolumn{4}{|c|}{ Jump Shot } \\
\hline & $\begin{array}{c}\text { Male } \\
\text { HY }\end{array}$ & $\begin{array}{l}\text { Male } \\
\text { AHY }\end{array}$ & $\begin{array}{c}\text { Female } \\
\text { HY }\end{array}$ & $\begin{array}{c}\text { Female } \\
\text { AHY }\end{array}$ & $\begin{array}{c}\text { Male } \\
\text { HY }\end{array}$ & $\begin{array}{l}\text { Male } \\
\text { AHY }\end{array}$ & $\begin{array}{c}\text { Female } \\
\text { HY }\end{array}$ & $\begin{array}{c}\text { Female } \\
\text { AHY }\end{array}$ & $\begin{array}{c}\text { Male } \\
\text { HY }\end{array}$ & $\begin{array}{l}\text { Male } \\
\text { AHY }\end{array}$ & $\begin{array}{c}\text { Female } \\
\text { HY }\end{array}$ & $\begin{array}{c}\text { Female } \\
\text { AHY }\end{array}$ & $\begin{array}{l}\text { Male } \\
\text { HY }\end{array}$ & $\begin{array}{l}\text { Male } \\
\text { AHY }\end{array}$ & $\begin{array}{c}\text { Female } \\
\text { HY }\end{array}$ & $\begin{array}{c}\text { Female } \\
\text { AHY }\end{array}$ \\
\hline Arkansas & 19 & 8 & 17 & 8 & 4 & 13 & 4 & 20 & 23 & 10 & 9 & 13 & 2 & 24 & 2 & 24 \\
\hline Missouri & 13 & 9 & 15 & 9 & 2 & 12 & 4 & 23 & 18 & 18 & 13 & 6 & 1 & 22 & 1 & 27 \\
\hline Nebraska & 5 & 28 & 2 & 16 & 2 & 22 & 4 & 20 & 7 & 20 & 10 & 12 & 6 & 17 & 4 & 28 \\
\hline South Dakota & 19 & 5 & 8 & 4 & 5 & 20 & 2 & 12 & 7 & 14 & 9 & 12 & 1 & 21 & 2 & 22 \\
\hline $\begin{array}{l}\text { Lesser snow } \\
\text { goose total }\end{array}$ & 56 & 50 & 42 & 37 & 13 & 67 & 14 & 75 & 55 & 62 & 41 & 43 & 10 & 84 & 9 & 101 \\
\hline Arkansas & 1 & 2 & 2 & 2 & 2 & 7 & 2 & 6 & 1 & 2 & 0 & 1 & 1 & 7 & 0 & 4 \\
\hline Missouri & 1 & 1 & 6 & 0 & 1 & 9 & 2 & 4 & 5 & 2 & 0 & 1 & 0 & 3 & 0 & 3 \\
\hline Nebraska & 0 & 4 & 2 & 0 & 2 & 3 & 0 & 0 & 1 & 3 & 0 & 4 & 0 & 2 & 0 & 5 \\
\hline South Dakota & 4 & 4 & 3 & 4 & 0 & 7 & 1 & 5 & 1 & 7 & 1 & 3 & 1 & 4 & 0 & 5 \\
\hline $\begin{array}{l}\text { Ross's goose } \\
\text { total }\end{array}$ & 6 & 11 & 13 & 6 & 5 & 26 & 5 & 15 & 8 & 14 & 1 & 9 & 2 & 16 & $\mathbf{0}$ & 17 \\
\hline
\end{tabular}




\section{SUPPLEMENTARY FIGURES}
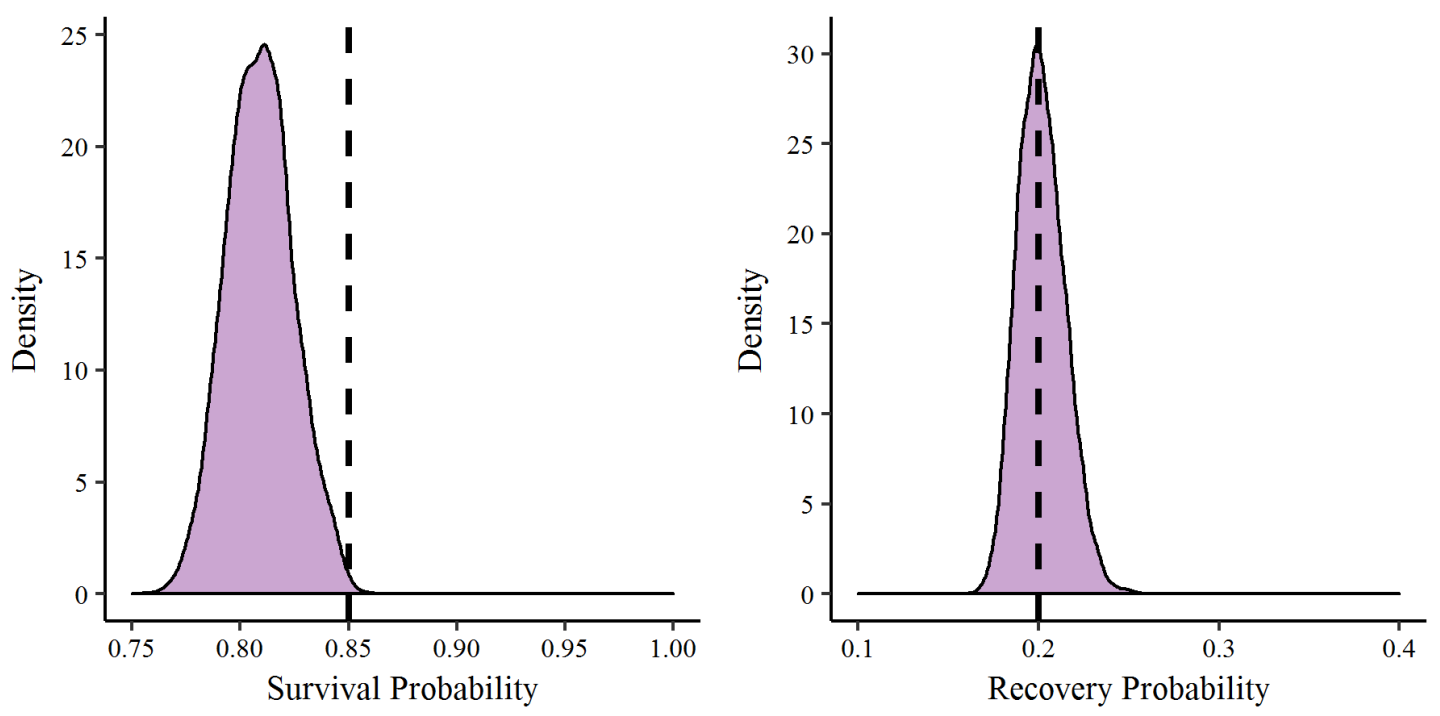

Supplementary Figure 2 - Posterior density plots of survival and recovery probabilities from simulated mark-recovery data analyzed using a Bayesian state-space model. Data were simulated to represent a mean survival of 0.85 with a variance of 0.6 (on the logit scale), and fixed recovery rate of 0.20 over 10 years. 500 individuals were marked each year. Estimates shown are based on a time constant survival and recovery model.

Individual variation in survival is not accounted for in this model. Black dashed vertical line represents the true parameter estimate of the simulated data. 

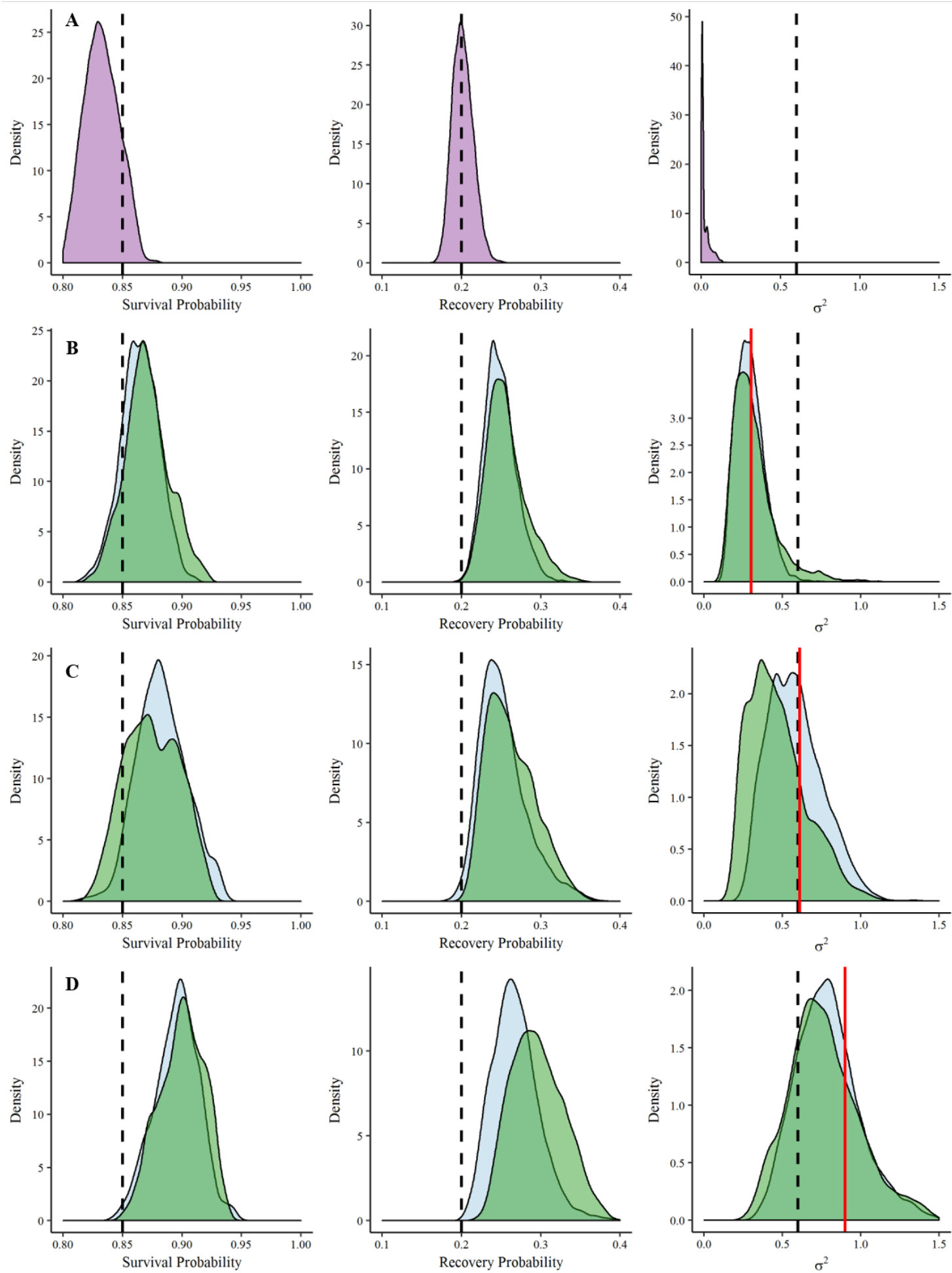

Supplementary Figure 3- Posterior density plots of survival and recovery probabilities from simulated mark-recovery data analyzed using Bayesian state-space models accounting for individual variation in survival probability. Estimates shown are based on 
time constant survival and recovery models with a random effect for individuals. Models variants include uninformative priors on individual variation in survival $\left(\sigma^{2}\right)(A)$ and informative priors on mean $\sigma^{2}$ below the true value of simulated $\sigma^{2}(B)$, equal to the true value of simulated $\sigma^{2}(\mathrm{C})$, and above the true value of simulated $\sigma^{2}(\mathrm{D})$. Models were repeated under two levels of precision in the prior parameter, tau $=5$ (green polygon), tau $=10$ (blue polygon). Data were simulated to represent a mean survival of 0.85 with a variance of 0.6 (on the logit scale), and fixed recovery rate of 0.20 over 10 years. 500 individuals were marked each year. Black dashed vertical line represents the true parameter estimate of the simulated data. Solid red vertical line represents mean value of $\sigma^{2}$ used in prior distribution. 

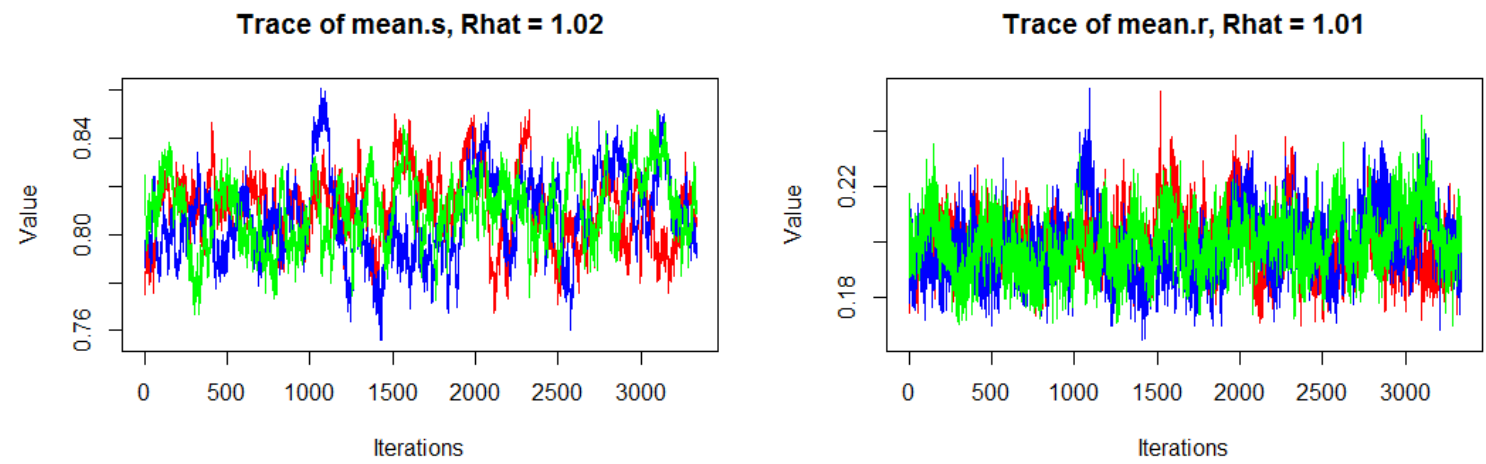

Supplementary Figure 4 - Trace plot of survival (left) and recovery (right) parameters from simulated mark-recovery data analyzed using a Bayesian state-space model without accounting for individual variation in survival. Data were simulated to represent a mean survival of 0.85 with a variance of 0.6 (on the logit scale), and fixed recovery rate of 0.20 over 10 years. 500 individuals were marked each year. Model was based on three Markov Chain Monte Carlo chains of 50,000 iterations after a burn-in of 20,000 and thinning interval of 10 . 

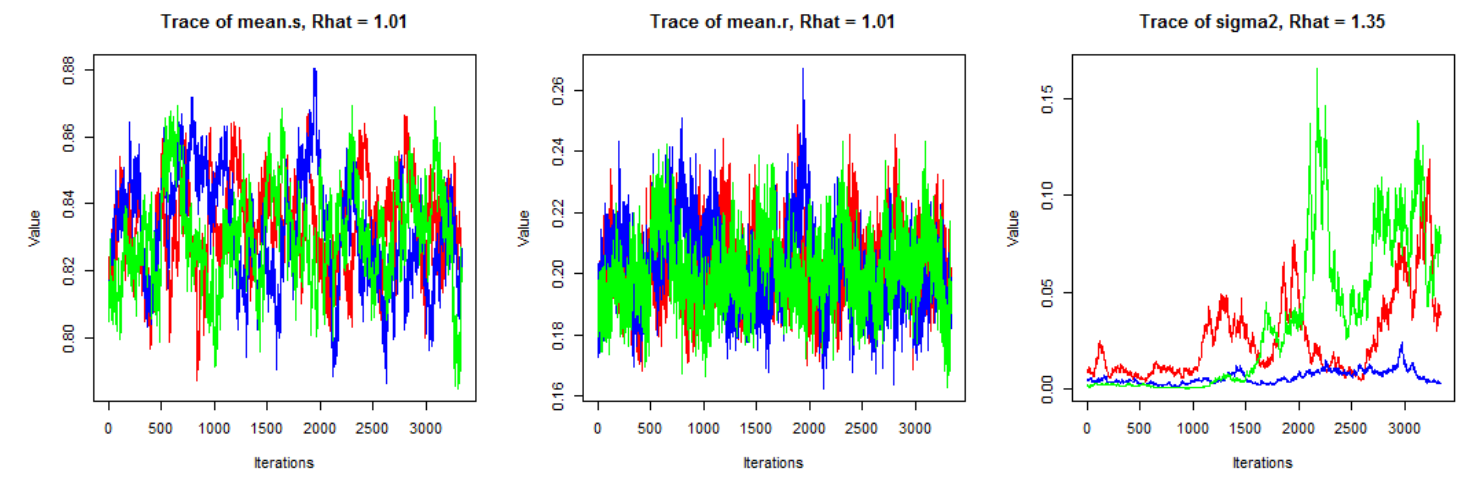

Supplementary Figure 5- Trace plot of survival (left), recovery (center), and survival variance $\sigma^{2}$ (right) parameters from simulated mark-recovery data analyzed using a Bayesian state-space model accounting for individual variation in survival with uninformative priors. Data were simulated to represent a mean survival of 0.85 with a variance of 0.6 (on the logit scale), and fixed recovery rate of 0.20 over 10 years. 500 individuals were marked each year. Model was based on three Markov Chain Monte Carlo chains of 50,000 iterations after a burn-in of 20,000 and thinning interval of 10 . 

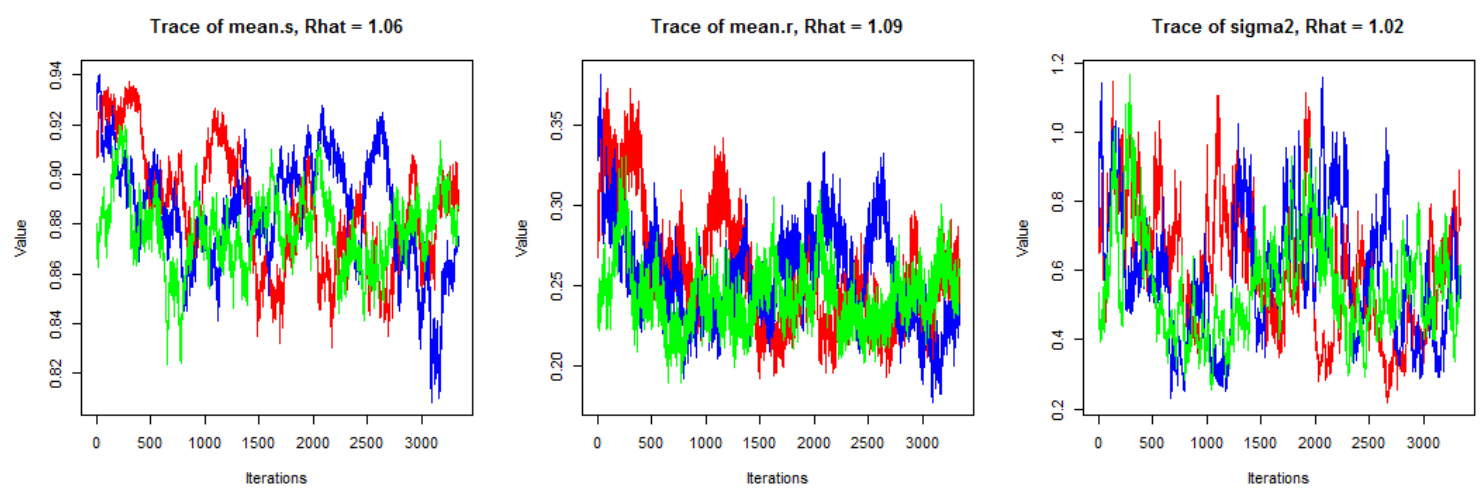

Supplementary Figure 6 - Trace plot of survival (left), recovery (center), and survival variance $\sigma^{2}$ (right) parameters from simulated mark-recovery data analyzed using a Bayesian state-space model accounting for individual variation in survival with informative priors $($ mean $=0.6$, precision $=10)$. Data were simulated to represent a mean survival of 0.85 with a variance of 0.6 (on the logit scale), and fixed recovery rate of 0.20 over 10 years. 500 individuals were marked each year. Model was based on three Markov Chain Monte Carlo chains of 50,000 iterations after a burn-in of 20,000 and thinning interval of 10 . 

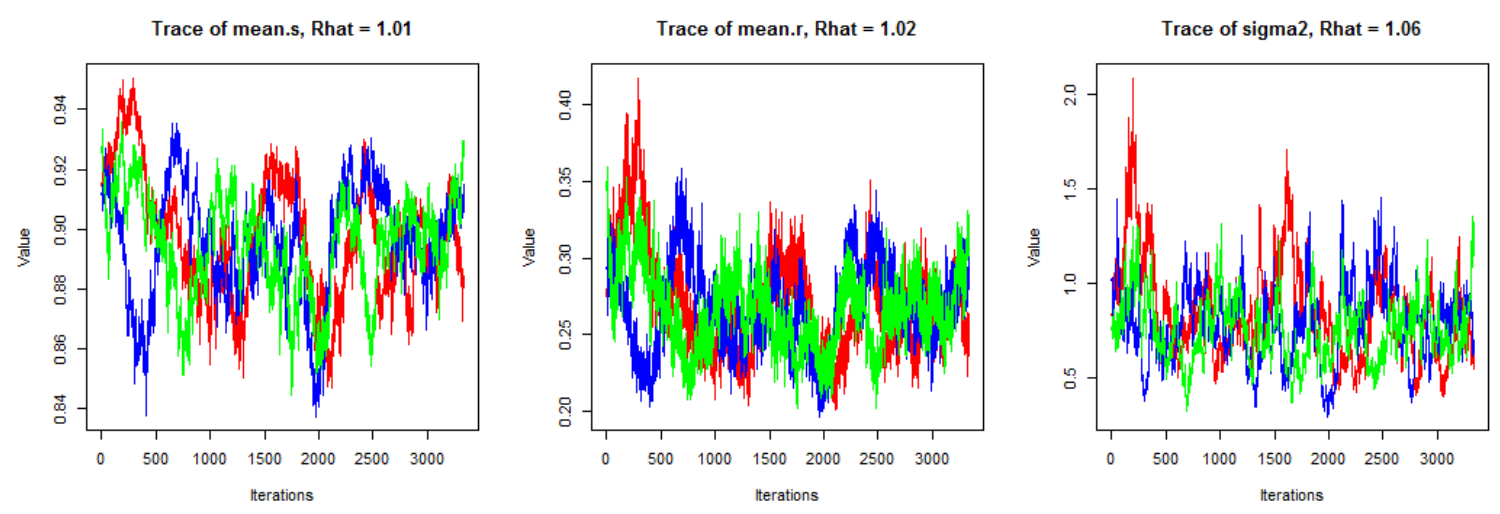

Supplementary Figure 7- Trace plot of survival (left), recovery (center), and survival variance $\sigma^{2}$ (right) parameters from simulated mark-recovery data analyzed using a Bayesian state-space model accounting for individual variation in survival with informative priors $($ mean $=0.9$, precision $=10)$. Data were simulated to represent a mean survival of 0.85 with a variance of 0.6 (on the logit scale), and fixed recovery rate of 0.20 over 10 years. 500 individuals were marked each year. Model was based on three Markov Chain Monte Carlo chains of 50,000 iterations after a burn-in of 20,000 and thinning interval of 10 . 

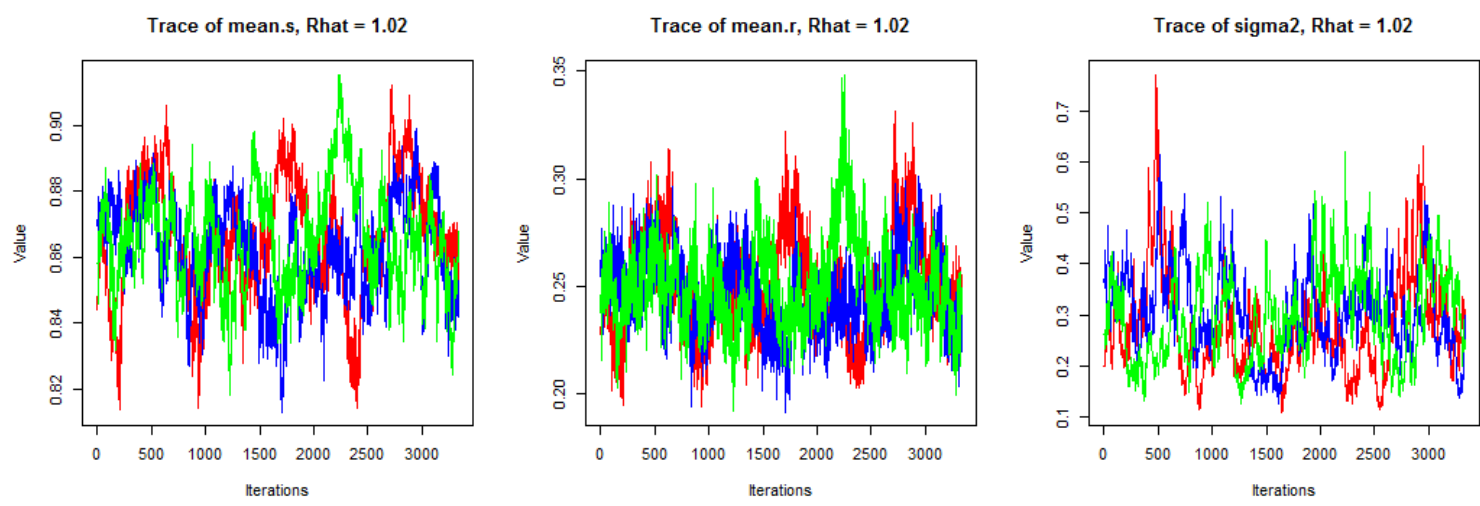

Supplementary Figure 8- Trace plot of survival (left), recovery (center), and survival variance $\sigma^{2}$ (right) parameters from simulated mark-recovery data analyzed using a Bayesian state-space model accounting for individual variation in survival with informative priors $($ mean $=0.3$, precision $=10)$. Data were simulated to represent a mean survival of 0.85 with a variance of 0.6 (on the logit scale), and fixed recovery rate of 0.20 over 10 years. 500 individuals were marked each year. Model was based on three Markov Chain Monte Carlo chains of 50,000 iterations after a burn-in of 20,000 and thinning interval of 10 . 

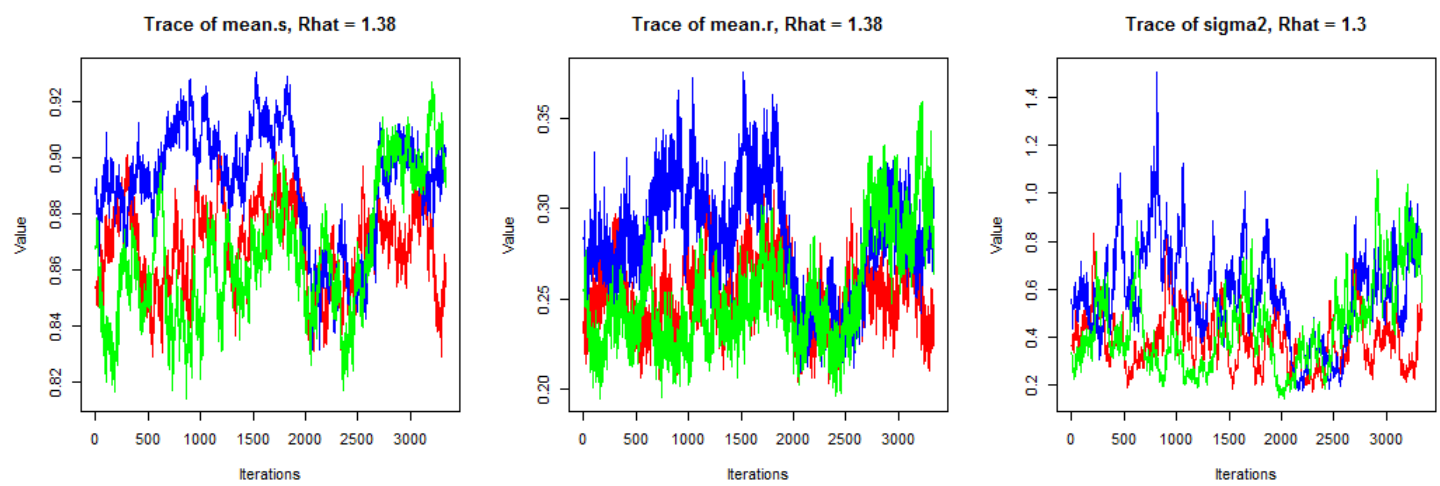

Supplementary Figure 9- Trace plot of survival (left), recovery (center), and survival variance $\sigma^{2}$ (right) parameters from simulated mark-recovery data analyzed using a Bayesian state-space model accounting for individual variation in survival with informative priors $($ mean $=0.6$, precision $=5)$. Data were simulated to represent a mean survival of 0.85 with a variance of 0.6 (on the logit scale), and fixed recovery rate of 0.20 over 10 years. 500 individuals were marked each year. Model was based on three Markov Chain Monte Carlo chains of 50,000 iterations after a burn-in of 20,000 and thinning interval of 10 . 

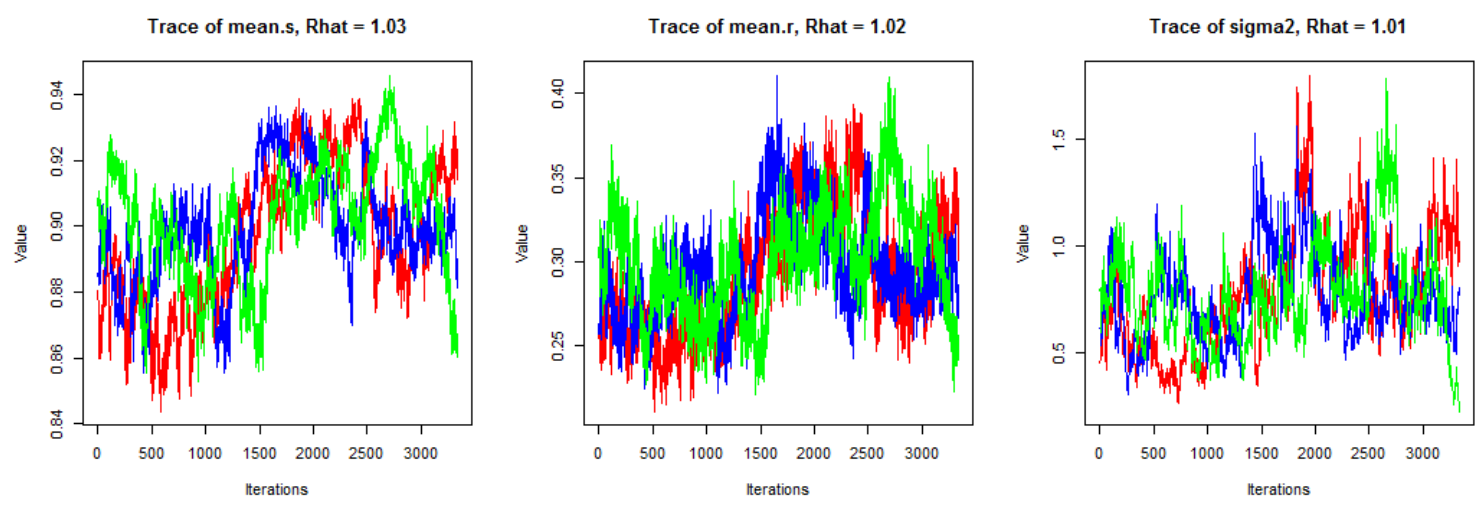

Supplementary Figure 10- Trace plot of survival (left), recovery (center), and survival variance $\sigma^{2}$ (right) parameters from simulated mark-recovery data analyzed using a Bayesian state-space model accounting for individual variation in survival with informative priors $($ mean $=0.9$, precision $=5)$. Data were simulated to represent a mean survival of 0.85 with a variance of 0.6 (on the logit scale), and fixed recovery rate of 0.20 over 10 years. 500 individuals were marked each year. Model was based on three Markov Chain Monte Carlo chains of 50,000 iterations after a burn-in of 20,000 and thinning interval of 10 . 

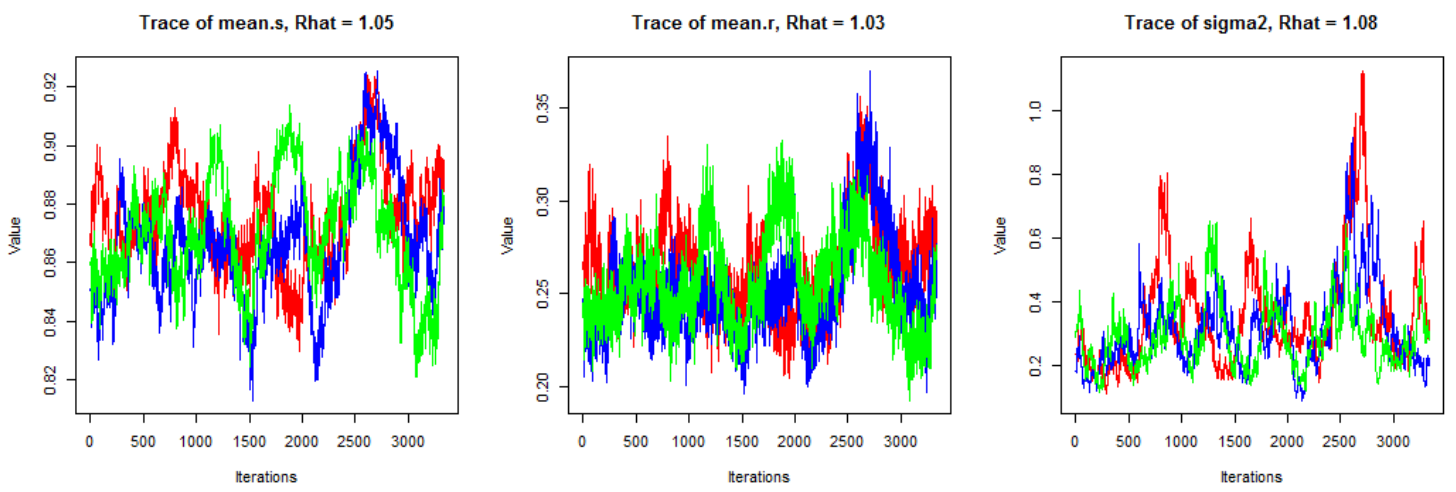

Supplementary Figure 11- Trace plot of survival (left), recovery (center), and survival variance $\sigma^{2}$ (right) parameters from simulated mark-recovery data analyzed using a Bayesian state-space model accounting for individual variation in survival with informative priors $($ mean $=0.3$, precision $=5)$. Data were simulated to represent a mean survival of 0.85 with a variance of 0.6 (on the logit scale), and fixed recovery rate of 0.20 over 10 years. 500 individuals were marked each year. Model was based on three Markov Chain Monte Carlo chains of 50,000 iterations after a burn-in of 20,000 and thinning interval of 10 . 
VITA

Drew Fowler was born in Richland, Washington, but was moved to Texas at three months of age. So much to the chagrin of Sammy King and John Vradenburg, he considers himself from Texas. Drew graduated with a Bachelors' of Science in Fisheries and Wildlife Sciences from Texas A\&M University in 2010. He obtained a Master's of Science in Renewable Natural Resources from Louisiana State University in 2013 where he evaluated wetland management practices in arid environments. Drew is married to Katie Fowler and they have two young daughters, Adelynn and Amelia, who are anxiously awaiting their first goose hunt with their Papa. As a family, Drew, Katie, Adelynn, and Amelia enjoy any opportunity to explore the outdoors for as long as the shortest attention span can tolerate. 